\title{
PHYSICAL ACTIVITY ON PRESCRIPTION
}

Studies on physical activity level, adherence and cardiovascular risk factors

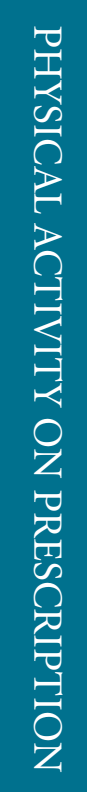

Lena Kallings 
From Department of Neurobiology, Care Sciences and Society Karolinska Institutet, Stockholm, Sweden

\section{PHYSICAL ACTIVITY ON PRESCRIPTION}

\section{Studies on physical activity level, adherence and cardiovascular risk factors}

Lena V Kallings

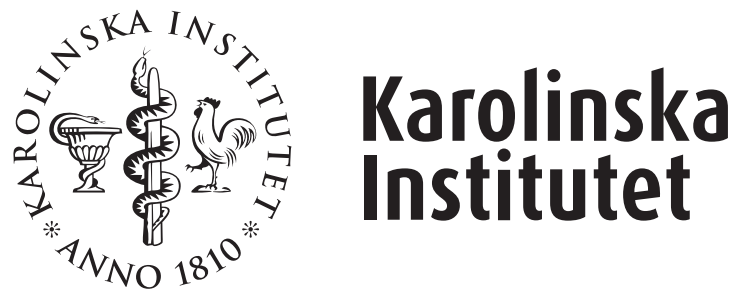

Stockholm 2008 
All previously published papers were reproduced with permission from the publisher.

Published by Karolinska Institutet.

(C) Lena Kallings, 2008

ISBN 978-91-7409-111-3

Printed by

$h \begin{aligned} & \text { REPROPRINT AB } \\ & \text { Stockholm } 2008\end{aligned}$

www.reproprint.se

Gårdsvägen 4, 16970 Solna 
"Carpe diem"

To my family 



\section{ABSTRACT}

Physical activity is one of the most important public health determinants, and the health care sector is highlighted as a central setting in the promotion of physical activity in the population as well as at an individual level. One method that has attracted attention over recent years, is physical activity prescribed by doctors or other health care professionals, even though there is insufficient evidence to determine that any method of promoting physical activity in the health care setting is superior to another. It is therefore important to investigate whether physical activity on prescription leads to a more physically active lifestyle and to possible health benefits in clinical settings.

This thesis investigated the effectiveness of individualized physical activity on prescription making use of two studies with different design and conducted within two different clinical settings. The study populations included patients in general primary health care centres $(n=481,75 \%$ female, mean age 50 years [12-81]) and elderly insufficiently physically active individuals with overweight and abdominal obesity recruited from a population based ongoing prospective cohort study $(\mathrm{n}=101,57 \%$ female, 67-68 years).

The main finding was that individualized prescriptions of physical activity increases physical activity level for at least six months. Physical activity on prescription can be suitable as conventional treatment in an ordinary primary health care setting to promote a more physically active lifestyle. Self-reported physical activity level, stages of change and quality of life increased significantly, and the adherence to physical activity on prescription was $65 \%$, which is as good as adherence to other treatments of chronic diseases. In elderly people with overweight physical activity on prescription is an effective method to increase physical activity level, as significantly higher improvements were seen in the intervention group (two to three times higher) than in the control group regardless of assessment method. Individualized physical activity on prescription also improves body composition and reduces cardiometabolic risk factors in older insufficient physical active overweight individuals.

This thesis shows that individualized physical activity on prescription (PAP) is effective in clinical settings.

- PAP can be carried out as a part of routine care and is effective in promoting physical activity.

- Adherence to PAP in primary health care settings is as good as adherence to other treatments of chronic diseases.

- Self-reported quality of life, both regarding physical and mental aspects increased 6 months after receiving PAP.

- PAP increased physical activity level three times more than in a control group.

- PAP reduced several cardiometabolic risk factors in elderly women and men with low physical activity level, overweight and abdominal obesity.

Therefore, physical activity on prescription has a potential to become an important method for promoting physical activity in a public health perspective, thus improving health and quality of life, and decreasing disease burden both for individuals as well as for the health care system. 


\section{LIST OF PUBLICATIONS}

The thesis is based on the following original articles, which will be referred to in the text by their roman numbers.

I. Kallings LV, Leijon M, Hellénius ML, Ståhle A. Physical activity on prescription in primary health care: a follow-up of physical activity level and quality of life. Scand J Med Sci Sports. 2008;18:154-161.

II. Kallings LV, Leijon ME, Kowalski J, Hellénius ML, Ståhle A. Self-reported adherence - a method for evaluating prescribed physical activity in primary health care patients. J Phys Act Health. In press.

III. Kallings LV, Ståhle A, Hemmingsson E, Höglund C, Kowalski J, Hellénius M-L. Individualized physical activity on prescription increases physical activity level in overweight individuals - results from a randomized controlled trial. Submitted.

IV. Kallings LV, Sierra Johnson J, Fisher RM, de Faire U, Ståhle A, Hemmingsson E, Hellénius M-L. Beneficial effects of individualized physical activity on prescription on body composition and cardiometabolic risk factors - results from a RCT. Eur J Cardiovasc Prev Rehabil. In revision. 


\section{CONTENTS}

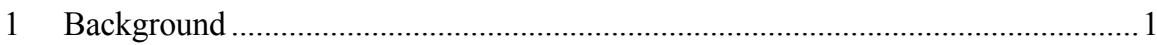

1.1 Physical activity assessments ....................................................................

1.2 Physical activity and public health .............................................................

1.2.1 Magnitude of the public health problem of physical inactivity..........2

1.2.2 Physical activity and health ................................................................

1.2.3 Physical activity and older adults .......................................................

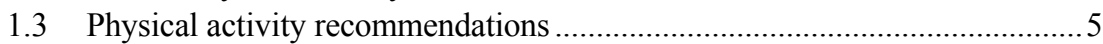

1.4 Physical activity levels in population ...........................................................

1.4.1 Sedentary behaviour in population..................................................... 6

1.5 Strategies for promoting health and physical activity ..................................

1.6 Methods of promoting physical activity in the health care setting.................. 8

1.6.1 Health care sector and public health................................................ 8

1.6.2 Theoretical behaviour change models .............................................. 10

1.6.3 Different methods in use ...............................................................11

1.6.4 Adherence to physical activity intervention ....................................... 13

1.6.5 Ethical aspects ........................................................................... 14

1.6.6 Effectiveness vs. efficacy studies .................................................. 14

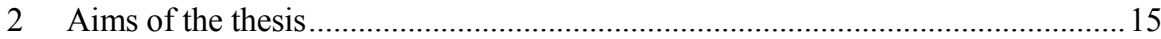

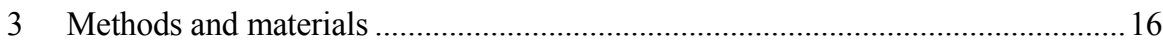

3.1 Physical activity on prescription in primary health care (Paper I and II).....16

3.1.1 Intervention ................................................................................ 17

3.2 Individualized physical activity on prescription to older adults with

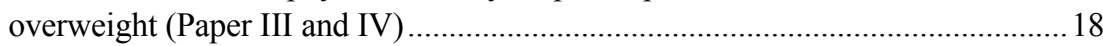

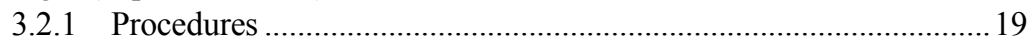

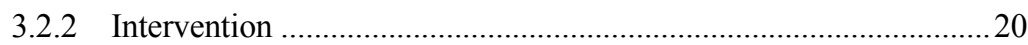

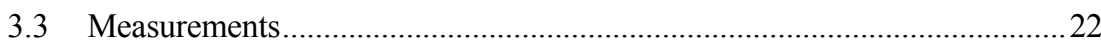

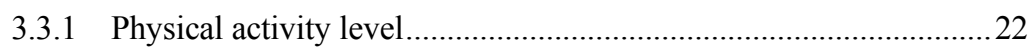

3.3.2 Adherence to prescribed physical activity..........................................24

3.3.3 Anthropometrics............................................................................25

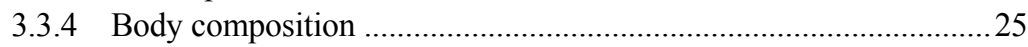

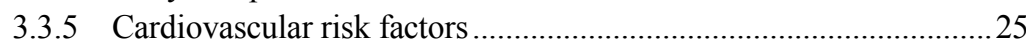

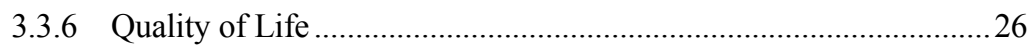

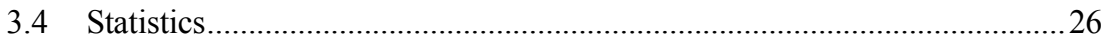

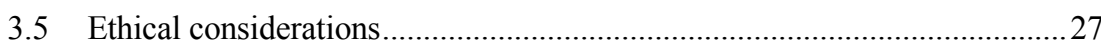

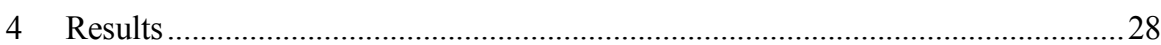

4.1 Characteristics of study population .............................................................28

4.1.1 Study A (Paper I and II) ………………………………………....... 28

4.1.2 Study B (Paper III and IV) ............................................................2

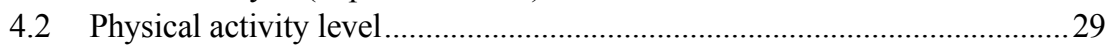

4.2.1 Total physical activity during the last year (Paper I)........................29

4.2.2 Total physical activity in leisure-time (Paper III) ..............................30

4.2.3 Readiness for change (Paper I) ........................................................

4.2.4 Recorded physical activity (Paper III) ..............................................32

4.2.5 Achievements of recommendations (Paper III)...............................32

4.2.6 Steps per day (Paper III)................................................................... 33 
4.2.7 Sedentary behaviour (Paper III) .................................................... 35

4.3 Adherence to physical activity on prescription (Paper II) .......................... 35

4.4 Body composition and cardiometabolic risk factors (Paper IV).................. 36

4.4.1 Anthropometrics and body composition........................................... 36

4.4.2 Cardiovascular risk factors ........................................................... 39

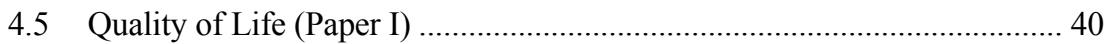

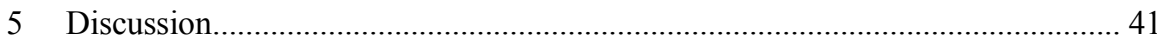

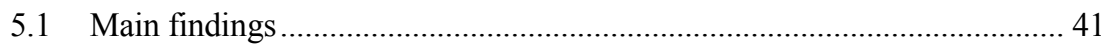

5.2 Effectiveness of individualized physical activity on prescription .............. 41

5.2.1 Physical activity level of study populations compared to general population levels .......................................................................................... 41

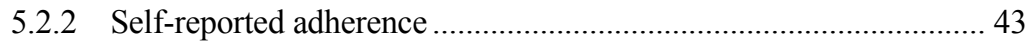

5.2.3 Sedentary behaviour ............................................................. 43

5.2.4 Physical activity on prescription versus control group .................. 43

5.2.5 Effects of physical activity on prescription on health outcomes ..... 44

5.3 Effects of the individualized physical activity on prescription of the current

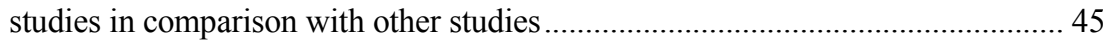

5.3.1 Proportion increasing physical activity level.................................. 45

5.3.2 Study A (Paper I and II) ............................................................... 45

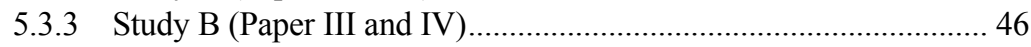

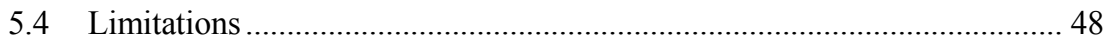

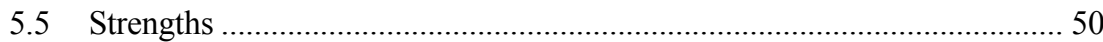

5.6 Translation of the method physical activity on prescription into health care practice

5.6.1 A Swedish perspective............................................................... 52

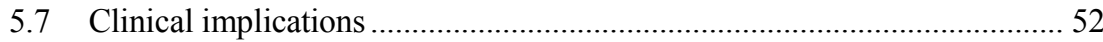

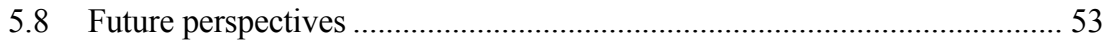

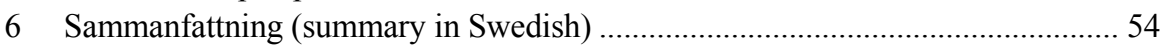

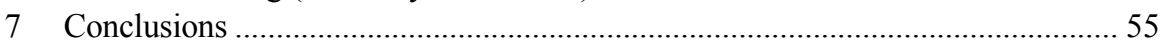

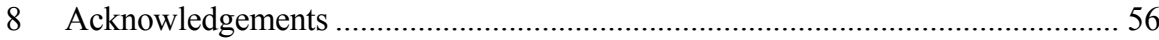

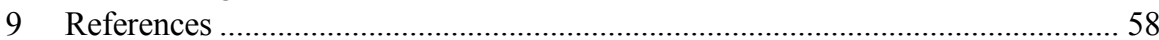

Paper I-IV 


\section{LIST OF ABBREVIATIONS}

$\begin{array}{ll}\text { Apo } & \text { Apolipoprotein } \\ \text { BMI } & \text { Body mass index } \\ \text { CI } & \text { Confidence interval } \\ \text { DALY } & \text { Disability-adjusted life years } \\ \text { HDL } & \text { High-density lipoprotein } \\ \text { IQR } & \text { Interquartile range } \\ \text { ITT } & \text { Intention to treat } \\ \text { LDL } & \text { Low-density lipoprotein } \\ \text { PA } & \text { Physical activity } \\ \text { PAP } & \text { Physical activity on prescription } \\ \text { RCT } & \text { Randomized controlled trial } \\ \text { RPE } & \text { Ratings of perceived exertion } \\ \text { SAD } & \text { Sagittal abdominal diameter } \\ \text { SD } & \text { Standard deviation } \\ \text { WHO } & \text { World health organization }\end{array}$





\section{BACKGROUND}

\subsection{PHYSICAL ACTIVITY ASSESSMENTS}

Physical activity is defined as any bodily movement produced by skeletal muscles that results in energy expenditure [1]. Physical activity is a complex and multidimensional behaviour difficult to measure. A variety of methods have been used to assess physical activity [2-4]. It could be measured as either the behaviour or the energy expenditure of the activity, even though physical activity and energy expenditure are not synonymous terms. Physical activity is a behaviour resulting in energy expenditure and the energy expenditure reflects the energy cost associated with a given activity.

Energy expenditure is a direct function of all metabolic processes involved with the exchange of energy required for muscle contraction associated with a given activity, and is influenced by, for instance, body weight, age and fitness level [5]. Direct methods of measuring energy expenditure are doubly labelled water and calorimetry (e.g. body heat production) and indirect methods are indirect calorimetry (e.g. oxygen uptake, production of carbon dioxide), physiologic measures (e.g. heart rate, ventilation, body temperature, estimated cardio-respiratory fitness) [5].

No single method is available to quantify all aspects of physical activity under freeliving conditions and complementary methods are needed, especially when measuring physical activity in people with low physical activity level or with chronic illnesses [68]. However, a combination of methods in intervention studies are seldom reported [9].

Physical activity level can be measured by indirect methods such as self-reported answers to questionnaires and fitness tests, or by direct methods such as motion sensors (accelerometer, pedometer), diaries and logs [7]. All methods have specific advantages and disadvantages $[2,4,5,10]$. In large population studies the only feasible method is self-reported physical activity collected through questionnaires [11]. Questionnaires is a cheap method and easily applicable on large samples and can be used to classify people into different categories of physical activity level and to monitor changes in population activity $[2,12]$. Limitations of using questionnaires are the limited reliability and validity, the dependence on respondents' memory and interpretation, and it can be influenced by social desirability. Many questionnaires also suffer from "floor effects" (i.e. the lowest score available is too high for some respondents) and fail to capture the lower end of the continuum of physical activity, and consequently can not measure low physical activity levels in sedentary people $[7,12]$.

Objective measurement with pedometer has the advantage of being simple and inexpensive, but assesses only number of steps and consequently misses to detect several important types of physical activities, such as bicycling, training of strength and swimming. Another limitation is the less accuracy at speeds less than $4 \mathrm{~km} / \mathrm{h}$ and both pedometer accuracy and walking speed decreases with age, weight, body mass index (BMI), waist circumference and pedometer tilt [13-15].

Several of the direct methods have the disadvantages of being time or labour intensive, costly, or put a burden on participants [10]. Described records, diaries and logs provide a detailed description of performed activities, but require the participants to record the individual bouts of activity as they occur during the day leading to a burden on both 
participants and data analysis [4]. An overview of assessment methods for physical activity as a behaviour is presented in Table $1.1[2-5,16]$.

Table 1.1. Overview of physical activity assessment methods

\begin{tabular}{|c|c|c|}
\hline Method & Advantages & Disadvantages \\
\hline \multicolumn{3}{|l|}{ Direct } \\
\hline $\begin{array}{l}\text { Direct } \\
\text { observation }\end{array}$ & $\begin{array}{l}\text { - Quantitative and qualitative } \\
\text { information }\end{array}$ & $\begin{array}{l}\text { - Time and labour intensive } \\
\text { - May alter normal physical activity behaviour } \\
\text { (reactivity) }\end{array}$ \\
\hline Accelerometer & $\begin{array}{l}\text { - Objective } \\
\text { - Recording of accelerations in } \\
\text { more than one plane and for } \\
\text { extended period } \\
\text { - Indication of intensity of the } \\
\text { movement }\end{array}$ & $\begin{array}{l}\text { - Expensive for both unit cost and data } \\
\text { management } \\
\text { - No recording of upper-body movements, } \\
\text { carrying a load }\end{array}$ \\
\hline Pedometer & $\begin{array}{l}\text { - Objective } \\
\text { - Simple and inexpensive }\end{array}$ & $\begin{array}{l}\text { - Only walking or running steps } \\
\text { - No recording of horizontal or upper-body } \\
\text { movements } \\
\text { - No information of specific activity or intensity }\end{array}$ \\
\hline $\begin{array}{l}\text { Records, logs, } \\
\text { diary }\end{array}$ & $\begin{array}{l}\text { - Quantitative and qualitative } \\
\text { information }\end{array}$ & $\begin{array}{l}\text { - Self-report } \\
\text { - Rely on respondents ability to provide good } \\
\text { information } \\
\text { - Burden on both participants and data analysis } \\
\text { - May alter normal physical activity behaviour } \\
\text { (reactivity) }\end{array}$ \\
\hline $\begin{array}{l}\text { Indirect } \\
\text { Questionnaires } \\
\text { and recalls }\end{array}$ & $\begin{array}{l}\text { - Quantitative and qualitative } \\
\text { information } \\
\text { - Inexpensive } \\
\text { - Possible to use in large-scale } \\
\text { studies and surveys }\end{array}$ & $\begin{array}{l}\text { - Self-report } \\
\text { - Rely on respondents ability to provide good } \\
\text { information }\end{array}$ \\
\hline
\end{tabular}

Sedentary behaviour is often not well defined and the least well measured dimension of measurable components of self-reported physical activity [7, 17-19]. As measurement of physical activity in people that are sedentary or with low physical activity level is difficult and existing self-report methods suffer from floor effects, it is important to measure the sedentary behaviour and not just define it as lack of physical activity [7, 17]. The most common method used, so far, has been questionnaires asking about television viewing, especially among youth. One questionnaire that has acceptable reliability and has been found valid for men and women from several countries for assessing total time per day spent sitting is the sitting items from short version of the IPAQ last 7-days questionnaire [17]. When using accelerometer sedentary behaviour is often defined as minutes with counts $<100$ per minute as this captures time spent sitting or lying still, such as while watching television and playing video games [17].

\subsection{PHYSICAL ACTIVITY AND PUBLIC HEALTH}

\subsubsection{Magnitude of the public health problem of physical inactivity} Insufficient physical activity constitutes a global health hazard, due to its worldwide prevalence, its large role in non-communicable disease risk and the fact that physical inactivity is one of ten powerful risk factors for dying prematurely [20, 21]. Increasing physical activity and obesity prevention are now considered to be as important as tobacco control to minimising the burden of non-communicable diseases [18, 21, 22]. 
Conservative estimate of the burden attributable to inactive lifestyles have been estimated, but it is probable underestimated [23]. Successful promotion of a more physical active lifestyle would prevent at least 2 million premature deaths and 20 million disability-adjusted life years (DALYs) worldwide [23]. Inactivity accounts for at least $22 \%$ of ischemic heart disease, $11 \%$ of ischemic stroke, $14 \%$ of type 2 -diabetes, $16 \%$ of colon cancer and $10 \%$ of breast cancer worldwide [23].

In Europe physical inactivity is the $5^{\text {th }}$ leading mortality risk factor, and the $4^{\text {th }}$ (women) or $7^{\text {th }}$ (men) leading risk factor for burden of disease [24]. Every year, physical inactivity is responsible for 600000 deaths (6\% of the total) and 5.3 million DALYs (3.5\% of the total) in the WHO European Region [25]. In addition, physical inactivity is also associated with three of the other leading risk conditions: high blood pressure, high blood cholesterol and overweight that are responsible for $12.8 \%, 8.7 \%$ and $7.8 \%$ of DALYs respectively [25]. In Sweden physical inactivity is the $5^{\text {th }}$ (women) or $6^{\text {th }}$ (men) leading risk factor for burden of disease, otherwise there are no major differences between WHO European Region data and Swedish data [26].

\subsubsection{Physical activity and health}

Strong evidence links higher levels of physical activity to improved health [16, 27-29]. Increased physical activity improves quality of life, and individuals reaching recommended physical activity levels are more likely to have a better overall healthrelated quality of life and perceived health status than those who did not [30-32].

Regular physical activity is widely accepted as a behaviour to improve a number if health outcomes and reduce all-cause mortality. However, fitness is a more common outcome than physical activity, when the association between physical activity and health is studied. Although, there is a dose-response relation between physical activity and fitness [33, 34], and Lee concludes that "Even little is good; more may be better" [34]. The dose-response relation between physical activity and health is evident in some cases, i.e. all-cause mortality, total cardiovascular diseases, coronary heart disease incidence and mortality, and for the incidence of type 2-diabetes [35]. On the other hand, it is more difficult to determine for other health outcomes, as it is not that well studied or due to methodological problems [35].

Insufficient physical activity and high BMI constitute a global health hazard, due to their worldwide prevalence and their association with increased risk for diseases such as type 2 -diabetes, ischemic heart disease, hypertension, stroke and several forms of cancer $[20,36]$. In addition enlarged waist, i.e. abdominal obesity, is associated with increased risk of cardiovascular diseases, type 2 -diabetes as well as mortality [37-41].

Epidemiological studies show that physically active individuals run a lower risk of type 2 -diabetes and a 50\% less risk of dying from cardiovascular diseases when compared to inactive persons. Furthermore, physical active overweight and obese individuals have a lower risk of all-cause and cardiovascular disease mortality than inactive overweight or obese individuals [28, 29, 42-44]. Avoiding a sedentary lifestyle during adulthood prevents cardiovascular disease independently of other risk factors and substantially expands the total life expectancy and the cardiovascular disease-free life expectancy [45]. Moderate and high physical activity levels led to 1.3 and 3.7 years more in total life expectancy and 1.1 and 3.2 more years lived without cardiovascular disease, respectively, for men aged 50 years or older compared with those who maintained a low physical activity level. For women the differences are 1.5 and 3.5 years in total life expectancy and 1.3 and 3.3 more years lived free of cardiovascular 
disease, respectively [45]. Three randomised controlled studies in overweight men and women with impaired glucose tolerance have shown that a combined intervention with diet and physical activity can reduce the risk for type 2-diabetes by approximately $50 \%$ [46-48]. Within the first year cardio-metabolic risk factors such as waist, glucose, insulin, lipids and blood pressure decreased significantly in the intervention group [47]. Although the Chinese Da Qing study investigated the separate effects of diet and exercise [46], the independent effect of increased physical activity is still not fully studied. In men with type 2-diabetes monitored for 15 years the total mortality was $50 \%$ less in those who undertook regular physical exercise [49]. Some randomised controlled studies have demonstrated that abdominal fat is reduced with more physical activity as well as the total weight $[50,51]$.

A review of epidemiological studies regarding mortality, coronary heart disease, diabetes, and specific metabolic risk factors conclude that inactivity (sitting) and low non-exercise activity may produce serious health problems, and this cannot simply be explained by exercise deficiency [52-54].

According to Pedersen and Saltin (2006) the evidence of physical activity in selected cases suggests that exercise therapy is just as effective as medical treatment - and in special situations more effective - or adds to the effect [27]. In the medical world it is traditional to prescribe the evidence-based treatment known to be the most effective and entailing the fewest side effects or risks. Today there are a number of documents that describe the health benefits of physical activity and its role in prevention and treatment of several disorders and diseases $[16,27,55,56]$. For instance insulin resistance, dyslipidemia, hypertension, obesity, coronary heart disease, osteoarthritis, cancer and depression. Therefore, it is urgent to find methods that may increase physical activity as well as reduce sedentary behaviour such as sitting.

\subsubsection{Physical activity and older adults}

Because most chronic diseases manifest themselves late in life, aging individuals need to adopt healthier behaviours, such as increased physical activity, to change risk factors and to avoid or delay preventable disability. However, risk factors such as overweight, obesity, and central obesity increases with age, while physical activity decreases with increased age [23, 57-61]. Increased physical activity might counteract age-related changes and performance loss [62]. In the age group 60 to 69 the relative risk estimate globally for physically inactive versus sufficiently active is 1.7 for ischemic heart disease, 1.5 for ischemic stroke, 1.7 for colon cancer, 1.4 for type 2 -diabetes and, for women, 1.3 for breast cancer [23]. In Sweden people 60-years of age have an accumulation of risk factors for developing type 2-diabetes and cardiovascular diseases. A cross-sectional study shows that $68 \%$ of 60 -year old women and men reported inactivity or light physical activity [63] and that $69 \%$ of the men and $60 \%$ of the women were overweight, $19 \%$ and $20 \%$ respectively obese, abdominal obesity was frequent and $32 \%$ of the men had a waist circumference of $>102 \mathrm{~cm}$ and $42 \%$ of the women had $>88 \mathrm{~cm}$ [64]. Also the prevalence of type 2-diabetes is worryingly high (10\% in the men and $5 \%$ in the women) and high prevalence of the metabolic syndrome were found ( $24 \%$ in men and $19 \%$ in women), with a three-fold risk of having the metabolic syndrome in the lowest compared to highest physical activity group $[63,64]$. Because the proportion of older people ( $>65$ years) in the population is rising worldwide $[65,66]$, and this group clearly exhibits several unhealthy risk factors $[23,24]$, it is important to develop and evaluate methods for promoting healthy behaviours to both women and men. 


\subsection{PHYSICAL ACTIVITY RECOMMENDATIONS}

In 1995 a public health recommendation on the types and amounts of physical activity needed for health promotion and disease prevention was launched by Centers for Disease Control and Prevention and the American College of Sports Medicine [67]. The recommendation for adults was "Every adult should accumulate 30 minutes or more of moderate-intensity physical activity on most, preferably all, days of the week". The recommendation emphasized that physical activity can be accumulated in relatively short bouts. This recommendation has recently (2007) been updated for healthy adults aged 18 to 65 year [68]:

- To promote and maintain health, all healthy adults need moderate-intensity aerobic (endurance) physical activity for a minimum of $30 \mathrm{~min}$ on five days each week or vigorous-intensity aerobic physical activity for a minimum of 20 min on three days each week. Combinations of moderate- and vigorous-intensity activity can be performed to meet this recommendation.

- Moderate-intensity aerobic activity (equivalent to a brisk walk and noticeably accelerated heart rate) can be accumulated toward the 30-min minimum by performing bouts each lasting 10 or more minutes.

- Every adult should perform activities that maintain or increase muscular strength and endurance a minimum of two days each week.

- Because of the dose-response relation between physical activity and health, persons who wish to further improve their personal fitness, reduce their risk for chronic diseases and disabilities or prevent unhealthy weight gain may benefit by exceeding the minimum recommended amounts of physical activity.

The physical activity recommendation for older adults (65+ years) and adults aged 50 64 with clinically significant chronic conditions (a person receives/should receive regular medical care and treatment for it) or functional limitations (impairs the ability to engage in physical activity) is similar to the recommendation for healthy adults but has several important differences [69]:

- The recommended intensity of aerobic activity takes into account the older adult's aerobic fitness.

- Activities that maintain or increase flexibility are recommended.

- Balance exercises are recommended for older adults at risk of falls.

- Older adults should have an activity plan for achieving recommended physical activity that integrates preventive and therapeutic recommendations.

- The promotion of physical activity in older adults should emphasize moderateintensity aerobic activity, muscle-strengthening activity, reducing sedentary behaviour, and risk management.

\subsection{PHYSICAL ACTIVITY LEVELS IN POPULATION}

There are few reports of trends in total physical activity, but an overall trend of declining total physical activity can be seen over the last 50 to 60 years $[70,71]$. Several studies have found an increase in leisure time physical activity at least in men [70-73]. Still, this can not compensate for the decrease in other dimension of physical 
activity, such as declining work-related activity, declining transportation activity, declining activity in the home, and increasing sedentary activity [70-72, 74]. Changes in society as industrialization and economic growth have resulting in a shift in the types of activities that people perform in their daily routines, with increased televisionwatching and computer use and a variety of daily tasks (such as clothes and dish washing, transportation to work and elevators) have been automated. This has resulted in less energy expenditure compared to performing the same tasks manually. One study has found that the magnitude of the energy impact of studied mechanized tasks was substantial (111 kcal/d) [75].

Estimation of physical activity levels in the population varies between studies as several different definitions are in use. Several studies with different definitions of recommended physical activity level have, found though that nearly one third of the population in the United States and Europe reach recommended physical activity level based on self-reported data $[23,76,77]$. However, in the study among 15 countries in the European Union the lowest prevalence was found for Sweden, were only $23 \%$ reported sufficient activity levels [77]. A Swedish study found on the other hand higher total physical activity level with the same questionnaire than the pan-European study [77-79].

According to WHO the global estimate for total inactivity is $17 \%$ (defined as doing no or very little physical activity at work, at home, for transportation or at leisure time), with a variation from 10 to $47 \%$ between different regions, age and sex categories [23]. The global estimate for insufficient activity is $41 \%$ (doing some physical activity but less than 150 minutes of moderate-intensity or 60 minutes of vigorous-intensity physical activity a week accumulated across work, home, transport or leisure time), with a variation between 32 and 52\%. Across most regions female were slightly more inactive than males and older adults more inactive than younger adults [23]. In Europe (WHO Region Europe A) inactivity prevalence is approximate $18 \%$, it increases by age and varies between 13 and $21 \%$ for males and 17 to $28 \%$ for females. Insufficient activity is approximate $51 \%$, with a variation between 42 and $57 \%$ [23].

\subsubsection{Sedentary behaviour in population}

Little is known about average amount of sedentary behaviour in the population, and the current estimate may be an underestimation as it rely mainly on screen time (television viewing or computer use) [80]. Sedentary and physical inactivity have been used as if they were equivalent and with several different definitions. Consequently, there are great variations in reported prevalence in population between studies and even contradicting results in classifications of countries [78, 81, 82]. European Union citizens report on average just over five hours sitting on a normal day, and in Sweden nearly six hours [82].

Objectively measured inactivity levels, assessed by accelerometers, indicate that 7.7 hours per day or $55 \%$ of waking hours are spent in very low levels of energy expenditure, both in the United States and in Sweden [80, 83]. In the United States it was found that the sedentary behaviour increased with age: older adults ( $>60$ years) spent nearly $60 \%$ (more than 8 hours/day) of their time sedentary [80]. 


\subsection{STRATEGIES FOR PROMOTING HEALTH AND PHYSICAL ACTIVITY}

There are several global, regional and national policy documents and strategies focusing on promoting health, where physical activity is highlighted as one leading health indicator [57, 84-87].

\subsubsection{National public health policy}

The national public health objective is to create social conditions to ensure good health, on equal terms, for the entire population [88]. The Swedish Parliament adopted in April 2003 a national health policy stipulating eleven general objectives that cover the most important determinants of Swedish public health [89]. This national health policy also stresses that improving health of those groups that are most vulnerable to ill-health is particularly important. This thesis focuses on two of the general objectives: increased physical activity and a more health-promoting health service.

The rational for the general objective "increased physical activity" is that physical activity has grown into a major public health issue at the municipal, regional and national levels. The issue has gone from being a matter for the individual to becoming an important issue for the society. The aim for society is to provide conditions for the entire population to increase their physical activity. This shall be brought about mainly by stimulating more physical activity in pre-schools, schools and at workplaces, more physical activity in leisure time and greater opportunities among senior citizens, people on long-term sick-leave and disabled persons to exercise on their own terms.

The rational for the general objective "a more health-promoting health service" is that health services are of considerable importance to long-term health trends through their specific expertise, authority, broad knowledge and ability to come into contact with a large part of the population. The aim is that a more health-promoting and disease-preventative perspective should permeate all health services and be an integrated part of all care and treatment. The health and medical care services already have a legal responsibility for the population's health and for conducting preventive measures, but the public health bill points out the current shortcomings in the medical care services' preventive efforts. The potential for being able to intervene at an early stage concerning physical activity and other lifestyles is poorly utilized and there is too much of a tendency to use pharmaceuticals as a preventive course of action instead of proposing non-medicinal measures. It is stated in the bill that primary care plays an important role in these health promotion efforts and by cooperating with other key actors in health promotion and preventative efforts the work aimed at the population can be done.

\subsubsection{National initiative to promote physical activity in the population}

A long-term strategy of change with the aim of promoting health and preventing disease by increased physical activity started with "Sweden on the move 2001" [90-92]. The main emphasis of the message was the importance of daily physical activity, including exercise, sport and recreation, to promote good health. The aims and objectives were based on the Ottawa charter and the five strategies: strengthen community action, develop personal skills, reorient health services, create supportive 
environments and build healthy public policy, as well as on the National Public Health Committee's proposals of aims for physical activity [93, 94]. The strategy of "Sweden on the move" was based on four settings; pre-school and school, workplace, health care, and leisure time.

The overall goals in the area of healthcare were to make healthcare professionals more aware of the preventive effects of physical activity, to develop guiding principles for different patient groups and to support research. Several strategies were used to reach these goals;

- A national recommendation for physical activity was developed by "Yrkesföreningar för fysisk aktivitet" (YFA, a part of the section for Sports Medicine in The Swedish Society of Medicine), i.e.: every individual ought to accumulate at least 30 minutes of at least moderate intensity of physical activity, preferable every day. Additional health benefits are likely when a greater amount of physical activity is performed [95].

- A evidence based handbook "FYSS (Physical activity in prevention and treatment of diseases)" on the effects of physical activity and health and how to prescribe physical activity was produced both as a internet source www.fyss.se and as a printed book [95].

- A prescription form for physical activity was created looking like the ordinary drug prescription form.

- A national study was initiated by the National Institute of Public Health in cooperation with The Centre for Public Health Sciences, Linköping, Sweden to study the concept of "Physical Activity on Prescription" (Swedish: Fysisk aktivitet på Recept, $\left.\mathrm{FaR}^{\circledR}\right)$. It was conducted in co-operation with 13 primary health care units in five counties. The objective of this study was to develop and describe the working method and structure of Physical Activity on Prescription (PAP) and the organised enhancement of physical activity in order to promote health and prevent disease [90].

\subsection{METHODS OF PROMOTING PHYSICAL ACTIVITY IN THE HEALTH CARE SETTING}

\subsubsection{Health care sector and public health}

To increase physical activity in the population, different types of intervention methods are required [96]. From a public health point of view, it is important to reach the most inactive groups in society and to increase their physical activity, as small changes in many have a greater potential to influence public health than large changes in a few [97].

The health care sector is highlighted as a central setting in the promotion of physical activity in the population as well as at an individual level in global, regional and national strategies for physical activity, diet and health [57, 84, 86, 87]. A unique situation prevails in the health and medical services, namely that they reach practically the entire population on the one hand and for the most part each person individually on the other hand [98]. Around two thirds of the population will meet a doctor at least once during a 12-months period [98, 99], and this provides health care professionals 
with an excellent opportunity for physical activity promotion. Several agencies recommend that physicians and other health professionals should routinely counsel patients to adopt and maintain regular physical activity $[67,84,85,100,101]$.

Research findings concerning how and to what extent healthcare institutions promote physical activity are limited in number. Studies indicate that promotion of physical activity in the health care setting is an underused method to promote health in the population as well as to prevent and treat diseases in high risk groups. Even though general practitioners believe they should give advice or counsel about physical activity, they are less likely to do so in practice, and more than half are sceptical about their ability to help patients practise regular physical activity [102, 103]. Existing data suggest wide variability in the number of patients who receive physical activity counselling from physicians. Around half of the GPs in Europe counsel sedentary patients [103], and in US 59\% of the GPs report that they counsel more than 50\% of their patients about physical activity, and $18 \%$ prescribe physical activity for more than $50 \%$ of their patients [102]. On the other hand direct observation of physician in US indicate that only $20 \%$ of visits to physician results in counselling about physical activity [104]. Twenty eight percent of adults in the US report receiving physician advice to increase their level of physical activity, and of this only $40 \%$ also reported receiving help in making a plan for physical activity or follow-up support [105]. Survey of clinical practice in Sweden in year 2005 indicates that healthcare units regard the promotion of physical activity as a vital ingredient of their overall responsibility and care professionals have great confidence in the benefits of physical activity and generally regard its promotion as integral to their duties [106-108]. Although all segments of healthcare (primary health care, occupational health care, hospital clinic and school health services), were actively involved in promoting physical activity, only in the occupational health care the majority had procedures and programs concerning how to do it [106-108]. The use of oral recommendation for promoting physical activity is common, but written prescriptions or referring patients to other healthcare professionals is less frequent and the concrete effort to promote physical activity varies greatly among and within various healthcare segments [106-108]. Also data from Finland indicates that discussion of physical activity is most common among physician in occupational health care [99].

However, there is still insufficient evidence to determine that any method of promoting physical activity in the health care setting is superior to another $[107,109,110]$. Common problems when evaluating the literature is insufficient description of intervention methods, to short follow-up periods (less than six months) to evaluate the permanence of the intervention, and difficulties assessing physical activity level [107]. One method that has attracted attention over recent years, is physical activity prescribed by doctors or other health care professionals [30, 110-117]. There is still insufficient evidence to determine whether counselling patients in primary care settings to promote physical activity leads to a sustained increase in physical activity level, as trials of physical activity counselling in primary care patients are of variable quality and shows mixed results [30,110,118-121]. A contributing reason is the great variation in methods used, such as what is included in the intervention, who have conducted it, what kind of physical activity that was prescribed, a standard prescription or an individualized. Nevertheless written prescription of physical activity has been implemented in several countries $[117,122]$. It is, therefore, important to conduct more randomized controlled trials (RCT) and investigate whether physical activity on prescription leads to a more physically active lifestyle and to possible health benefits in 
clinical settings in order to determine if physical activity on prescription is an effective method.

\subsubsection{Theoretical behaviour change models}

Theories and models can help to explain behaviour and why people are not caring for themselves and their health or not following public health and medical advices. These methods may suggest ways to achieve behaviour change [123]. During the various stages of planning, implementing, and evaluating interventions theories can be useful. Even though various theoretical models of health behaviour may reflect the same general ideas, each theory focus on specific factors considered important. Today, no single theory or conceptual framework dominates research or practice in health promotion and education. Instead, one can choose from a variety of theories. Many studies of different physical activity interventions are based on theoretical behaviour change models, usually the social cognitive theory and the transtheoretical model or multiple components from different theories [107, 124, 125].

\subsubsection{Social Cognitive Theory}

The Social Cognitive Theory emphasizes the interaction among people, their surroundings and their behaviour [123]. The theory stresses the importance of greater self-efficacy, i.e. people's beliefs about their capabilities to be for instance physically active at different situations, environments, seasons, weather conditions etc. Common techniques used are discussions on knowledge of health risks and benefits of physical activity, outcome expectations about costs and benefits for changed physical activity, goal setting and concrete plans and strategies for realizing them. Self-monitoring of physical activity is also an important factor.

\subsubsection{The Transtheoretical Model}

The transtheoretical model has been applied to many health behaviours to understand the stages through which individuals progress, and the cognitive and behavioural processes they use while changing health behaviours [107, 126, 127]. The model postulates that individuals engaging in a new behaviour move through five stages of change:

- Precontemplation is the stage at which there is no intention to change behaviour in the foreseeable future. Many individuals in this stage are unaware or "underaware" of their problems.

- Contemplation is the stage in which people are aware that a problem exists and are seriously thinking about overcoming it but have not yet made a commitment to take action.

- Preparation is a stage that combines intention and behavioural criteria. Individuals in this stage are intending to take action in the next month and have unsuccessfully taken action in the past year.

- Action is the stage in which individuals modify their behaviour, experiences, or environment in order to overcome their problems. Action involves the most overt behavioural changes and requires considerable commitment of time and energy.

- Maintenance is the stage in which people work to prevent relapse and consolidate the gains attained during action. 
Movement through these stages could be both linear and cyclical as many individuals must make several attempts at behaviour change before their goals are realized [128]. Some common components of the transtheoretical model that have been applied to physical activity are decisional balance (the pros and cons of change) and self-efficacy (confidence in the ability to change across problem situations). There is a ongoing debate of the merit of the transtheoretical model [129]. Evidence for the construct validity of the method as applied to exercise is mixed, but two recent reviews suggest that the transtheoretical model can be applied to physical activity [107, 127].

\subsubsection{5 A's organizational construct}

One method that have been proposed by several agencies as a minimal contact interventions that can be provided by a variety of clinical staff in primary care settings is the $5 \mathrm{~A}$ 's organizational construct for clinical counselling [130-132]. The $5 \mathrm{~A}$ 's are a sequential series of steps to use during health care interactions, which facilitate patientcentred care and patient self-management. The five steps are assess, advice, agree, assist, and arrange. They represent an approach that emphasizes collaborative goal setting, patient skill building to overcome barriers, self-monitoring, personalized feedback, and systematic links to community resources [132]. It is stressed that several tasks associated with the scheme can be completed by clinical staff other than the physician. For example, nurses, dieticians, or educators can work with patients following physician's advice to develop the more time-consuming barrier-based coping strategies and action plans, and to conduct follow-up [131]. According to WHO the key to success in using $5 \mathrm{~A}$ 's is to employ all $5 \mathrm{~A}$ 's at each visit, use open-ended questions to enhance patient-centeredness, to provide proactive care and follow-up, document delivery of 5 A's and provide patient copy of action plan [132]. The 5 A's will work if implemented consistently, most successful health care teams share the $5 \mathrm{~A}$ 's workload among several team members, and each health care team needs to tailor or customize how the 5 A's are implemented - the "who, what, when, and how".

\subsubsection{Different methods in use}

Different methods are in use for promoting physical activity in the health care setting, and no consensus has been reached about best practice. This is probably not possible to find, as the health care is organized in diverse ways in different countries and health care professionals have partly different roles in different cultures. A common method is counselling in primary health care $[110,133]$. Two frequent strategies are physical activity on prescription and exercise referral schemes, even though they are named in a various ways [30,101, 117, 134]. Physical activity on prescription means counselling by health care professionals resulting in a written prescription. It is, however, great variations in methods used regarding who counsels, what kind of physical activity that is prescribed, if there is any theory base techniques involved etc. Physical activity on prescription is in use in for instance New Zeeland, Australia, Sweden and Finland. An exercise referral scheme directs someone to a service offering an assessment of need, development of a tailored physical activity programme, monitoring of progress and a follow-up. It is in use in for instance United Kingdom and Denmark and the most common model of exercise referral system involve referral from a primary care practitioner to a 10-14 week exercise programme run by local leisure services [134136]. However, two newly presented RCT suggest that there are no extra benefits of referral to supervised exercise further than the effect of physical activity on prescription 
$[137,138]$. An overview of different methods of promoting physical activity in the health care setting is presented in Table 1.2.

Table 1.2. An overview of different methods* of promoting physical activity in the health care setting

\begin{tabular}{ll}
\hline Method & Description \\
\hline Advice and Counselling & $\begin{array}{l}\text { Direct advice from a healthcare professional to a patient, and a dialogue } \\
\text { between two equivalent partners [107] }\end{array}$ \\
$\begin{array}{l}\text { Theory-based Behavioural } \\
\text { Interventions }\end{array}$ & $\begin{array}{l}\text { Interventions based on theoretical behaviour change models, two main } \\
\text { models used: the Social Cognitive Theory and the Transtheoretical Model } \\
{[107]}\end{array}$ \\
$\begin{array}{l}\text { Supervised Exercise in } \\
\text { Group and individualized }\end{array}$ & $\begin{array}{l}\text { Some type of organised and professionally supervised exercise - usually } \\
\text { on an outpatient basis at a hospital or care facility - and/or } \\
\text { individualized, professionally supervised home exercise programs [107] }\end{array}$ \\
$\begin{array}{l}\text { Exercise/Physical Activity } \\
\text { on Prescription }\end{array}$ & $\begin{array}{l}\text { Counselling by health care professionals resulting in a written } \\
\text { prescription }\end{array}$ \\
$\begin{array}{l}\text { Swedish version of } \\
\text { Physical Activity on } \\
\text { Prescription (FaR) }\end{array}$ & $\begin{array}{l}\text { A formal prescription either for supervised group-based exercise or } \\
\text { lifestyle-based physical activity or recreation outside the health care } \\
\text { system. A fundamental part is the collaboration between the health care } \\
\text { system and societal organisations with long experience of working with } \\
\text { physical activity, exercise and training, such as sports- and leisure } \\
\text { organisations. After initial prescription from legitimate medical staff, the } \\
\text { patient is then referred to formal or informal activities [139]. }\end{array}$ \\
$\begin{array}{l}\text { Exercise Referral Schemes } \\
\text { Referring patient into a recognised system, with appropriately qualified } \\
\text { staff. Based on partnerships between health and local authorities, } \\
\text { especially leisure professionals [140]. }\end{array}$ \\
\hline
\end{tabular}

*Within every method, great variation in conducted intervention are described

\subsubsection{Sweden}

In the 1980s several cardiovascular prevention programmes started in the primary health care in Sweden for example in Sollentuna, Norsjö, Habo and Strömstad [141143]. The programmes had a population based strategy with intervention of several risk factors including counselling about lifestyles such as physical activity. It was found feasible to counsel patients in primary health care and positive effects were found on health outcomes [50,142, 143]. The physical activity intervention in Sollentuna included individualized written prescriptions of physical activity and referrals to a local public physical activity organisation and was performed by general practitioners, nurses and physiotherapist. An increased physical activity level was still significant after 18 months [144]. Although these positive effects found in Swedish primary health care, the method of prescribing physical activity was not disseminated throughout the country, only local initiatives were found. In light of the broader knowledge base from different countries and the public health recommendation for physical activity from 1995, a national work started to develop a structure for "Physical Activity on Prescription" (PAP, Swedish: Fysisk aktivitet på Recept, FaR ${ }^{\circledR}$ ) and implement it in the primary health care. The work was based on experiences from national and international practice and research $[90,114]$.

The PAP method is based on patient-centre counselling and includes an individualized written prescription of physical activity and an overall solution with supporting environment in the society [90]. It can be issued to both healthy and ill individuals to prevent or treat diseases. Physical activity on prescription can be used in combination 
with or instead of drugs. The prescription should be based on the evidence based handbook "FYSS (Physical activity in prevention and treatment of diseases)" that describe the effects of physical activity in the prevention and treatment of diseases [55, 95]. The prescription should be written. Depending on the patients preferences and motivational level the prescription could either be to formal supervised group-based exercise or to more lifestyle-based physical activity or physical activity outside formal programmes. It is important with supporting environment which helps the patient to begin with physical activity and to increase adherence to the prescription. A supporting environment could be a well defined structure from primary health care organizations of activities, special designed activity groups and special trained physical activity instructors or motivational support. As with all treatments the PAP should be follow-up in order to check if the physical activity is feasible for the patient, leads to desired health effects, the dosage need adjustments, to stress the importance of physical activity etc. The PAP method in Sweden is based on five corner stones (Figure 1.1) and then the exact structure is adapted to local pre-requisites.

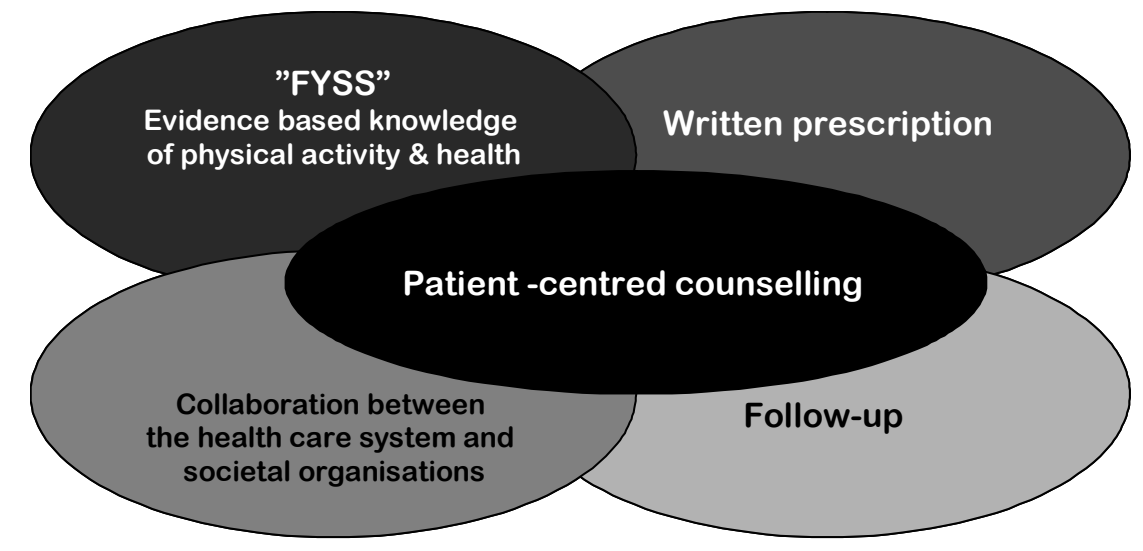

Figure 1.1. An overview of the method of individualized physical activity on prescription

\subsubsection{Adherence to physical activity intervention}

Accurate assessment of adherence is necessary for evaluation of methods to promote physical activity, as poor adherence limits the effectiveness of the treatment and, thereby, the possibility to improve patients' health and quality of life [145]. Adherence to prescribed treatments is one of the key aspects of successful methods. Several studies have focused on factors related to physical activity adherence, but few intervention studies have examined adherence as a primary outcome variable [146]. To our knowledge, there are no validated questions to investigate the patient's own view on adherence to physical activity interventions, and no gold standard for assessment of adherence [145]. The existing literature mostly focuses on medication adherence [145]. There are several concepts used to describe how well a patient follows a prescription or lifestyle advice. Adherence implies the patient's active choice in following medical recommendations, in contrast to passive compliance [147]. In Paper II the WHO definition of adherence to long-term therapy was used: "the extent to which a person's behaviour - taking medication, following a diet, and/or executing lifestyle changes, corresponds with agreed recommendations from a health care provider" [145]. 
There are also major gaps between research and practice [107, 148]. Randomized controlled trials have shown the efficacy of interventions tested under controlled conditions (focus on internal validity), but there is a need for studies that show the effectiveness of promoting physical activity in everyday clinical practice (focus on external validity) $[148,149]$. Poor adherence to treatment, including both medications and lifestyle changes, is a worldwide problem. In developed countries, the adherence to long-term therapy for chronic illness averages $50 \%$, and so far the literature has mostly focused on medication adherence [145]. Despite the increased interest in physical activity promotion in primary health care, there is a lack of studies documenting patients' self-reported adherence as a primary outcome. Adherence is often used as a dichotomous variable, adherence or non adherence, but appropriate adherence must be situational defined and follows a continuum [150]. Assessment of adherence could be more accurate, when using two or more methods that compensate for each other if they have a relation in their results [150]. When adherences to physical intervention studies are measured it could for example be as number of sessions attended divided by prescribed sessions or change in fitness level.

\subsubsection{Ethical aspects}

When working with individual's lifestyle and behaviour, such as physical activity, it is important to recognize the autonomy of the individual and use a patient-centred approach. Neither should unwillingness to invade the privacy of patients go so far that health care professional refrain from recommending physical activity even when they know that it will be highly beneficial. The goal should be to focus on the patients in a way that gives them the opportunity to actively participate in decisions about the most suitable method of treatment. Optimal use of various methods of promoting physical activity demands strict attention to their ethical and social aspects [107].

\subsubsection{Effectiveness vs. efficacy studies}

Several methods used in practice has been started without a thoroughly evaluation and in order to use resources most efficiently it is important to know that interventions really promote physical activity. On the other hand, there is also a call to translate effective interventions into practice. This gap between research and practice is found in many areas of health care and public health [151-153]. In order to increase translation of research into practice, evidence from RCT are needed in combination with studies conducted in the setting where the intervention are going to be used in practice [153]. Estabrooks and Gyurcsik suggested in 2003 three research phases for the development of health promotion programs [149]:

- Efficacy trials evaluate if a program does more good than harm when delivered under optimum conditions. RCT are typically used. Primary goal is to determine if the intervention work. Positive or negative effects can be directly attributed to the intervention since the strict control and standardization of an efficacy trial. However, there is no guarantee that an efficacious intervention will be effective in a real world setting.

- Effectiveness trials evaluate if a program does more good than harm when delivered under real-world conditions. Primary goal is to determine if the intervention works in actual practice. Less stringent control and standardization, resulting in only positive effects can be directly attributed to the intervention, and if no changes occur it might be caused by improper deliver of the intervention.

- Demonstration studies determine the effect of an efficacious intervention on public health when delivered in whole systems. 


\section{AIMS OF THE THESIS}

The general objective of this thesis was to investigate the effectiveness and efficacy of individualized physical activity on prescription (PAP) as a method of promoting physical activity in health care settings.

The specific aims were to evaluate:

- the feasibility and effects of PAP on physical activity level in a routine clinical setting within primary health care

- self-reported adherence to PAP in patients in primary health care settings

- the effects of PAP on self-reported quality of life in primary health care settings

- the efficacy of PAP to increase physical activity level in insufficiently physically active elderly women and men with overweight and abdominal obesity

- the efficacy of PAP to reduce cardio-metabolic risk factors in elderly women and men with low physical activity level, overweight and abdominal obesity 


\section{METHODS AND MATERIALS}

\subsection{PHYSICAL ACTIVITY ON PRESCRIPTION IN PRIMARY HEALTH CARE (PAPER I AND II)}

This study (Study A) was part of a national programme "Sweden on the move - 2001" that focuses on people's need for physical activity (PA) in order to promote health and well-being [91, 92]. The strategy of "Sweden on the move" was based on settings, one of which was the healthcare system. The overall goals in the area of healthcare were to make healthcare professionals more aware of the preventive effects of physical activity, to develop guiding principles for different patient groups and to support research. A national study was, therefore, initiated by the Swedish National Institute of Public Health in cooperation with The Centre for Public Health Sciences, Linköping, to develop and describe the working method and structure of "Physical Activity on Prescription" (PAP) [90]. Thirteen health care units (ten primary care and three occupational health care units) geographically spread in Sweden and working under different conditions as regards their size, location and population, participated in the study during 2001-2003. The health care units were located in five counties. Primary care units were responsible for establishing interaction between health and leisure time service personnel and for creating a community-based network with other public health organisations in the field of physical training. The head of each unit decided which professions (physician, physiotherapists, nurses or other health care professionals) that were allowed to prescribe PAP. If routine care patients had a diagnosis that could be related to insufficient physical activity or a need to be more physically active to prevent a future disease, they were considered as candidates for receiving PAP. The professionals and the patients agreed on the suitability of physical activity on prescription.

Paper I and II are based on patients receiving PAP willing to take part in the follow-up and answered the baseline questionnaire. The patients were included prospectively during 12 months in 2001-2002. The whole procedure of recruiting patients and collecting data were performed by the ordinary staff in the participating health care centres. At the time of receiving PAP all the patients answered a comprehensive questionnaire (baseline). Six months later they were asked to answer a shorter followup questionnaire distributed by mail from the primary health care units. No reminder was sent. Once a month the health care units sent collected data to The Centre for Public Health Sciences in Linköping, where all questionnaires were scanned.

Paper I include all patients $(\mathrm{n}=481)$ from baseline to 6-month follow-up after the patients received PAP. Data from 298 patients were available at the 6-month follow-up $(62 \%)$. In Paper II patients $(n=240)$ who reported their adherence to prescribed physical activity at the six-month follow-up were included. The recruitment procedures are illustrated in Figure 3.1. 


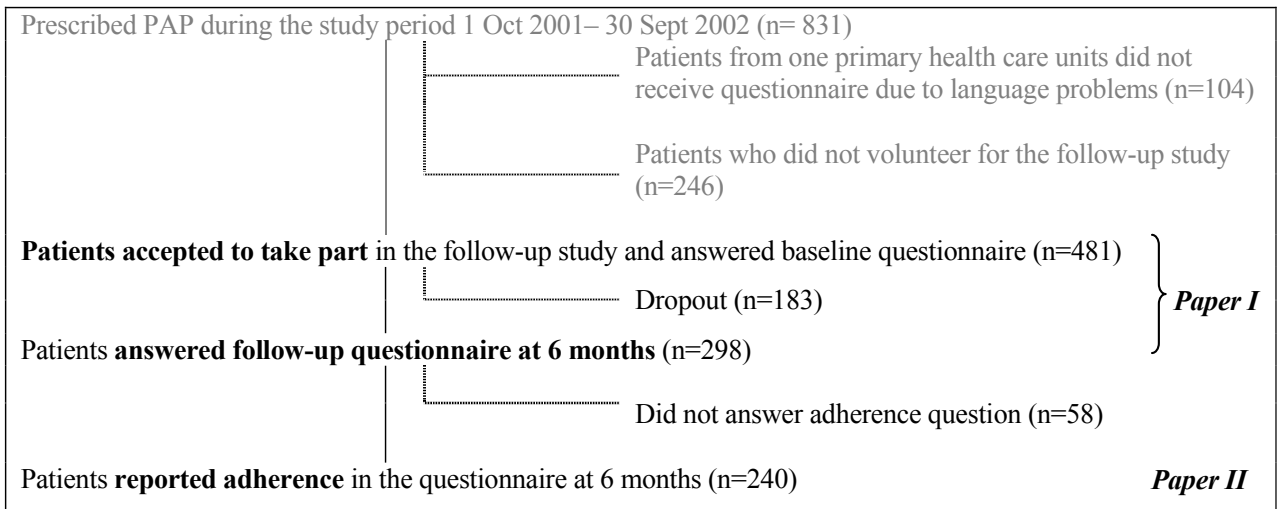

Figure 3.1. Flowchart of participants in the study of physical activity on prescription (Paper I and II).

\subsubsection{Intervention}

The counselling on physical activity was patient-oriented and based on FYSS [95]. If, after a patient-centred motivational counselling, physical activity was found to be suitable, individualized written physical activity was prescribed. The prescription-form reminded of the ordinary common Swedish drug prescription form, and included specified types of physical activities and intensity, frequency, and duration of the different activities. It was also possible to fill in time for follow-up visit and who to contact for the specified activities. On the back of the prescription a simple PA-diary was printed. The prescribed physical activity could be either self-monitored or organised by public physical activity organisations. Examples of issued self-monitored physical activity are walking, running, gardening, cross-country skiing, dancing and strength training. Examples of issued physical activities organised by public physical activity organisations are aerobics, strength training and water aerobics. Patient were often contacted by a person from the organisation and paid the normal fee to the organisation. A supporting environment was organised to help the patients to follow the prescribed physical activity, with a well-defined structure from primary health care to organisations of physical activity. An overview of the method of PAP is presented in Figure 3.2 and more detailed description is presented in Paper I. 


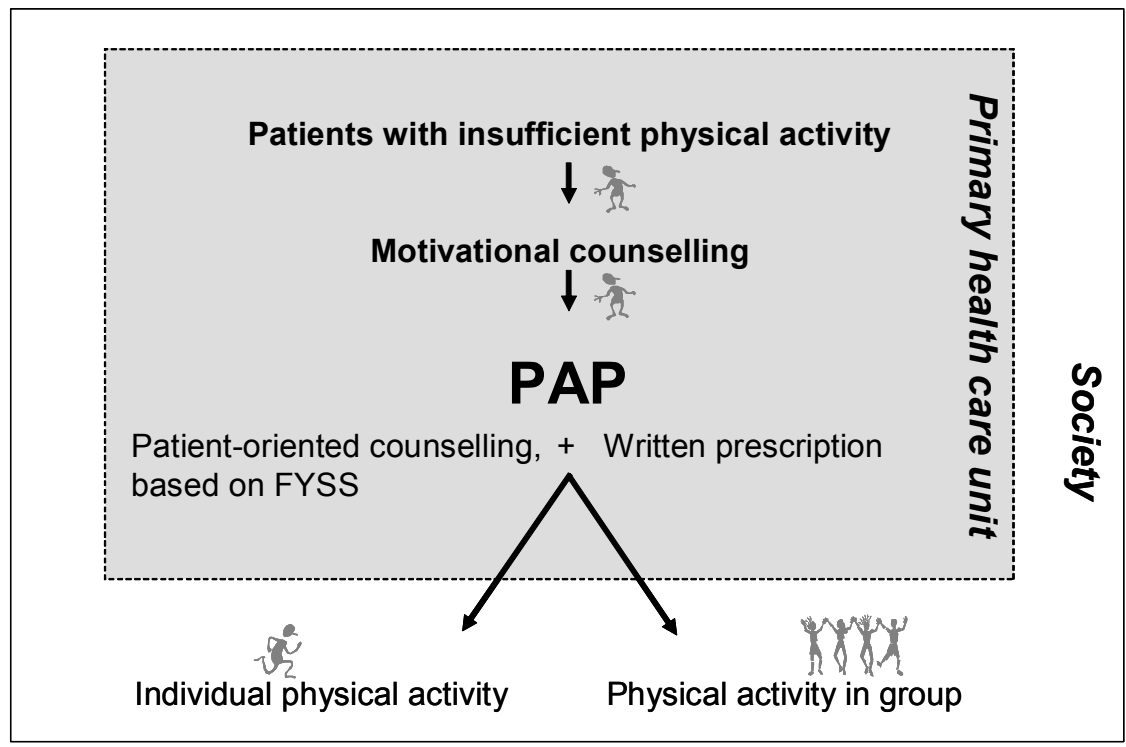

Figure 3.2. The method of Physical activity on prescription (Paper I and II).

\subsection{INDIVIDUALIZED PHYSICAL ACTIVITY ON PRESCRIPTION TO OLDER ADULTS WITH OVERWEIGHT (PAPER III AND IV)}

Participants in Study B (Paper III and IV) were recruited by written invitation from an ongoing prospective cohort investigation.

In 1997 to 1999, every third man and woman ( $\mathrm{n}=5460 ; 2681$ men, 2779 women) living in Stockholm County, Sweden, born between 1937 and 1938, was invited to participate in a health screening survey. Of all invited, 4232 individuals agreed to participate (2036 men and 2192 women; 78\% response rate), representing the general population of individuals aged 60 [63].

In 2005, an invitation and a pre-screening questionnaire were sent to 407 individuals who had met the inclusion criteria during the initial health screening in the late 1990s, which were: healthy but insufficiently physically active individuals with overweight (BMI $25-40 \mathrm{~kg} / \mathrm{m}^{2}$ ) and abdominal obesity (waist circumference $\geq 88 \mathrm{~cm}$ for women, $\geq 102 \mathrm{~cm}$ for men). Exclusion criteria were self-reported current heart disease, pharmacological treatment for hypertension or hyperlipedemia, tablet- or insulintreated type 2-diabetes, cancer, or other serious chronic diseases.

Of 246 individuals who agreed to take part in the present study, 116 met the inclusion criteria. Fifteen of these were excluded before randomization due to migration, death, or serious acute illness. In total, 101 subjects were randomized and included in the study between January and June 2006. A flowchart of participants is presented in Figure 3.3. 


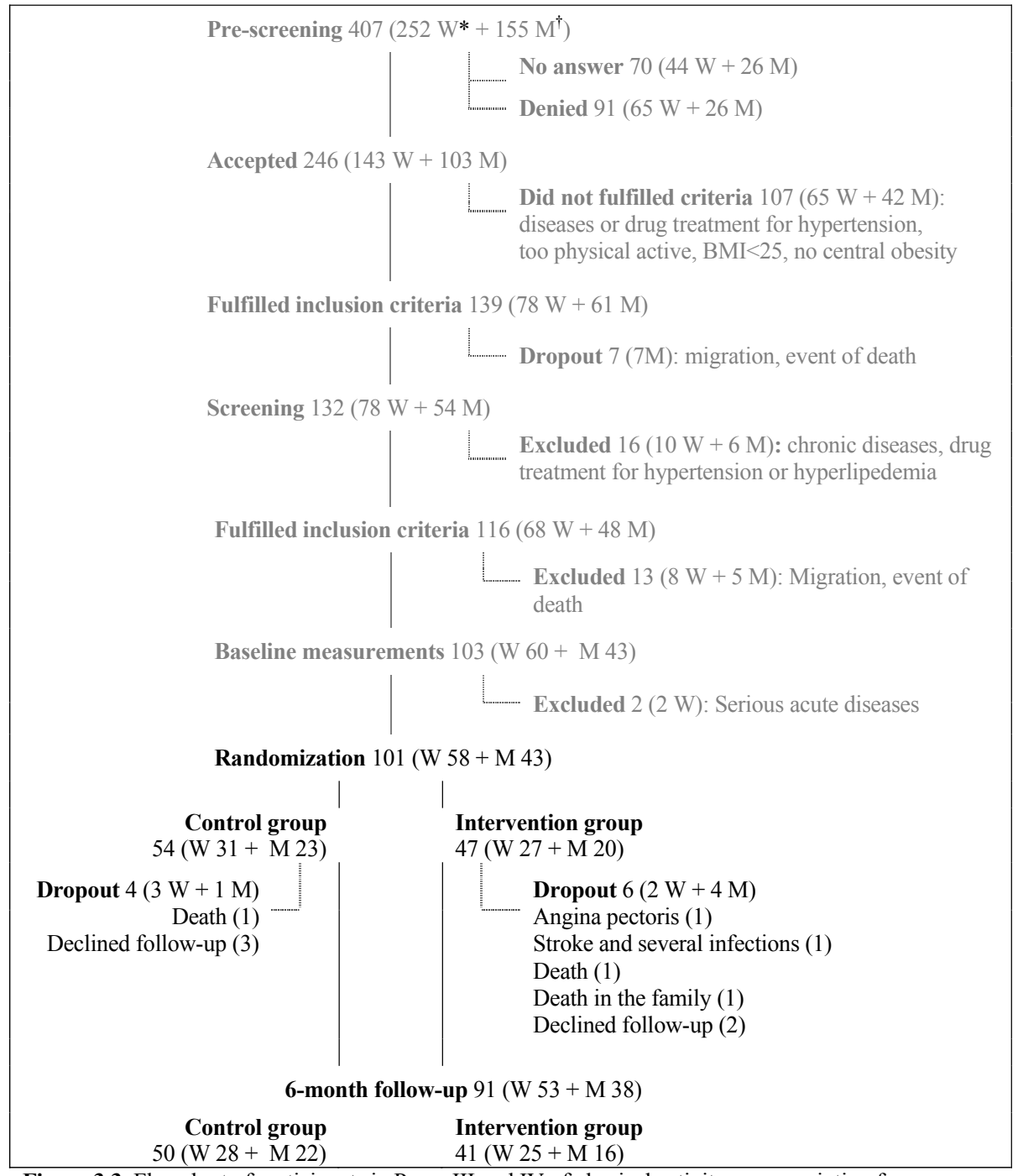

Figure 3.3. Flowchart of participants in Paper III and IV of physical activity on prescription from prescreening to 6-month follow-up. *Women, †Men

\subsubsection{Procedures}

Participants visited an outpatient clinic at the Obesity Unit at Karolinska University Hospital Huddinge in the morning, having fasted since $8 \mathrm{pm}$ the night before. Trained nurses conducted anthropometric and body composition assessment, measured blood pressure and collected venous blood samples. All study subjects completed a survey with background characteristics including sex, civil status, working conditions, smoking status as well as PA level. Oral and written instructions on how to use the pedometer and how to fill in the 7-day diary registration of physical activity level were given individually to all participants.

Randomization was performed at baseline, and calendar days were randomized as intervention or control days to prevent discussions between participants in different groups. The nurses who scheduled the study visits and those who performed the 
measurements were blinded to randomization, as were study participants. Nurses and participants knew only that the two groups would receive different levels of support for increasing their PA. Only the staff members involved in the intervention was aware of which group was control and which intervention.

A medical screening with an exercise test was performed on another day at two different clinical physiological centres (the GlobenHeart centre in Stockholm or the Department of Clinical Physiology at Karolinska University Hospital Huddinge) to exclude unstable coronary heart disease or untreated heart failure that may be a contraindication for moderate or vigorous exercise.

A health care professional trained in motivational counselling for PA met all participants individually, and delivered the intervention of physical activity on prescription to intervention group or the minimal intervention to the control group (the intervention is described in more detail below).

At the 6-month follow-up all assessments were done in the same way as at baseline. Data entering were done in duplicate by two different individuals and the questionnaires were scanned at the Centre for Public Health Sciences, Linköping.

\subsubsection{Intervention}

\subsubsection{Control group}

Due to ethical reasons the control group received minimal intervention with one page with written general information about the importance of PA for health. The information was downloaded from the Swedish public service information about health and healthcare information (www.sjukvardsradgivningen.se). The control group was not supported in any other way regarding changes in PA level. All participants were given the principle results of the baseline tests within 1-2 months.

\subsubsection{Intervention group}

In addition to the minimal intervention given to the control group, the intervention group received patient-centred counselling on the importance of PA for health and an individualized written prescription of PA. This intervention was based on a systematic review of methods of promoting PA in the health care setting [107], and experience from an uncontrolled study in clinical practice (Paper I and II) of the Swedish version of PAP. The theoretical framework for the intervention was based on social cognitive theory, the transtheoretical model, motivational interviewing, and supportive environment [107, 127, 154, 155].

Each subject in the intervention group was offered total approximately 90 minutes of intervention contacts. The study physician (a GP) raised the question of increased PA as an essential part good health at baseline examination (3-5 minutes). A health care professional trained in motivational counselling for PA, conducted the major part of the intervention, approximately 30 minutes of individualized patient-centred counselling conducted directly after baseline examination. An overview of the intervention is described in Table 3.1 . 
Table 3.1. Components of the physical activity on prescription used in the intervention group in Paper III and IV. Health care professional and fractions by time point. Different components of the patient-centred counselling and the written prescription are presented

\begin{tabular}{|c|c|c|}
\hline \multirow[t]{2}{*}{ Time point } & \multicolumn{2}{|c|}{ Health care professional } \\
\hline & Physician $(G P)$ & $\begin{array}{l}\text { Health care professional trained in motivational } \\
\text { counselling for } P A\end{array}$ \\
\hline Baseline & $\begin{array}{l}\text { Increased awareness of } \\
\text { physical activity as an essential } \\
\text { part good health }(5 \mathrm{~min})\end{array}$ & $\begin{array}{l}\text { Approximately } 30 \mathrm{~min} \text { (ranging } 20-40 \mathrm{~min} \text { ) of } \\
\text { individualized patient centred counselling and written } \\
\text { prescription of physical activity }\end{array}$ \\
\hline Within 1 month & Group ses & on (60 min) \\
\hline & Individualized letter & Short telephone follow-up (3-5 min) \\
\hline 6-month follow-up & & $\begin{array}{l}\text { Approximately } 30 \mathrm{~min} \text { (ranging } 15-35 \mathrm{~min} \text { ) of } \\
\text { individualized patient centred counselling and written } \\
\text { prescription of physical activity }\end{array}$ \\
\hline
\end{tabular}

The counselling was adjusted to each patient's readiness to change and the Five A's construct was also be applied [130]. The counselling included:

- Discussion of the patient's experiences of physical activity

- Exploring the patient's "pros and cons" of increased physical activity

- Patient's self-efficacy in being physically active in different environments, on different occasions, and during various times of the year

- Increased knowledge about physical activity and the individual health

- Guide to formulate goals for physical activity

- Plan of action

- Agreement for follow-up

- Encouragement for self-registration of physical activities and daily steps in a diary

All patients in the intervention group were provided with a pedometer and were encouraged to register all PA in a diary for at least three months, but preferably for six months. In the pre-printed diary the patients recorded the type of activity, duration, and intensity (according to G. Borg's Ratings of Perceived Exertion scale [the RPE-scale]) [156] of each session, and the number of steps taken each day. At the same occasion as the counselling session, written materials were also distributed: a booklet with encouragement and ideas for everyday activities, written general information on physical activity and health and, if requested, information about where to find suitable group activities and more written information about physical activity and health.

The counselling resulted in a written prescription of physical activity, i.e. an agreement for increasing PA written on a prescription form. The PAP included specified types of physical activities and intensity, frequency, and duration of the different activities. For each individual their present physical activity level, the reason for PAP, eventual contraindications, and the patients own goals were also written on the prescription form. Information on who to contact if there were problems with the prescribed physical activity were also specified.

A plan for follow-up of the counselling was arranged. An agreement was set upon if the participants wanted to be contacted by telephone as a follow-up of the counselling within a couple of weeks. All participants were informed of the possibilities of discussion of the PAP at a group session and that a renewed counselling and 
prescription were planned to be conducted at the 6-month follow-up. The patientcentred counselling session were completed by the subject reading through the prescription form and confirming the agreement of the counselling and the written prescription.

Within one month from baseline examination the intervention group was invited to a group session (60 minutes). This meeting included a lecture by a physician about physical activity and health and time for discussion and questions. The participants were encouraged to bring a relative or friend to the group meeting for enhancing the social support. A letter with individualized advice by the physician concerning the importance of increasing physical activity level for reducing the individual's risk factors (based on baseline tests and individual's mean number of steps per day) was sent out within one to two months.

The goal was to reach the current recommended health-enhancing PA, but on an individual level the prescription was individualized. The main purpose of the intervention was to achieve at least 30 minutes daily physical activities such as walking or gardening, as well as at least 30 minutes two or three times a week of aerobic and strength exercises of moderate intensity (e.g., Nordic walking [pole striding], dancing, strength training, cycling, swimming). The participants were encouraged to gradually increase their PA to accumulate 30 minutes or more of moderate-intensity PA on most, preferably all, days of the week and to include aerobic and strength training, as well as exercises for improved flexibility and balance [157]. All participants in the intervention group were also encouraged to reduce their time spent in sedentary behaviour, such as watching television [69], and to gradually increase their number of steps per day.

\subsection{MEASUREMENTS}

\subsubsection{Physical activity level}

Important criteria for selection of assessment methods of physical activity level were that they should be feasible to use in clinical practice. Previously used questionnaires (described below) in the Swedish population were used to be able to compare the physical activity level in the study populations with population levels. In Paper I and II we only used questionnaires to assess physical activity level. In Paper III and IV we also chose several other complementary methods to assess physical activity level as well as sedentary behaviour. As all methods have specific advantages and disadvantages [4], we combined the objective pedometer with a diary that added information about type of activity, time and intensity and also detected most kind of PA in contrast to pedometer that only assess number of steps.

\subsubsection{Questionnaires}

In Paper I and II two questions were used to assess the total physical activity level during the last year; physical activity in daily life over the last 12 months (ranging from none to every day) and exercise over the last 12 months, beyond physical activity in daily life (ranging from hardly anything to vigorous activity on regular basis). This set of questions has been used before in population surveys in two of the five participating counties [158]. An index of total physical activity was created from these questions; four activity levels were used, ranging from "hardly any physical activity" to "fulfilling public health recommendation of physical activity". The activity levels corresponded to how well the subject fulfils the recommended physical activity level of at least 30 
minutes of moderate physical activity at least five days a week and/or vigorous physical activity three times a week $[16,159]$.

In Paper III and IV a question for total leisure time physical activity was selected that is widely used in population surveys in Sweden and has been shown to be valid for categorising people into different categories of activity [160]. The question asked about leisure time physical activity during the past year and included four categories: (1) sedentary leisure-time ( $<2$ h of light PA/week, e.g., walking, cycling); (2) light PA ( $\geq 2$ $\mathrm{h}$ /week generally without sweating, e.g., walking, cycling, gardening); (3) regular moderate exercise (1-2 times/week, $\geq 30$ min each occasion, e.g. jogging, swimming, tennis, badminton) and (4) regular exercise ( $\geq 3$ times/week, $\geq 30$ min each time, e.g. running, swimming, tennis, aerobics, or other strain exercise). Physical activity during leisure time was analyzed as change from baseline to follow-up and categorized as increase, no change, or decrease.

To evaluate if the patients adopted or maintained an increased physical activity level, the "stages of change" was used in Paper I and II. The instrument has acceptable validity and reliability $[127,128,161]$. According to a meta-analysis, stage belonging is associated with different levels of physical activity, and the level of physical activity increases as individuals moves to a higher stage of change [162]. Stage of change refers to a person's readiness to engage in regular physical activity. To be able to compare with population levels, the same question was used that has been used in a PanEuropean survey aimed at identifying the stage that the patient had reached [163]. The question consisted of seven equally exclusive options, according to which patients were assigned to one of the six stages of change groups as follows: precontemplation (not active, no intention to increase PA), contemplation (not active, thinking of increasing PA), preparation (not active, decided to increase PA), action (active, but only last 6 months), maintenance (active, and have been that for more than 6 months), or relapse.

\subsubsection{Sedentary behaviour}

In Paper III and IV sedentary behaviour was defined as total sitting time, measured with the sitting questions in the short version of the IPAQ last 7-days questionnaire [17]. Participants were asked to estimate total time per day spent sitting for a weekday and a weekend day (at work, while doing course work, at home, and during leisure time). An alternative answer, "I do not know/can not estimate," was also available. Time sitting was analyzed as change from baseline to follow-up.

\subsubsection{Diary}

A pre-printed self instructed diary was created. Participants were instructed to record for seven consecutive days any PA or exercise and report the type, duration in minutes, and intensity as measured by Borg's RPE-scale. Participants were carefully instructed in use of the scale [156]. Number of sessions and durations in minutes of PA at light (RPE 10-11), moderate (RPE 12-13), and vigorous or strenuous intensity ( $\geq 14)$ [16] were recorded and analyzed as changes from baseline to follow-up.

At the 6-month follow-up participants were categorized according to the criteria in Table 3.2 as either fulfilling or not fulfilling the intervention goals of increased PA (as measured by the PA diary). From the PA diary, the participants were also categorized as to whether or not they fulfilled the public health recommendation of PA as defined by the updated recommendation from 2007 for older adults (Table 3.2) [69]. 
Table 3.2. Physical activity goals and public health recommendations [69] of physical activity used in Paper III and IV.

\begin{tabular}{|c|c|}
\hline Physical activity goals & Public health recommendations \\
\hline $\begin{array}{l}\text { 1. Achieving the intervention goal of at least } 30 \\
\text { minutes of PA ( } \geq 5 \text { days) daily and exercise of }\end{array}$ & $\begin{array}{l}\text { A. Moderate-intensity aerobic } \mathrm{PA} \geq 30 \text { min on five } \\
\text { days each week. }\end{array}$ \\
\hline $\begin{array}{l}\text { moderate intensity ( } \mathrm{RPE} \geq 12 \text { ) for at least } 30 \\
\text { minutes, two times a week. }\end{array}$ & $\begin{array}{l}\text { B. Vigorous-intensity aerobic activity } \geq 20 \text { min on } \\
\text { three days each week. }\end{array}$ \\
\hline $\begin{array}{l}\text { 2. An increased mean number of daily step counts } \\
\text { with } \geq 3000 \text { steps. }\end{array}$ & $\begin{array}{l}\text { C. Combination of A and B to meet public health } \\
\text { recommendation. }\end{array}$ \\
\hline 3. Combined goal of 1 and & D. Muscle strengthening using the major muscle \\
\hline $\begin{array}{l}\text { 4. Increased total PA level on moderate or vigorous } \\
\text { intensity ( } R P E \geq 12) \text {. }\end{array}$ & $\begin{array}{l}\text { groups } \geq \text { two days each week at moderate to high } \\
\text { intensity ( } 10-15 \text { repetitions for each exercise). }\end{array}$ \\
\hline
\end{tabular}

\subsubsection{Pedometer}

The Yamax Digiwalker SW-200 (Yamax Corporation, Tokyo, Japan) pedometer was chosen as it has been shown to be the most accurate in brand-to-brand comparisons and frequently used in research [164-167]. This pedometer contains a horizontal, springsuspended lever arm that deflects with vertical acceleration (the up-and-down motion) of the hips during ambulation (e.g. walking). An electrical circuit opens and closes with each deflection detected (requires a force $\geq 35 \mathrm{~g}$ ) and an accumulated step count is displayed digitally on a feedback screen). Participants were instructed to wear their pedometer for seven consecutive days at all times other than sleeping, bathing, or swimming, and to read and record number of total steps in the PA diary before they took the pedometer off for the night without reading it during the day. Average steps per day were calculated for every subject by dividing total recorded steps by the number of days for which pedometer information was recorded. If 7 days of data were not provided, this construct was still calculated based on fewer days ( $\geq 3$ days).

Steps per day were analyzed as changes from baseline to follow-up. Number of participants that added at least 3000 steps per day was also analyzed. This increase corresponds to approximately 30 minutes of moderate-intensity walking [168].

Steps were also analyzed with different cut-off levels, and were used to classify PA level: less than 5000 steps/day was considered as insufficient active, 5000-7499 steps/day as low active, 7500-9999 as somewhat active and participants taking 10000 and more steps/day were classified as active [168]. Changes from baseline to follow-up in the categorical variables steps per day were further categorized into three levels: increase, no change, and decrease.

\subsubsection{Adherence to prescribed physical activity}

To assess the patients' self-reported adherence to prescribed physical activity in Paper II, the patients were asked if they adhered to PAP, and were thereafter classified in four categories, depending on their answers:

- Group A adhered (answered: I stuck to the prescription),

- Group B adhered but altered nothing more than the type of physical activity (answered: I stuck to the prescription, but chose another type of physical activity),

- Group C partly adhered (answered: I stuck to the prescription at the beginning but not any more),

- Group D did not adhere at all (answered: I did not follow the prescription at all). 
Using adherence as a dichotomous variable, Groups A and B formed the group that adhered and Groups $\mathrm{C}$ and $\mathrm{D}$ the group that did not adhere. The rational for letting group $\mathrm{A}$ and $\mathrm{B}$ form the adherence group was the importance for participants to increases their physical activity level according to the agreed intensity, frequency and duration, and not that they stick to the exact same type of physical activity.

Patients in groups A and B were asked to report the most important reasons for their increased physical activity, while patients in groups $\mathrm{C}$ and $\mathrm{D}$ were asked why they did not follow the prescribed physical activity at 6-month follow-up.

\subsubsection{Anthropometrics}

In Paper I and II height and weight were self-reported, collected through the questionnaire.

In Paper III and IV height was measured to the nearest $0.5 \mathrm{~cm}$ in an upright position without shoes, weight was measured to the nearest $0.1 \mathrm{~kg}$ using an electronic scale, and BMI calculated. Waist circumference was measured in a standing position midway between the lower rib margin and the iliac crest with a tape measure to the nearest 0.5 $\mathrm{cm}$. With the patient in supine position, neck circumference was measured with a tape measure to the nearest $0.1 \mathrm{~cm}$ and sagittal abdominal diameter (SAD) was determined to the nearest $0.1 \mathrm{~cm}$ using a ruler and a water level.

\subsubsection{Body composition}

Body composition in Paper IV was measured by bioelectrical impedance analysis, with a Tanita BC-418 eight-contact electrode system (Tanita Corp., Tokyo, Japan).

Measurements of the impedance across the tissues of the participants is measured by 8 electrodes that are positioned so that electric current is supplied from the electrodes on the tips of the toes of both feet and the fingertips of both hands, and voltage is measured on the heel of both feet and the thenar side of both hands. Information was entered into the equipment of the participant's age, height, and body type (all study subjects were classified as "standard body type" and none as "athletic"), direct measurements of weight and impedance are done, and the device calculates body composition using an equation based on these values. The prediction equation supplied in the software is based on data obtained by Dual Energy X-ray Absorptiometry. The device calculates body fat percentage, fat mass, fat free mass in whole body and trunk.

\subsubsection{Cardiovascular risk factors}

In Paper IV blood pressure was measured with the subject in a sitting position after five minutes of rest, using a standard auscultatory method with a $12 * 35 \mathrm{~cm}^{2}$ cuff. Both systolic and diastolic blood pressures were calculated as the mean of two determinations.

Blood samples were drawn from an antecubital vein after overnight fasting. The samples were analyzed online by accredited methods in the clinical chemistry laboratory at the Karolinska University Hospital Huddinge, i.e. glucose (Gluco-quant Glucose/HK, Roche), HbA1c (Variant II Turbo Reorder Pack, Bio-Rad), apolipoprotein A1 and apolipoprotein B (Roche), and cholesterol, triglycerides and HDL-cholesterol (Roche). LDL-cholesterol was estimated using the Friedewalds method. LDL/HDL and apoB/apoA1 were calculated. 


\subsubsection{Quality of Life}

To measure Quality of Life two validated questionnaires were used in Paper I, Short Form 36 (SF-36) and EuroQol EQ-5D [169-172]. Short Form 36 has been translated into Swedish and validated in a representative sample of the population [173]. It includes 36 questions and generate a health profile of eight sub-scale scores: physical functioning, role limitations due to physical problems, bodily pain, general health, vitality, social functioning, role limitations due to emotional problems, and mental health $[169,173]$. The first four scales can be regarded as measuring primarily physical aspects of health and the latter four primarily mental aspects, though the general health and vitality measure health in more general terms [174]. The scores on all sub-scales are transformed to a scale from 0 (worst score) to 100 (best score). EuroQol's EQ-5D involves two parts. One visual analogue scale (VAS) ranging from 0 (worst possible state) to 100 (best possible state) and a health classification of five items (mobility, selfcare, usual activities, pain/discomfort and anxiety/depression), each having three alternatives $(1=$ no problem, $2=$ moderate problems and $3=$ severe problems $)$. The combination of answers forms a index and gives a number between -0.59 and 1.0 [172, $175]$.

\subsection{STATISTICS}

Continuous variables are presented as mean and standard deviation (SD) or median and interquartile range (IQR) for non-normal distributed data. Ordinal scaled variables are presented using median and range and categorical variables with frequency and the relative frequency. In the uncontrolled clinical study analyses for differences between groups at baseline were performed using unpaired t-test or Kruskal-Wallis and MannWhitney (post hoc comparisons) for ordinal data and the Chi-square test $\left(X^{2}\right)$ for categorical data. Change from baseline to follow-up within treatment groups were tested using paired $t$-test (continuous data), Wilcoxon's signed-rank test (ordinal data) or the Chi-square test or Fischer exact test (categorical data). Changes (6-month values - baseline values) were tested between intervention and control treatment using the $t$ test for continuous data, the Mann-Whitney for ordinal data and the Chi-square test or Fischer's exact test for categorical data. The level of statistical significance was set at $\mathrm{p} \leq 0.05$. All the statistical analyses were performed with Intercooled Stata 9.0 for Windows (Stata Corporation).

For the intention to treat (ITT) analysis in the primary health care clinical study a conservative method were used, whereby baseline observations were carried forward for missing data on all outcome variables.

Four participants did not complete the physical activity diary at baseline in the RCT; analyses of PA changes regarding diaries and steps reports are based on complete cases at baseline and follow-up. Sensitivity analysis was conducted for differences in change between intervention group and control group in the main outcomes with using the ITT population i.e. all randomized participants, where missing values were imputed using the change equal to zero. ITT analyzes were also used for the proportion of participants who fulfilled the intervention goals and recommendations of physical activity level. 


\subsection{ETHICAL CONSIDERATIONS}

Patients in Paper I and II gave their informed consent to participate in the study and the regional ethical review boards in Stockholm classified the study as a guarantee-ofquality project, and thereby did not require approval (04-547). Paper III and IV were approved by the regional ethical review board in Stockholm (04-520/2), and all participants provided written informed consent. 


\section{RESULTS}

\subsection{CHARACTERISTICS OF STUDY POPULATION}

\subsubsection{Study A (Paper I and II)}

The study population consisted of 481 patients who received PAP. Patient characteristics are presented in Table 4.1 and in more detail in Paper I.

Data from 298 patients were available from the 6-month follow-up (62\%) in Paper I. There were no significant differences between participants with or without (drop-out group) the 6-month follow-up as regards patient characteristics, physical activity level, stages of change or quality of life other than that the individuals in the drop-out group were somewhat younger (48.7 compared to 51.9 years).

In Paper II 240 patients were included, i.e. those who reported their adherence to prescribed physical activity at the six-month follow-up. No significant differences were detected in patient characteristics by group of adherence (A-D) at baseline, but differences in physical activity in everyday life and total physical activity were seen (presented in Paper II).

Table 4.1. Patient characteristics and physical activity level in Study A at baseline; total group ( $\mathrm{n}=481$ ), follow-up group (patients who remained at the 6-month follow-up, $\mathrm{n}=298$ ) and those who reported their adherence to prescribed physical activity at 6-month $(n=240)$. Variables are presented as proportions (percentage) or means with SD and range

\begin{tabular}{|c|c|c|c|}
\hline Variable & $\begin{array}{c}\text { Total group } \\
(\mathbf{n}=\mathbf{4 8 1}) \\
\%\end{array}$ & $\begin{array}{l}\text { Follow-up group } \\
\qquad \begin{array}{c}(\mathbf{n}=\mathbf{2 9 8}) \\
\%\end{array}\end{array}$ & $\begin{array}{c}\text { Those who reported } \\
\text { their adherence } \\
(n=240) \\
\%\end{array}$ \\
\hline Age (years; mean (SD) [range]) & $51(13)[12-81]$ & $52(13)[12-80]$ & $51(13)[12-80]$ \\
\hline Sex (male/female) & $25 / 75$ & $23 / 77$ & $25 / 75$ \\
\hline BMI $\left(\mathrm{kg} / \mathrm{m}^{2}\right.$; mean $(S D)$ [range] $)$ & $27.5(5.4)[17.3-49.3]$ & $27.4(5.3)[17.3-48.9]$ & $27.2(5.5)[17.3-48.9]$ \\
\hline Fraction with $\mathrm{BMI} \geq 25$ & 61 & 60 & 58 \\
\hline Fraction with $\mathrm{BMI} \geq 30$ & 28 & 26 & 26 \\
\hline \multicolumn{4}{|l|}{ Total physical activity level* } \\
\hline Hardly any physical activity & 10 & 8 & 8 \\
\hline Some physical activity & 33 & 33 & 32 \\
\hline Could be more physically active & 47 & 49 & 49 \\
\hline $\begin{array}{l}\text { Approximately } 30 \text { minutes of } \\
\text { physical activity/day }\end{array}$ & 11 & 10 & 10 \\
\hline \multicolumn{4}{|c|}{ Readiness for change to a physical active lifestyle } \\
\hline Precontemplation & 2 & 1 & 2 \\
\hline Contemplation & 24 & 21 & 19 \\
\hline Preparation & 41 & 43 & 45 \\
\hline Action & 4 & 5 & 4 \\
\hline Maintenance & 13 & 14 & 14 \\
\hline Relapse & 13 & 12 & 12 \\
\hline Do not know & 3 & 3 & 3 \\
\hline
\end{tabular}

*Index calculated from physical activity and exercise. Corresponds to how well the subject fulfils recommended physical activity level, i.e. at least 30 minutes of moderate physical activity at least five days a week (preferably every day) and/or vigorous physical activity three times a week [16, 159]. 


\subsubsection{Study B (Paper III and IV)}

The study population consisted of 101 subjects: 47 (20 men and 27 women) in the intervention group and 54 (23 men and 31 women) in the control group. Patient characteristics and PA levels are presented in Table 4.2. At baseline all participants were between 67 and 68 years old and 57\% were women. Anthropometrics, body composition and cardiometabolic risk factors at baseline were similar in the two groups (see Paper III and IV). Subjects were included in the study based on their screening results and during the time the baseline investigation were performed, a few subjects made small changes in physical activity level, resulting in lower BMI-value or waist circumference or higher physical activity level than stipulated by the inclusion criteria.

Table 4.2. Baseline characteristics and physical activity level (PA) at baseline in Study B (Paper III and IV). Variables are presented as percentage (\%), mean (SD) or median (IQR)

\begin{tabular}{lcc}
\hline Variable & $\begin{array}{c}\text { Intervention } \\
\text { group (n=47) } \\
\%\end{array}$ & $\begin{array}{c}\text { Control } \\
\text { group (n=54) } \\
\%\end{array}$ \\
\hline Sex (male/female) & $43 / 57$ & $43 / 57$ \\
Weight $(\mathrm{kg}$, mean [SD]) & $88.0(14.2)$ & $88.3(11.1)$ \\
BMI (kg/m ${ }^{2}$, mean [SD]) & $29.7(3.4)$ & $30.4(2.9)$ \\
Waist circumference (cm, mean [SD]) & $105.2(9.2)$ & $106.4(7.8)$ \\
Physical activity level & & \\
PA on at least moderate intensity (RPE $\geq 12)$, sessions/w & $2(1-5)$ & $2(1-5)$ \\
(median [IQR]) & & \\
PA on at least moderate intensity (RPE $\geq 12)$, min/w (median $[\mathrm{IQR}])$ & $120(0-220)$ & $130(40-215)$ \\
Steps per day (mean [SD]) & $5390(2791)$ & $4980(2763)$ \\
Sitting time (hours/day) (median [IQR]) & $5(3-7)$ & $5(4-7)$ \\
Leisure time PA during last year & & \\
$\quad$ Sedentary leisure-time & 11 & 13 \\
$\quad$ Light activity & 59 & 67 \\
$\quad$ Regular moderate exercise & 20 & 16 \\
$\quad$ Regular exercise & 9 & 4 \\
\hline
\end{tabular}

Ten participants (10\%) dropped-out from baseline to 6-month follow-up (Figure 3.3). Four participants ( 1 in intervention group and 3 in control group) did not complete the PA diary at baseline and $16(8+8)$ participants at the 6-month follow-up. However, the sensitivity analysis showed similar results for the main outcome (PA session and minutes of at least moderate intensity ( $\mathrm{RPE} \geq 12)$ and steps per day), and therefore results are presented for complete cases ( 38 participants in the intervention group and 45 in the control group).

\subsection{PHYSICAL ACTIVITY LEVEL}

\subsubsection{Total physical activity during the last year (Paper I)}

The intention to treat analysis (Paper I) showed a significant increase, from baseline to the 6-month follow-up, in self-reported physical activity level over the last 12-month period, both in physical activity in daily life $(p<0.001, n=477)$ and in exercise $(p<0.001$, $n=473)$. The follow-up group increased $(p<0.001)$ both physical activity on daily life and exercise (Figure 4.1). Half of the participants were physical active in daily life every day and more than one third exercised on moderate intensity at least once per week at 6-month follow-up. An increased total physical activity level was reported by $39 \%$ of the patients. The fraction of participants that in average fulfilled the recommended 30 min of physical activity per day was doubled. 


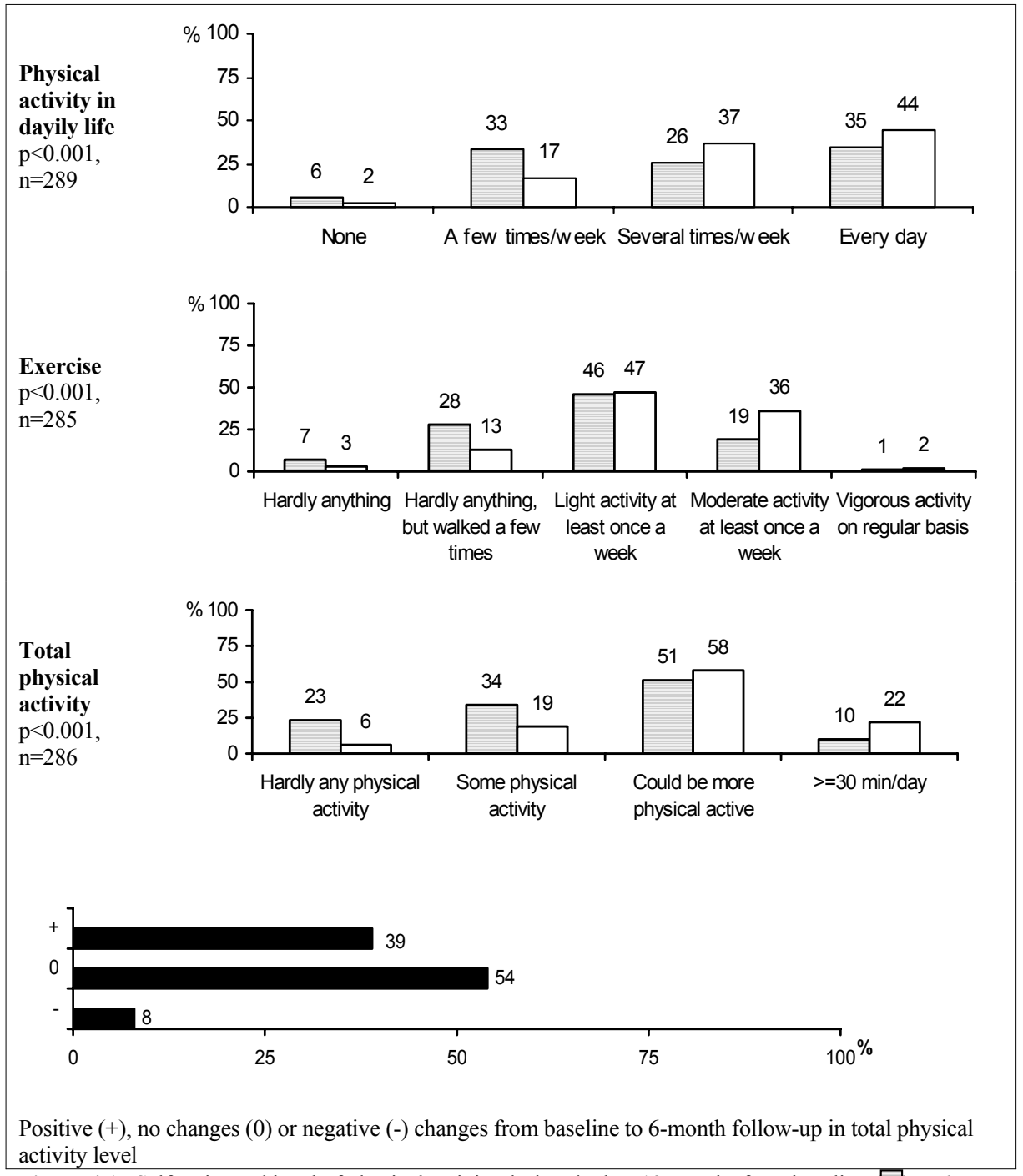

Figure 4.1. Self-estimated level of physical activity during the last 12 months from baseline $(\square)$ to 6month follow-up $(\square)$ in Paper I.

\subsubsection{Total physical activity in leisure-time (Paper III)}

Self-reported PA in leisure-time increased in the intervention group $(\mathrm{p}<0.001)$ and in the control group $(p<0.05)$, but to a higher degree $(p<0.01)$ in the intervention group (Figure 4.2). An increased total physical activity level was reported by $51 \%$ of the participants in the intervention group and by $27 \%$ in the control group. 


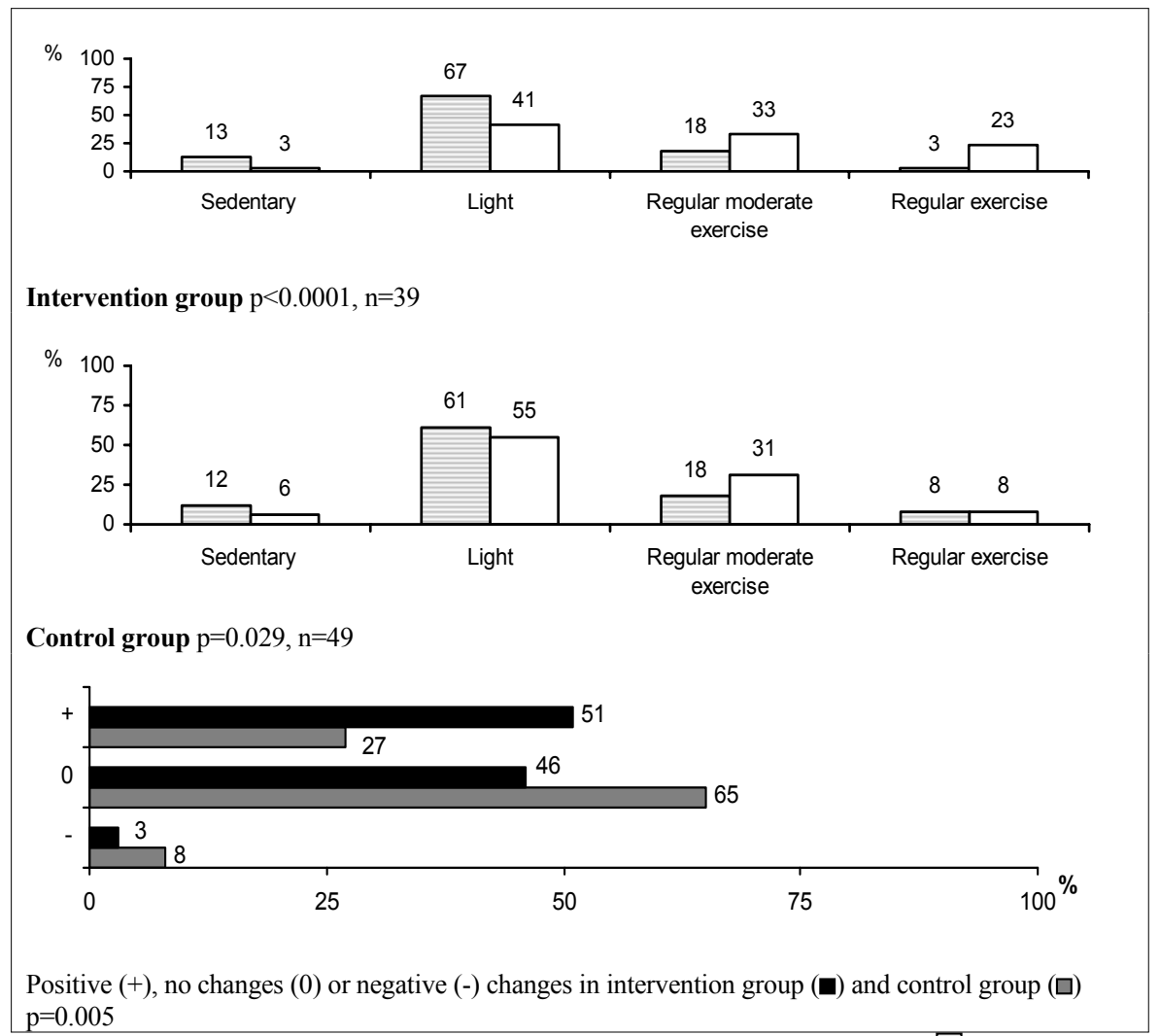

Figure 4.2. Changes in reported physical activity level in leisure time from baseline ( $\square$ ) to 6-month follow-up ( $\square$ ) in Paper III and IV.

\subsubsection{Readiness for change (Paper I)}

At baseline (Paper I) most patients ( $\mathrm{n}=471)$ were in the stage of contemplation $(24 \%)$, preparation $(41 \%)$ and relapse $(13 \%)$. The intention to treat analysis showed a significant decrease in the stages of contemplation, preparation and relapse and an increase in the stages of action and maintenance. Figure 4.3 (follow-up group) shows changes from baseline to 6 months in readiness for change in physical activity. The figure shows a shift in readiness for change from contemplation and preparation to action and maintenance, and $42 \%$ of the participants increased to a more active stage.

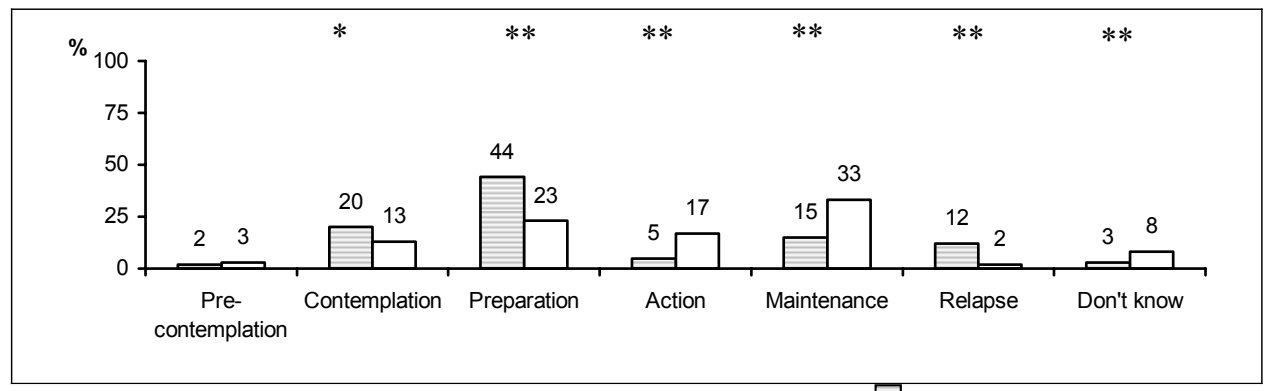

Figure 4.3. Physical activity level measured by stages of change at baseline ( $⿴$ ) and 6-month follow-up $(\square)$ in Paper I ( $\mathrm{n}=275)$. Within every stage, a significant difference from baseline to follow-up is indicated by stars, ${ }^{*} \mathrm{p}<0.05$ and $* * \mathrm{p}<0.01$. 


\subsubsection{Recorded physical activity (Paper III)}

Within-group analysis (Paper III) showed a significant increase in registered PA with at least moderate intensities (RPE $\geq 12)$ from baseline to 6-month follow-up in the intervention group with 3 sessions (IQR $0-5 ; \mathrm{p}=0.0003$ ) or 159 minutes (IQR 0-430; $\mathrm{p}=0.0005$ ) per week. No changes were found in the control group (Figure 4.4).

Between-group analysis confirmed that number of session per week increased significantly more in the intervention group compared to the control group both when analyzed as complete cases $(\mathrm{p}=0.0001)$ and with a restrictive ITT analysis $(\mathrm{p}=0.0056)$. Duration in minutes per week increased more in the intervention group compared to the control group both when analyzed as complete cases $(p=0.0299)$ and with a restrictive ITT analysis $(p=0.0283)$. Data from the activity diaries in the form of number of sessions and minutes/day of PA stratified in moderate and vigorous PA are presented in Paper III.

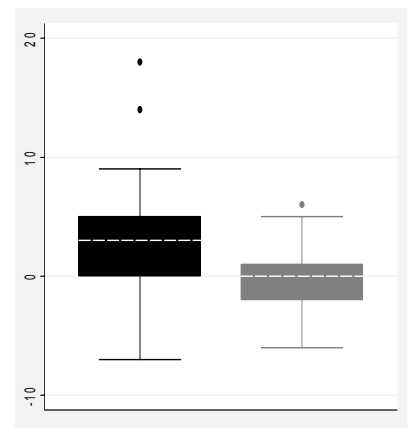

\section{Sessions}

Figure 4.4. Change in recorded physical activity of at least moderate intensity per week, from baseline to 6-month follow-up in intervention group $(\square)$ and control group $(\square)$ in Paper III. Box plots showing median values and the $10^{\text {th }}, 25^{\text {th }}, 75^{\text {th }}$ and $90^{\text {th }}$ percentiles, and outliers.

\subsubsection{Achievements of recommendations (Paper III)}

Between-group analysis (Paper III) showed that a larger proportion of participants in the intervention group than in the control group achieved the different PA goals at 6month follow-up (Figure 4.5).

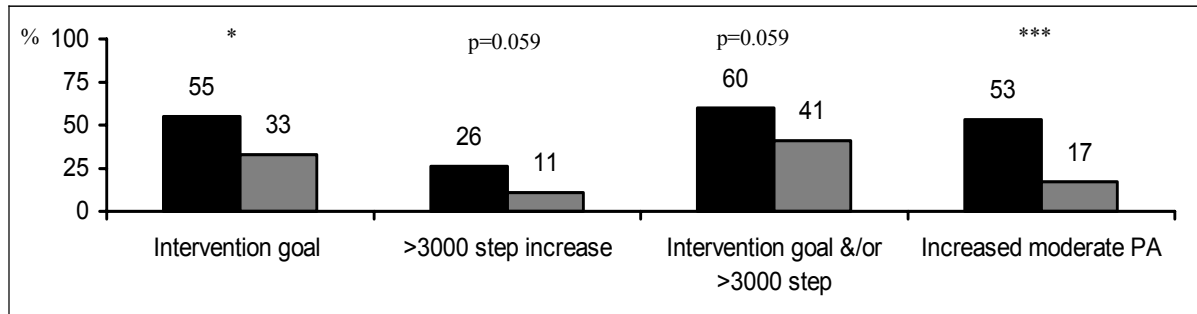

Figure 4.5. Proportion of participants in intervention $(\square, n=47)$ and control $(\square, n=54)$ group achieving intervention goals at 6-month follow-up, in an intention to treat analysis. Significant difference between groups is indicated by stars, $* \mathrm{p}<0.05$ and $* * * \mathrm{p}<0.001$. 
As illustrated in Figure 4.6 the proportion of individuals fulfilling different recommendations in physical activity was larger in the intervention group. Although the within-group analysis could not detect any significant increases in proportion of participants that fulfilled the different recommendations from baseline to the 6-month follow-up, the between-group analysis confirmed that a larger proportion of participants in the intervention group than in the control group fulfilled the different recommendations at follow-up. The increase in attaining the recommended moderateintensity aerobic PA was higher in the intervention group than in the control group $(21 \%$ vs. $10 \%$ [p=0.005]). Although not significantly, a similar pattern was seen in fulfilments of the other recommendations: vigorous-intensity aerobic activity ( $10 \% \mathrm{vs}$. $0, p=0.22)$, combination of the two aerobic recommendations ( $20 \%$ vs. $0, p=0.33)$, and muscle strength training $(19 \%$ vs. $3 \%, p=0.084)$. At the 6 -month follow-up, compared to the control group, more than twice $(\mathrm{p}=0.014)$ more participants in the intervention group formed moderate-intensity aerobic PA for a minimum of 30 minutes on 5 days each week, and three times $(\mathrm{p}=0.044)$ more performed vigorous-intensity aerobic activity for a minimum of 20 minutes on 3 days each week. A combination of these two aerobic recommendations tended to be met by $65 \%(p=0.078)$ more participants in the intervention group than in the control group at follow-up. Recommended strength training tended to be fulfilled by more than twice $(\mathrm{p}=0.09)$ more subjects in the intervention group than in the control group.

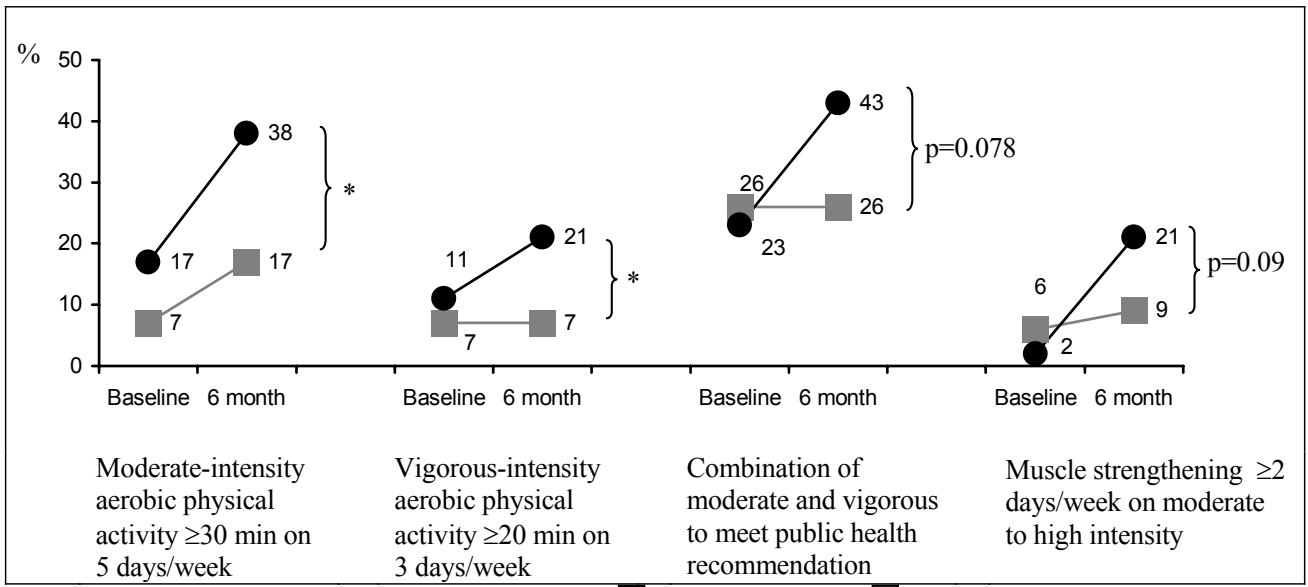

Figure 4.6. Proportion of participants in intervention $(\square, n=47)$ and control $(\square, n=54)$ group that meet public health recommendation of physical activity level [69], at baseline and at the 6-month follow-up in an intention to treat analysis. Significant difference at 6-month follow-up is indicated by stars, ${ }^{*} \mathrm{p}<0.05$. The increase in attaining the recommended moderate-intensity aerobic physical activity were higher $(\mathrm{p}<0.01)$ and recommended muscle strength training tended to be higher $(\mathrm{p}=0.08)$ in the intervention group compared to the control group.

\subsubsection{Steps per day (Paper III)}

The intervention group (Paper III) increased by 1663 steps/day $(30 \% ; \mathrm{p}<0.01)$ compared to 871 steps/day $(17 \% ; \mathrm{p}<0.05)$ for the control group (Figure 4.7$)$, without significant differences between the groups (791 steps [95\% CI, -571 to 2154]). With a restrictive ITT analysis the difference in increase between the intervention group and the control group was 634 steps $(95 \% \mathrm{CI},-483$ to 1752$)$. 
Figure 4.7. Increased number of steps per day from baseline to 6-month follow-up in intervention group ( $\square$ ) and control group $(\square)$. Box plots showing median values and the $10^{\text {th }}$, $25^{\text {th }}, 75^{\text {th }}$ and $90^{\text {th }}$ percentiles, and outliers.

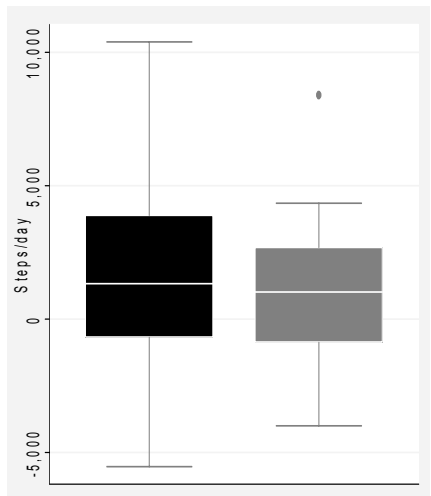

In the intervention group $47 \%(p<0.01)$ of the participants increased at least one physical activity level as categorized by steps/day, while no significant differences were found in the control group or between the groups (Figure 4.8).

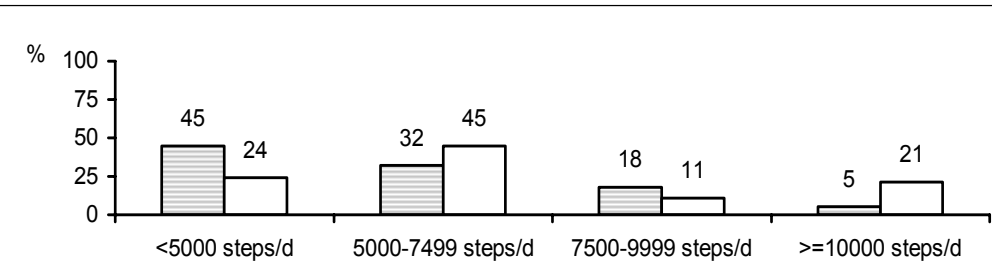

Intervention group $\mathrm{p}=0.0092, \mathrm{n}=38$

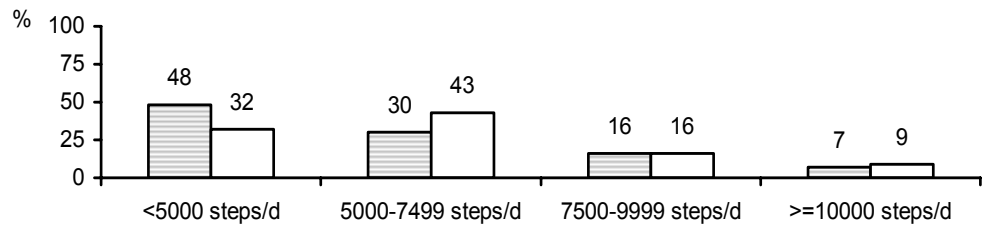

Control group $\mathrm{p}=0.13, \mathrm{n}=44$

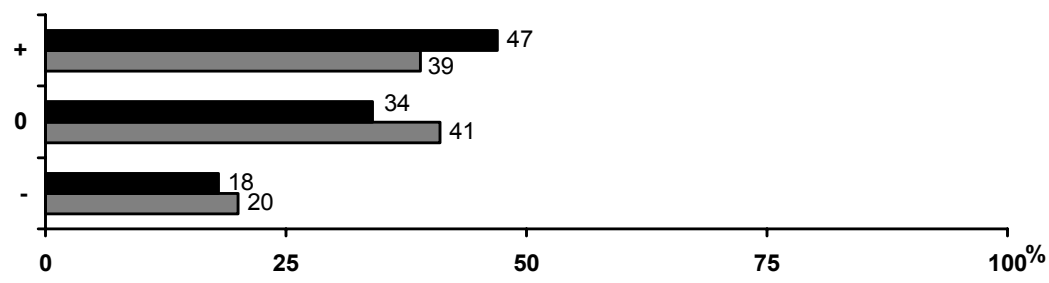

Positive (+), no changes (0) or negative (-) changes in intervention group ( $\square$ ) and control group ( $\square$ ) $\mathrm{p}=0.32$

Figure 4.8. Changes in steps per day from baseline $(\square)$ to 6-month follow-up $(\square)$ corresponding to physical activity levels; insufficient active $<5000 \mathrm{steps} /$ day, low activity 5000-7499 steps/day, somewhat active 7500-9999 steps/day and active $\geq 10000$ steps/day. 


\subsubsection{Sedentary behaviour (Paper III)}

Both groups in Paper III reduced sitting time on weekdays by follow-up, the intervention group by median 2 hours $(\mathrm{n}=24, P=0.0058)$ and the control group by median 1 hour $(\mathrm{n}=31, \mathrm{p}<0.001)$, without significant difference between the groups (Figure 4.9).

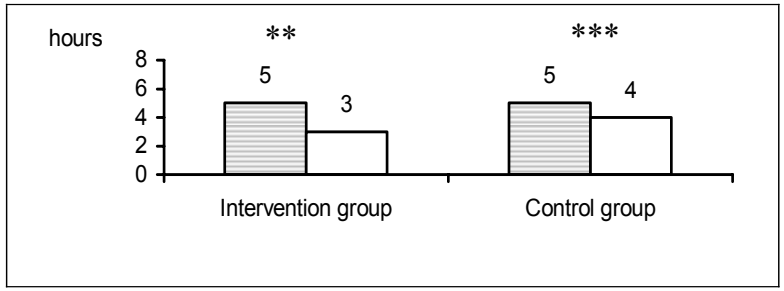

Figure 4.9. Reported sedentary behaviour on weekdays from baseline (回) to 6-month follow-up $(\square)$, in the intervention group $(\mathrm{n}=24)$ and in control group $(\mathrm{n}=31)$. Significant difference from baseline to follow-up is indicated by stars, $* * \mathrm{p}<0.01$ and $* * * \mathrm{p}<0.001$.

At baseline 24 participants, and at follow-up 25 participants, answered "I do not know/can not estimate" time sitting on a weekday; for weekend days, 28 participants at baseline and at follow-up were unable to estimate sitting time. Reported values over 20 hours per day (5 values) were excluded because the sum of sitting and sleeping would be over 24 hours per day.

\subsection{ADHERENCE TO PHYSICAL ACTIVITY ON PRESCRIPTION (PAPER} II)

A majority $(65 \%)$ of the patients receiving PAP in Paper II reported that they adhered to the prescription (Figure 4.10); 53\% adhered fully (Group A, $n=128$ ) and $12 \%$ adhered but altered nothing more than the type of physical activity (Group B, $\mathrm{n}=28$ ). Partial adherence (Group C, $n=46$ ) was reported by the $19 \%$ that initially followed the prescription but had ceased to do so by the time of follow-up, while the remaining $16 \%$ reported total non-adherence (Group $\mathrm{D}, \mathrm{n}=38$ ). With a restrictive ITT analysis (all missing data in the follow-up questionnaire were assumed to be non-adherent), the adherence rate was $52 \%(156 / 298)$ for the entire population.

Figure 4.10. Adherence to prescribed physical activity on prescription (Paper II) after 6-month ( $\mathrm{n}=240)$ : 53\% adhered fully ( $\square, 12 \%$ adhered but altered type of physical activity $(\square)$, partial adherence $(\square)$ was reported by $19 \%$, and $16 \%$ reported total non-adherence $(\square)$.

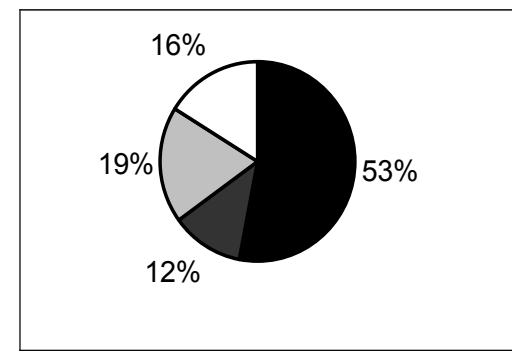

A relation between self-reported adherence and a shift between baseline and follow-up in readiness for change were found. Adherence group A showed significant shift from the stages of preparation and relapse towards action and maintenance $(p<0.001)$. A significant difference was found between the adherence groups in the increase in the stages of action or maintenance $(p<0.05)$. An increase in either of these stages was 
reported by $45 \%$ in Group A, 35\% in Group B, 23\% in Group C, and 29\% in Group D. The result in the adherence groups together (group A and B) were $40 \%$ improvement in stages of change (47\% improved and $7 \%$ declined), compared to $6 \%$ (26\% improved and $20 \%$ declined) in those that did not adhere at follow-up (group C and D). At follow-up $66 \%$ in group A and 54\% in group B were physical active, i.e. in the stages of action or maintenance. Corresponding figures were $34 \%$ in group $\mathrm{C}$ and $32 \%$ in group D.

Nearly $60 \%$ in both Group A and Group B experienced increased well-being at six months compared to baseline. In those groups that did not adhere to PAP, 44\% (Group C), and 25\% (Group D) experienced an increased well-being.

Reported reasons for starting to be more physically active (Group A and B) are presented in Figure 4.11 and the main reasons for non-adherence (Group C and D) are presented in Figure 4.12.

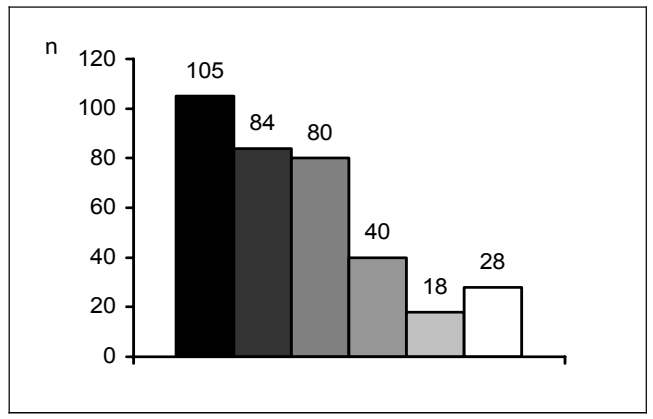

Figure 4.11. Reported reason for adherence to prescribed physical activity $(\mathrm{n}=156)$ : existing decision before coming to the appointment which then strengthened the decision to action ( $\square)$, counselling $(\square)$, prescription $(\square)$, increased knowledge $(\square)$, and contacted by leisure service personnel $(\square)$. Other reasons ( $\square$ ) were related to the subject's health status and the reason for the prescription, such as getting rid of pain and stiffness, being given help with finding suitable strength or mobility exercises, or having enough time to start due to sick-leave.

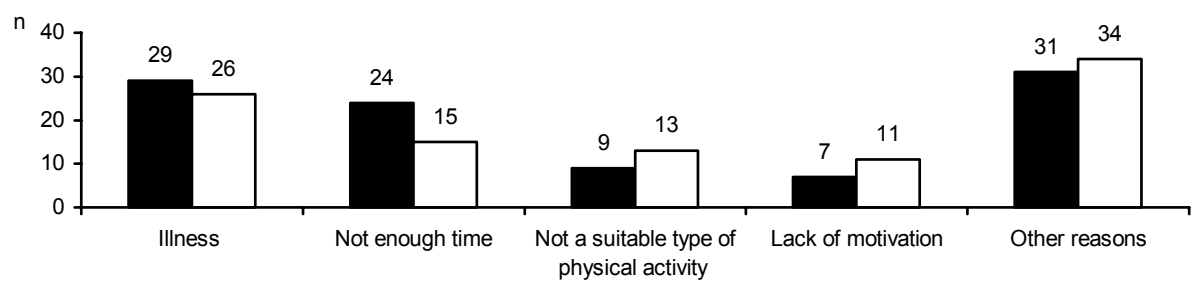

Figure 4.12. Reported reason for non-adherence to prescribed physical activity by those that initially followed the prescription but had ceased to do so by the time of follow-up (n=46, $\square$ ) and those that reported total non-adherence $(n=38, \square)$. Other reasons mainly consisted of the organised group exercise having ended for the term: family or financial reasons, improvement or deterioration in the health problem, or tiredness. Some reported that they found other kind of physical activities by themselves, or that they were not contacted by the public physical activity organisations.

\subsection{BODY COMPOSITION AND CARDIOMETABOLIC RISK FACTORS (PAPER IV)}

\subsubsection{Anthropometrics and body composition}

Within-group analysis showed a significant decrease in all anthropometric and body composition parameters (except for fat free mass), i.e. weight, BMI, waist 
circumferences, SAD, neck circumferences, body fat percentage, body fat mass, fat percentage and fat mass in trunk in the intervention group. The absolute changes are presented in Table 4.3. The relative decrease in the intervention group regarding weight and BMI were $2.1 \%(\mathrm{p}=0.006)$, waist circumferences $2.2 \%(\mathrm{p}=0.0003), \mathrm{SAD} 6.3 \%$ $(p<0.0001)$, neck circumference $3.1 \%(p<0.0001)$, body fat percent $3.5 \%(p=0.0013)$, body fat mass $5.3 \%(\mathrm{p}=0.0001)$, fat percent in trunk $3.4 \%(\mathrm{p}=0.0126)$, and fat mass in trunk $5 \%(\mathrm{p}=0.0034)$. Significant deceases in the control group were waist circumferences $(1.3 \%, \mathrm{p}=0.0013), \mathrm{SAD}(3.6 \% \mathrm{p}=0.004)$, neck circumferences $(1.5 \%$ $\mathrm{p}=0.014)$ and body fat mass $(1.4 \% \mathrm{p}=0.039)$.

Table 4.3. Absolute changes in anthropometrics, body composition and cardiometabolic risk factors from baseline to the 6-month follow-up in the intervention and control groups* in Paper IV.

\begin{tabular}{|c|c|c|c|c|c|}
\hline \multirow[t]{2}{*}{ Variable } & \multicolumn{2}{|c|}{ Intervention group $(n=41)$} & \multicolumn{2}{|c|}{ Control group $(n=50)$} & \multirow[t]{2}{*}{ p-value ${ }^{\S}$} \\
\hline & Mean (SD) & $95 \% \mathrm{CI}$ & Mean (SD) & $95 \% \mathrm{CI}$ & \\
\hline Weight (kg) & $-1.8(0.5)$ & -2.8 to -0.8 & $-0.5(0.3)$ & -1.1 to 0.1 & 0.023 \\
\hline BMI (weight/height ${ }^{2}$ ) & $-0.6(0.2)$ & -0.9 to -0.3 & $-0.2(0.1)$ & -0.4 to 0.0 & 0.023 \\
\hline Waist circumference $(\mathrm{cm})$ & $-2.3(0.6)$ & -3.5 to -1.1 & $-1.4(0.4)$ & -2.2 to -0.6 & 0.20 \\
\hline $\mathrm{SAD}(\mathrm{cm})$ & $-1.5(0.3)$ & -2.1 to -0.9 & $-0.9(0.3)$ & -1.5 to -0.3 & 0.16 \\
\hline Neck circumference $(\mathrm{cm})$ & $-1.2(0.2)$ & -1.6 to -0.8 & $-0.6(0.2)$ & -1.0 to -0.2 & 0.019 \\
\hline Body fat (\%) & $-1.2(0.4)$ & -2.0 to -0.5 & $-0.5(0.2)$ & -1.0 to -0.0 & 0.09 \\
\hline Fat mass (kg) & $-1.7(0.4)$ & -2.5 to -0.9 & $-0.6(0.3)$ & -1.2 to -0.1 & 0.032 \\
\hline Fat free mass $(\mathrm{kg})$ & $-0.2(0.3)$ & -0.8 to 0.4 & $0.2(0.2)$ & -0.3 to 0.7 & 0.29 \\
\hline Body fat in trunk $(\%)$ & $-1.2(0.5)$ & -2.1 to -0.3 & $-0.4(0.3)$ & -1.1 to 0.2 & 0.18 \\
\hline Fat mass in trunk (kg) & $-0.9(0.3)$ & -1.4 to -0.3 & $-0.3(0.2)$ & -0.7 to 0.1 & 0.11 \\
\hline Fat free mass in trunk $(\mathrm{kg})$ & $-0.1(0.2)$ & -0.4 to 0.3 & $0.1(0.2)$ & -0.2 to 0.4 & 0.42 \\
\hline Systolic blood pressure (mmHg) & $0.2(2.2)$ & -4.3 to 4.7 & $-4.1(1.7)$ & -7.5 to -0.6 & 0.12 \\
\hline Diastolic blood pressure ( $\mathrm{mmHg}$ ) & $-1.0(1.3)$ & -3.5 to 1.6 & $-1.7(1.3)$ & -4.4 to 0.9 & 0.68 \\
\hline Glucose $(\mathrm{mmol} / \mathrm{l})$ & $-0.2(0.1)$ & -0.3 to -0.1 & $-0.1(0.1)$ & -0.2 to -0.0 & 0.48 \\
\hline $\mathrm{HbAlc}(\%$ of totHb) & $-0.1(0.1)$ & -0.2 to 0.0 & $0.2(0.0)$ & 0.1 to 0.3 & 0.001 \\
\hline Cholesterol (mmol/1) & $-0.3(0.2)$ & -0.6 to 0.0 & $0.1(0.1)$ & -0.1 to 0.1 & 0.042 \\
\hline Triglycerides (mmol/l) & $-0.2(0.1)$ & -0.3 to -0.0 & $-0.0(0.1)$ & -0.1 to 0.1 & 0.08 \\
\hline $\operatorname{HDL}(\mathrm{mmol} / \mathrm{l})$ & $0.0(0-0)$ & -0.1 to 0.1 & $-0.0(0.0)$ & -0.1 to 0.1 & 0.75 \\
\hline $\operatorname{LDL}(\mathrm{mmol} / \mathrm{l})$ & $-0.1(0.1)$ & -0.2 to 0.1 & $0.1(0.1)$ & -0.1 to 0.3 & 0.13 \\
\hline LDL/HDL & $-0.1(0.1)$ & -0.2 to 0.1 & $0.1(0.1)$ & -0.0 to 0.2 & 0.07 \\
\hline ApoA1 (g/l) & $0.01(0.02)$ & -0.04 to 0.05 & $0.01(0.02)$ & -0.04 to 0.06 & 0.89 \\
\hline ApoB (g/l) & $-0.11(0.03)$ & -0.18 to -0.05 & $-0.07(0.02)$ & -0.11 to -0.04 & 0.25 \\
\hline ApoB/ApoA1 & $-0.09(0.03)$ & -0.14 to -0.04 & $-0.06(0.02)$ & -0.09 to -0.03 & 0.31 \\
\hline
\end{tabular}

Between-group analysis revealed that weight, BMI, neck circumference and fat mass decreased significantly more in the intervention group compared to the control group after 6 months, with differences between groups of $1.3 \mathrm{~kg}$ body weight $(95 \% \mathrm{CI} ; 0.2$ to 2.4), $0.4 \mathrm{~kg} / \mathrm{m}^{2}$ BMI ( $95 \% \mathrm{CI} ; 0.1$ to 0.8$), 0.6 \mathrm{~cm}$ neck circumference (95\% CI; 0.1 to $1.1)$ and $1.0 \mathrm{~kg}$ fat mass $(95 \% \mathrm{CI} ; 0.1$ to 2.0$)$. There was a consistent trend of a greater decrease in the intervention group compared to the control group although the differences between the two groups were not statistically significant in all cases (Figure 4.13). Both groups decreased their waist circumference, SAD and body fat percentage, with no significant differences between the groups; $0.9 \mathrm{~cm}$ waist circumference $(95 \%$ CI; -0.5 to 2.3$), 0.6 \mathrm{~cm} \mathrm{SAD} \mathrm{(95 \%} \mathrm{CI;}-0.3$ to 1.5$)$, and $0.7 \%$ body fat $(95 \% \mathrm{CI} ;-0.1$ to 1.6). 


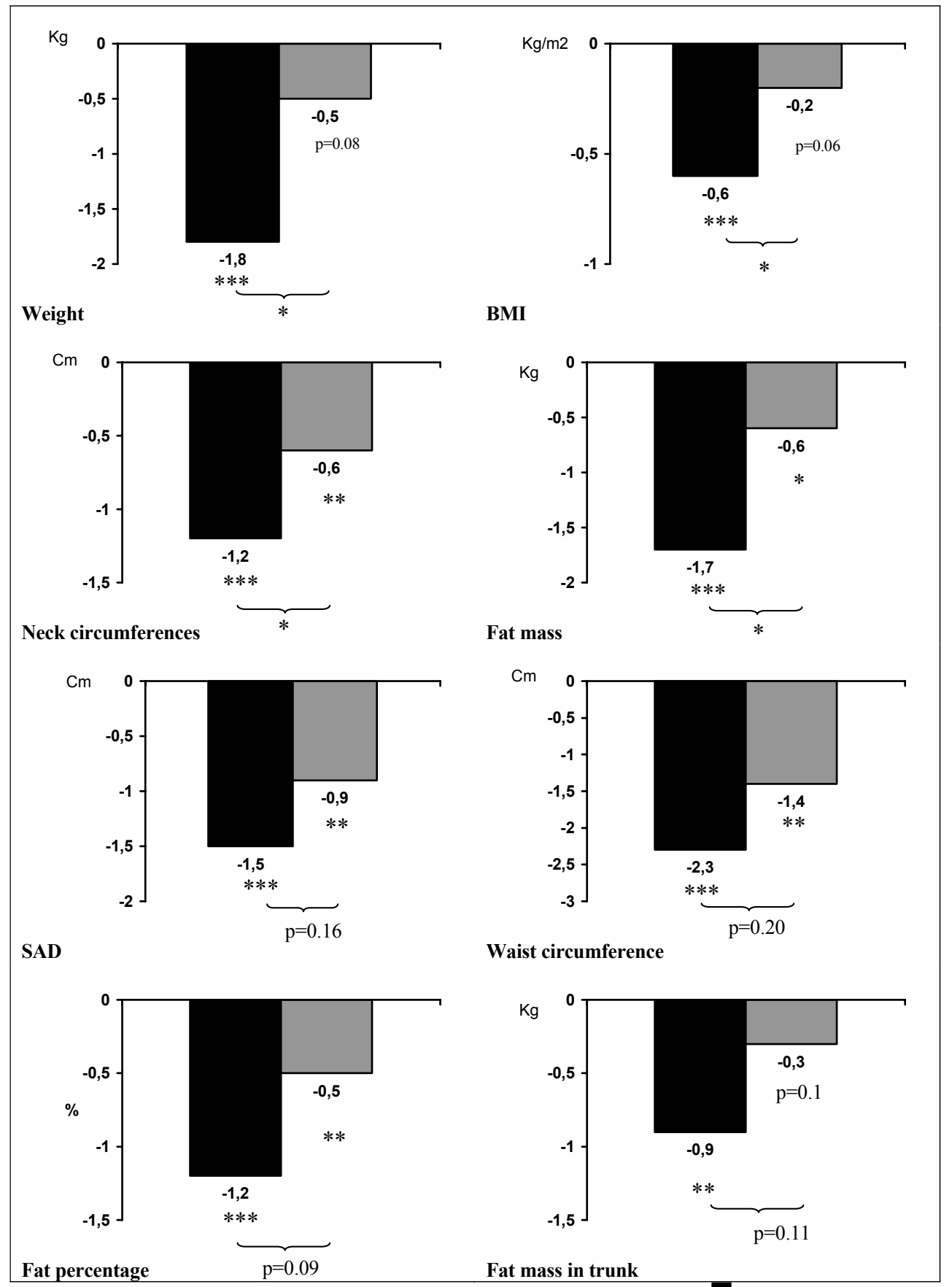

Figure 4.13. Differences within and between groups in Paper IV (intervention group (L) and control group $(\square)$ regarding changes in anthropometrics and body composition from baseline to 6-month followup. Significant differences indicated by stars, ${ }^{*} \mathrm{p}<0.05, * * \mathrm{p}<0.01$ and $* * * \mathrm{p}<0.001$. 


\subsubsection{Cardiovascular risk factors}

Within-group analysis showed significant changes in several cardiovascular risk factors. The absolute changes are presented in Table 4.3. The relative decrease was in glucose $3.4 \%(p=0.0092)$, triglycerides $13.1 \%(p=0.0113)$, apoB $10.2 \%(p=0.0014)$, and the apoB/apoA1 ratio $10.9 \%(\mathrm{p}=0.0012)$ in the intervention group. The control group decreased glucose $(2.4 \%, \mathrm{p}=0.0183)$, apoB $(6.8 \%, \mathrm{p}=0.0001)$, the apoB/apoA1 ratio $(7.8 \%, \mathrm{p}=0.0007)$ and systolic blood pressure $(2.9 \%, \mathrm{p}=0.0217)$, and increased $\operatorname{HbA1c}(3.6 \%, \mathrm{p}=0.0002)$.

Between-group analysis revealed that $\mathrm{HbA} 1 \mathrm{c}[0.25 \%$ of total $\mathrm{Hb}(95 \% \mathrm{CI} ; 0.12$ to $0.37)]$ and cholesterol $[0.3 \mathrm{mmol} / \mathrm{l}(95 \% \mathrm{CI} ; 0.01$ to 0.7$)]$ changed significantly in the intervention compared to the control group after six months (Figure 4.14). There was a trend towards differences in triglycerides $(0.15 \mathrm{mmol} / 1,95 \% \mathrm{CI} ;-0.02$ to 0.32$)$ and $\mathrm{LDL} / \mathrm{HDL}$ ratio $(0.15,95 \% \mathrm{CI} ;-0.02$ to 0.31$)$.

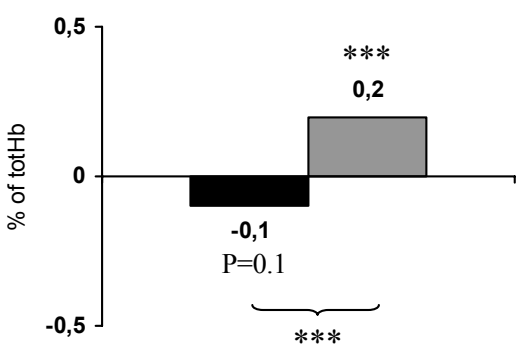

HbA1c

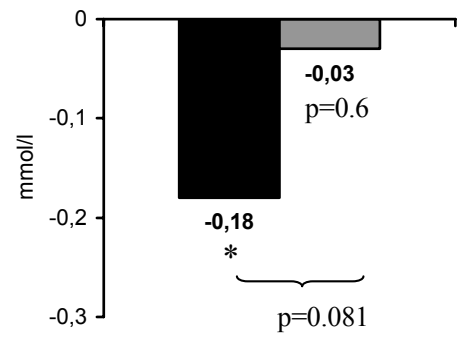

Triglycerides

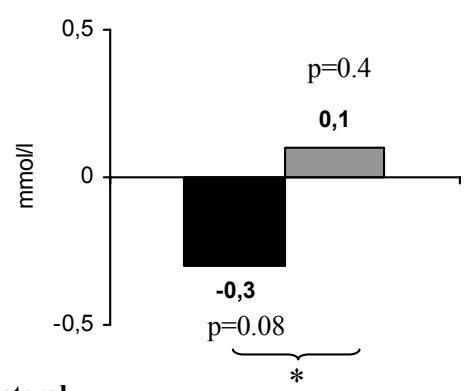

Cholesterol

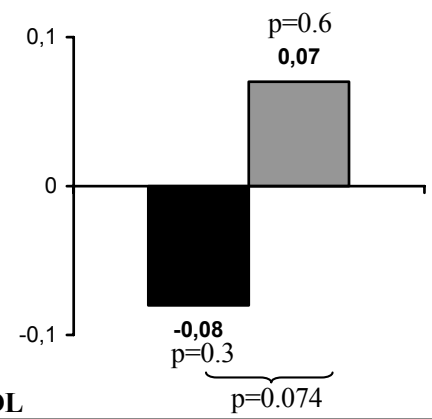

Figure 4.14. Differences within and between groups in Paper IV (intervention group ( $\square$ ) and control group $(\square)$ regarding changes in cardiometabolic risk factors from baseline to 6-month follow-up. Significant difference indicated by stars, ${ }^{*} \mathrm{p}<0.05, * * \mathrm{p}<0.01$ and $* * * \mathrm{p}<0.001$. 


\subsection{QUALITY OF LIFE (PAPER I)}

There were significant increases, according to the intention to treat analysis, in all dimensions of SF-36 six months after PAP (Paper I), except for physical functioning, which had a borderline p-value of 0.053 . Role-physical, bodily pain, general health, vitality, social functioning, role-emotional, mental health as well as the summary measures of physical health and mental health improved significantly $(\mathrm{p}<0.01)$. A significant $(p<0.01)$ improvement were also seen in EuroQol-5D and the visual analogue scale measurement of life quality. Changes in well-being and quality of life data for the follow-up group are presented in Table 4.4 and Figure 4.15.

Table 4.4. Well-being and quality of life $(n=298)$ at baseline and after 6 months (Paper I). Data are presented as mean values with $95 \%$ confidence intervals in brackets

\begin{tabular}{|c|c|c|c|c|}
\hline Variable & Baseline values & 6-month values & Mean changes & p-values (n) \\
\hline \multicolumn{5}{|l|}{$S F-36$} \\
\hline Physical functioning & $75.7(73.5-78.0)$ & $77.3(74.9-79.6)$ & $1.6(0.0-3.1)$ & $0.053(n=287)$ \\
\hline $\begin{array}{l}\text { Role limitations due to } \\
\text { physical problems }\end{array}$ & $54.4(49.4-59.5)$ & $65.7(60.8-70.5)$ & $11.2(6.3-16.2)$ & $<0.001(\mathrm{n}=272)$ \\
\hline Bodily pain & $54.8(51.8-57.8)$ & $60.1(57.0-63.2)$ & $5.3(2.9-7.8)$ & $<0.001(\mathrm{n}=287)$ \\
\hline General health & $60.6(58.0-63.2)$ & $63.3(60.7-65.9)$ & $2.7(0.9-4.5)$ & $<0.01(\mathrm{n}=280)$ \\
\hline Vitality & $47.8(45.1-50.5)$ & $55.4(52.7-58.1)$ & $7.6(5.2-9.9)$ & $<0.001(\mathrm{n}=282)$ \\
\hline Social functioning & $76.5(73.7-79.3)$ & $82.7(80.1-85.3)$ & $6.2(3.4-9.1)$ & $<0.001(\mathrm{n}=288)$ \\
\hline $\begin{array}{l}\text { Role limitations due to } \\
\text { emotional problems }\end{array}$ & $69.3(64.7-74.0)$ & $80.4(76.6-84.3)$ & $11.1(6.6-15.6)$ & $<0.001(\mathrm{n}=269)$ \\
\hline Mental health & $71.4(69.2-73.6)$ & $75.2(73.1-77.3)$ & $3.8(1.8-5.8)$ & $<0.001(\mathrm{n}=282)$ \\
\hline Physical Component Summary & $42.7(41.4-44.0)$ & $44.2(42.9-45.5)$ & $1.5(0.5-2.4)$ & $<0.01(\mathrm{n}=257)$ \\
\hline Mental Component Summary & $44.8(43.3-46.3)$ & $48.3(47.1-49.5)$ & $3.5(2.2-4.9)$ & $<0.001(\mathrm{n}=257)$ \\
\hline \multicolumn{5}{|l|}{ EuroQol } \\
\hline EQ-5D & $0.70(0.68-0.73)$ & $0.74(0.71-0.77)$ & $0.04(0.01-0.06)$ & $<0.01(\mathrm{n}=271)$ \\
\hline VAS & $61.4(59.2-63.7)$ & $67.3(65.2-69.5)$ & $5.9(4.0-7.8)$ & $<0.001(\mathrm{n}=255)$ \\
\hline
\end{tabular}

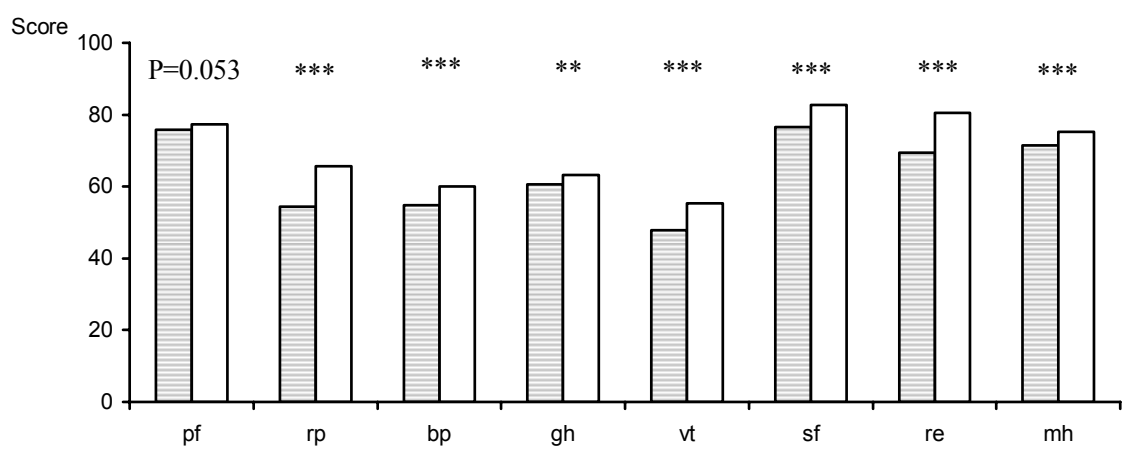

Figure 4.15. Quality of life measured by SF-36 from baseline $(\square)$ to 6-month follow-up $(\square)(\mathrm{n}=298)$ (Paper I). The eight sub-scale scores of SF-36 are: physical functioning (PF), role limitations due to physical problems (RP), bodily pain (BP), general health $(\mathrm{GH})$, vitality (VT), social functioning (SF), role limitations due to emotional problems (RE), and mental health $(\mathrm{MH})$. Significant increase in respective sub-scale is indicated by stars, ${ }^{* *} \mathrm{p}<0.01$ and $* * * \mathrm{p}<0.001$. 


\section{DISCUSSION}

This thesis investigated the effectiveness of individualized physical activity on prescription (PAP) making use of two studies with different designs and conducted within two different clinical settings. The study populations included patients in primary health care centres and insufficient physically active individuals with overweight and abdominal obesity recruited from a population based ongoing prospective cohort study.

\subsection{MAIN FINDINGS}

The main findings from this thesis were that individualized prescriptions of physical activity increases physical activity levels for at least six months, and positively influences cardiovascular risk factors.

Physical activity on prescription is an appropriate method and effective as conventional treatment in ordinary primary health care settings to promote a more physically active lifestyle. Self-reported physical activity level, stages of change and quality of life increased significantly (Paper I). Adherence to physical activity on prescription was $65 \%$ and as good as adherence to other treatments of chronic diseases (Paper II).

In elderly individuals with overweight and low physical activity level physical activity on prescription is an efficacious method to increase physical activity level as significantly higher improvements were seen in the intervention group (two to three times higher) than in the control group regardless of assessment method (Paper III). Individualized physical activity on prescription also improves body composition and cardio-metabolic risk factors in older insufficient physically active overweight individuals (Paper IV).

\subsection{EFFECTIVENESS OF INDIVIDUALIZED PHYSICAL ACTIVITY ON PRESCRIPTION}

Individualized physical activity on prescription is effective in primary health care setting to promote physical activity and have good efficacy compared to a control group. This was evident as both studies showed that physical activity on prescription increases physical activity level for at least six months.

\subsubsection{Physical activity level of study populations compared to general population levels}

Both study populations reported at baseline lower, or for some measurements similar, physical activity level than the general population. Six months after study subjects received physical activity on prescription, the activity levels had increased above the levels seen in the general population. This effect is even further reinforced by the fact that this was true regardless of way of assessing physical activity level, as illustrated below. 


\subsubsection{Total physical activity level}

Even though different questions were used for measuring total physical activity level, both studies showed the same pattern with a shift from low physical activity per week towards more regular exercise six months after receiving the prescription. The fact that the intervention group increased the self-reported total physical activity to higher degree than the control group in Study B strengthens the results from Study A. Compared to population surveys with identical question in two of the five counties where Study A was launched, the patients total physical activity level changed from the same level towards and beyond that of the general population [158]. Results from Study B on self-reported total physical activity during leisure time can be compared to results from a Swedish population survey (with the same question and investigation year) [176], as well as to the cohort population in late 1990s [63]. Table 5.1 is included to illustrate that study subjects in the intervention group was less active than population levels (both in late 1990s and in 2006) at baseline, but the control group was comparable to population levels. At follow-up the intervention group had increased far beyond both the control group and average population level in 2006 (regular exercise $\geq$ 1 times/week $56 \%$ vs. $29 \%$ and $\geq 3$ times/week $23 \%$ vs. $11 \%$ ).

Table 5.1. Self-reported total physical activity during leisure time in a Swedish population survey 2006, the whole cohort population in late 1990-ies and the study population (Paper III) in 2006 at baseline and 6-month follow-up. Data is presented as proportion (\%) classified in the different physical activity categories

\begin{tabular}{|c|c|c|c|c|c|c|}
\hline \multirow{2}{*}{$\begin{array}{l}\text { Leisure time } \\
\text { physical } \\
\text { activity during } \\
\text { last year }\end{array}$} & \multirow{2}{*}{$\begin{array}{c}\text { Swedish } \\
\text { population 65- } \\
\text { 70 years old } \\
\text { 2006* } \\
\mathrm{n}=531 \\
\end{array}$} & \multirow{2}{*}{$\begin{array}{c}\text { 60-year } \\
\text { cohort in } \\
\text { late 1990s }{ }^{\dagger} \\
n=3864\end{array}$} & \multicolumn{2}{|c|}{$\begin{array}{c}\text { Study population } \\
\text { Baseline-values }\end{array}$} & \multicolumn{2}{|c|}{$\begin{array}{c}\text { Study population } \\
\text { 6-month follow-up }\end{array}$} \\
\hline & & & $\begin{array}{c}\text { Intervention } \\
\text { group } \\
(n=47)\end{array}$ & $\begin{array}{l}\text { Control } \\
\text { group } \\
(n=54)\end{array}$ & $\begin{array}{c}\text { Intervention } \\
\text { group } \\
(n=39)\end{array}$ & $\begin{array}{l}\text { Control } \\
\text { group } \\
(\mathrm{n}=49)\end{array}$ \\
\hline $\begin{array}{l}\text { Sedentary } \\
\text { leisure-time }\end{array}$ & 12 & 11 & 13 & 11 & 3 & 6 \\
\hline $\begin{array}{l}\text { Light activity } \\
\text { Regular }\end{array}$ & 58 & 57 & 67 & 59 & 41 & 55 \\
\hline $\begin{array}{l}\text { moderate } \\
\text { exercise }\end{array}$ & 18 & 23 & 16 & 20 & 33 & 31 \\
\hline $\begin{array}{l}\text { Regular } \\
\text { exercise }\end{array}$ & 11 & 8 & 4 & 9 & 23 & 8 \\
\hline
\end{tabular}

* The population values for the fraction of 65 to 70 years old in the national Swedish population survey in year 2006 (personal communication Cecilia Wadman, Swedish National Institute of Public Health, July 7, 2008). $\uparrow$ Data modified from reference [63].

\subsubsection{Readiness for change}

Physical activity on prescription had a positive effect as participants moved through the behavioural stages from contemplation or preparation to adopting and maintaining of a more physically active lifestyle. At baseline in Study A (Paper I) most study subjects $(64 \%)$ or two to three times more than comparable population levels (35\% Swedish population and $21 \%$ the population in European Union) were in the stages of contemplation or preparation [163]. Compared to Swedish population the patients had, at 6-months follow-up, increased their stages of action and maintenance above the population value (50\% vs. 39\%) [163]. This indicate that health care professionals were successful in identifying suitable patients, as those patients' receiving physical activity on prescription were thinking of or prepared to change behaviour to a more physical activity lifestyle. Further, that physical activity on prescription had a potential to increase the physical activity level to a great extent from less to more than the general population level. 


\subsubsection{Steps per day}

Approximately 5000 steps per day were recorded at baseline in Study B, this is similar to the mean steps per day for overweight people over 60 years found in earlier studies $[167,177]$. The increased number of steps found in the intervention group at six months follow-up, is about the same as in normal weight older people [167]. This indicates that our study population was representative of other overweight people around the world regarding steps per day. If physical activity on prescription could promote walking in older overweight people to the same amount as normal weight people walk, this might lead to a reduction in weight.

That physical activity on prescription increases physical activity levels from less than to above the levels seen in an average population in both Study A and B, supports the method's ability to promote physical activity level in clinical practice.

\subsubsection{Self-reported adherence}

The difficulties of assessing physical activity level [2] in clinical practice illustrate a need for simple methods to evaluate treatment and preventive efforts. The results in Paper II suggest that self-reported adherence could be a suitable way to assess the effectiveness of lifestyle counselling such as physical activity on prescription in a routine primary health care setting. Our results indicates that adherence to physical activity on prescription is $65 \%$, and as good as adherence to pharmacological and other treatments of chronic diseases as reported by WHO [145]. Self-reported adherence can be a suitable measure for follow-up at return visits or during telephone calls, and could be used to complement short questions concerning physical activity level, as patients may have changed their activity pattern despite maintaining the same physical activity frequency. This is significant, as even a small increase in physical activity is important both on an individual level and for public health [97].

\subsubsection{Sedentary behaviour}

Reported total time sitting was higher in Study B at baseline (Paper III) compared to Swedish population at the age of 55-74 years (5 vs. 4 hours) [79]. Both groups in Study B decreased their sitting time significantly at the 6-month follow-up. However, the median value of the intervention group (3 hours) was less than that at population level, and the control group's sitting time was similar to population level (4 hours). That the study subjects sat more than the general Swedish population at baseline and less six months after physical activity on prescription, demonstrates the possibility to influence peoples sitting habits.

\subsubsection{Physical activity on prescription versus control group}

Physical activity is a complex behaviour, but in Study B the intervention group clearly increased physical activity levels more compared to the control group (receiving a minimal intervention) by several means, including recorded physical activity levels of at least moderate intensity, increases of $\geq 3000$ steps per day, and self-reported physical activity in leisure time.

In addition, more participants in the intervention group attained the different physical activity goals and recommended physical activity levels at the 6-month follow-up. In the intervention group we noted three additional sessions or 159 minutes more of at least moderately intense activities (including 2 sessions, $128 \mathrm{~min}$ of vigorous or strenuous intensity) and 30\% more steps per day than baseline. In the control group there were no changes in recorded physical activity, but $17 \%$ more steps per day. 
Furthermore, there were agreements between different measurements of physical activity, as at least half of the intervention group increased their total physical activity level according to various assessment methods.

If interventions such as the present method for prescribing physical activity could result in $50 \%$ of subjects increasing their physical activity level, 22 percentage units more achieving recommended physical activity level, and lead to overweight older individuals reaching the same daily step count as normal weight individuals, this may have important public health implications.

\subsubsection{Effects of physical activity on prescription on health outcomes}

Despite implementation of written prescription of physical activity in several countries to increase physical activity level [117], only a few studies have evaluated the effects of physical activity on prescription on health outcomes, in particular compared to a control group [30]. Paper I showed that prescription of physical activity improved both physical and mental health significantly, in spite of the known difficulties for the possibility of one single intervention to influence all the dimensions in health related quality of life.

Individualized physical activity on prescription also improves body composition and cardio-metabolic risk factors in sedentary older overweight individuals, as shown in Paper IV. All measures of central obesity (waist circumference, SAD, fat mass and fat percentage in trunk) decreased significantly in the group receiving physical activity on prescription. In addition, the reduction in body weight of almost two $\mathrm{kg}$ seems to be explained by a decrease in total fat mass (trunk fat decreased by $1 \mathrm{~kg}$ ). This might have a significant health impact, since central obesity is associated with insulin resistance, type 2-diabetes, dyslipidemia, hypertension and cardiovascular diseases $[37,38,40$, 41]. The present intervention might positively influence the metabolic problems associated with central obesity. The effect of physical activity on prescription on cardio-metabolic risk factors is probably stronger if concurrent to weight loss [178]. Also other favourable changes in anthropometrics, body composition, glucose, $\mathrm{HbA1c}$, blood lipids and apolipoproteins were seen in the intervention group. However, in the control group some positive changes were also noted. Bodyweight, neck circumference, fat mass, cholesterol and $\mathrm{HbAlc}$ decreased significantly more in the intervention group. There was a consistent trend of a greater decrease in anthropometrics and body composition in the intervention group compared to the control group, although the differences between the two groups were not statistically significant in all respects.

The fact that we have demonstrated positive effects from physical activity on prescription on health outcome emphasizes the usefulness of the method in clinical practise. Physical activity on prescription has great potential to become an important method for promoting physical activity and self-reported health, as well as reducing overweight, abdominal obesity, and associated cardio-metabolic risk factors. 


\subsection{EFFECTS OF THE INDIVIDUALIZED PHYSICAL ACTIVITY ON PRESCRIPTION OF THE CURRENT STUDIES IN COMPARISON WITH OTHER STUDIES}

Comparisons with other studies are difficult, mainly due to the variations in methods used to promote physical activity, lack of intervention description, short follow-up time ( $<6$ months), or no measurement of physical activity level [107, 117, 179].

\subsubsection{Proportion increasing physical activity level}

A systematic review of different physical activity on prescription interventions conducted in general practice concluded that despite differences in interventions, physical activity on prescription has a moderate positive effect on physical activity level compared to controls in approximate $10 \%$ more of the patients [117]. The Swedish version of physical activity on prescription seems to be more effective, as we noted an increase from baseline to the 6-month follow-up in 30 to $50 \%$ of the patients. The difference varied depending on assessment method. In Study A, total physical activity increased in 39\% of the patients and 30\% more were in the stages of action and maintenance. In the intervention group in Study B total physical activity increased in $51 \%$ of the participants, $53 \%$ increased recorded physical activity on at least moderate intensity, and $47 \%$ increased at least one physical activity category based on steps/day. The absolute differences in proportion between intervention with physical activity on prescription and control group (minimal intervention) were for total physical activity $24 \%$, increased recorded physical activity on at least moderate intensity $36 \%$, and increased at least one physical activity category based on steps/day $8 \%$.

\subsubsection{Study A (Paper I and II)}

The effectiveness of physical activity on prescription as a method of promoting physical activity level in routine primary health care patients (Study A) has recently been confirmed in a large clinical study in routine primary health care patients $(n=6300$, during the year 2004-05) from one of the counties where Study A was launched [180]. Although different questions were used in the two studies, the proportion that increased physical activity level was rather similar (40\% in our study compared to $50 \%$ in the other). The large number of patients in the newly conducted study made it possible to do sub-group analyses, and Leijon and co-workers (in press) found that the patient's activity level at baseline, the type of physical activity as well as the reason for the prescription were associated with increased physical activity. However, the patient's age or the profession of the prescriber was not associated with differences in effectiveness [180]. Preliminary results from the same study demonstrated similar adherence rate as in our study after 3 and 12 month (personal communication ME Leijon July 10, 2007).

As adherence is assessed with various methods and seldom reported, it is difficult to compare the results from our study with other studies. For exercise referral schemes the adherence is often very low, often $80 \%$ drop out before programme ends [181].

Results from Study A are in accordance with randomised controlled trials in routine primary health care which have found increased physical activity $[30,113,116]$, movement in stages of change [182] and changes in general health, role limitations due to physical problems, vitality and bodily pain scores of SF-36 [30]. On the other hand, 
our results disagree with some studies showing no positive effect of physical activity on prescription on the level of physical activity $[118,119]$.

\subsubsection{Study B (Paper III and IV)}

\subsubsection{Physical activity level}

Studies that describe partly similar interventions as in Study B have also shown an increased physical activity level, but not to the same extent as in the present study. Two previous randomised controlled studies have used comparable prescription of physical activity and included subjects over the age of 65 years [30, 183], one study included patients up to 65 years (mean 47 years) [116], and one men up to 60 years (mean 46 years) $[50,144]$. For participants over the age of 65 years the studies showed a difference between intervention and control group on at least moderate intensity of 33 minutes in the study from New Zealand, where $10 \%$ more in the intervention group tended to undertake 2.5 hours/week compared to the control group (12 month followup), and in an US based study the intervention group increased with two sessions more in all forms of physical activity (approximate half on moderate intensity) and on average they performed three session or 106 minutes per week on at least moderate intensity at 12 month follow-up [30, 183, 184]. A similar intervention in Finland included patients up to 65 years (mean 47 years) and showed that the intervention increased 0.9 session per week more on at least moderate intensity than the control group (6 months follow-up) [116]. In a Swedish study in primary health care, men 30 to 60 years old (mean 46 years) increased their physical activity on at least moderate intensity 1.5 sessions more per week than controls ( 6 months follow-up) and there was still an increased activity levels after 18 months [50, 144]. Another study from Australia with counselling, individualized advice about physical activity and a pamphlet with a plan for physical activity resulted in an increase with two sessions of vigorous activity ( 6 months follow-up), which were more than the control group that also showed increased activity [185]. In summary, these studies in elderly showed a difference of 30 minutes or 1-2 sessions more per week on at least moderate intensity for intervention versus control, although results were based on questionnaires only [30, 183]. We believe that several complementary methods of assessment are needed to detect a real improvement in physical activity level, as well as to capture the complete behaviour of physical activity.

As earlier studies and systematic reviews have shown that theory-based behavioural intervention may increase physical activity levels more than usual care, the intervention in this study was based on several theoretical frameworks [107, 127, 154, 155]. The Activity Counseling Trial (ACT) in USA compared two levels of counselling with usual care (advice from physician). At the 6-month follow-up physical activity level increased in all groups with no significant differences compared to the group receiving usual care [113]. Although advice regarding physical activity is generally recommended [100], this is seldom implemented in clinical practice [103, 107, 186]. The contradictory results between the ACT study and the present study (Study B) could be explained by the fact that our controls received less intervention than the ACT control group. Further the physical activity on prescription intervention is somewhere between the intervention in the control group and the intermediate counselling intervention in the ACT. The usual care group in the ACT received a rather extensive intervention, and it seems that more extensive behavioural interventions further boost physical activity, though with a declining marginal effect [107]. Most theory-based behavioural interventions are more extensive than the present study, and therefore not comparable. Our theory-based behavioural intervention seems to be a feasible and 
effective method for promoting physical activity in clinical practice, as participants in the intervention group positively changed their physical activity level and mode.

Changes in steps per day have not been reported earlier in a randomised controlled study with physical activity on prescription. However, a recently conducted systematic review of interventions using pedometer to increase physical activity showed a higher increase in absolute number of steps, but the participants in the present Study B increased their number of steps by the same percentage as reported in the review [187]. Although the increase in the intervention group was double that in the control group, the difference was not statistically significant. This may be explained in part by the great variation in range of changes, as well as the small study population. However, an increase of $\geq 3000$ steps per day was significantly more common in the intervention group, indicating that the present intervention was effective [168, 177].

\subsubsection{Sedentary behaviour}

No studies with similar interventions have measured changes in sedentary habits, but one high intensity theory-based 6-month randomised controlled study found significant reductions in sitting time of almost one hour in both groups [188]. At baseline the intervention group was less active than the population level, and the control group was similar to the population level [58]. At follow-up the intervention group had increased far beyond both the control group and average population values.

Total time sitting was higher in Study B at baseline compared to Swedish population age 55-74 years (5 vs. 4 hours) [79], although both the intervention and control groups had decreased sitting time at the 6-month follow-up, the median value of the intervention group ( 3 hours) was less than population and the control group similar to population (4 hours). Though no significant difference could be detected between the groups, probably due to low power, this result is promising. If minimal intervention can reduce total sitting time, this can have great impact on public health, as this effort hardly take any extra time to conduct in routine care and therefore can be offered to a great number of patients and might be cost-effective. If many people reduce sedentary behaviour a bit, this influence public health more than great reduction in few [97]. If physical activity on prescription reduces total sitting time more than minimal intervention, this intervention could be offered to patients at higher risk.

As these two ways of evaluating changes in sedentary behaviour are in accordance, it seems that physical activity on prescription could be a feasible intervention to reduce sedentary behaviour. However, also the minimal intervention may have some effect. Caution must be taken, though, as this is, to our knowledge, one of the first studies to evaluate effects on sedentary behaviour of interventions in a health care setting. More randomised controlled studies that combine several assessment methods of sedentary behaviour are needed, as epidemiology studies shows that sedentary behaviours, independent of exercise, are associated with significantly elevated risk of obesity and type 2-diabetes [54].

\subsubsection{Health outcome}

To our knowledge, only two previous randomised controlled studies with a comparable intervention have evaluated health outcome. One did not show any significant differences in health outcomes between intervention and control groups [30, 189]. The other demonstrated that even small increase in physical activity level induced significantly changes in middle-aged men regarding BMI, waist circumference and blood pressure compared to control group, six months after intervention [50]. Another 
randomised controlled study with a more intensive intervention that resulted in approximately the same increase in physical activity of moderate intensity as in our study, found no differences at the three months follow-up. At 12 months follow-up the absolute change in body composition in intervention group where less than in Study B, but the difference between groups was similar [51]. The fact that some significant changes occurred in the control group in our randomised controlled study were probably due to the minimal intervention this group received. Somewhat surprisingly, the systolic blood pressure decreased in the control group without any change in the intervention group, but no significant difference between groups was detected. Another study insufficiently active elderly patients found similar results [189].

\subsection{LIMITATIONS}

General limitations for clinical studies regarding physical activity are the methodological problem of adequate measurement of physical activity, as all methods have specific advantages and disadvantages [4]. Even the assessment of physical activity may influence the respondent's behaviour [3], and thus be minimal intervention that could mask the difference between the treatment groups $[116,187]$. The sole fact that people are invited to participate may influence them to comply with the supposed wishes of the researchers because of the special attention received or regression to the mean might also be important [190]. The voluntary participations in studies is a ethical requirement, but this is not a major problem in this kind of studies, as physical activity on prescription as all other lifestyle changes rely on the motivation of individuals in both studies as well as in clinical practice. Another problem that most trials have in common is the selection of participants to studies, as the use of inclusion and exclusion criteria strengthen the internal validity at the same time it can limit the external validity. Naturally intervention with behavioural changes can not be blinded to the participants. Randomization could also be problematic in studies with patient focussed approach, such as the present physical activity on prescription studies. Since a physical active lifestyle has to be carried out for length of life, the 6-month follow-up time in Study A and B is limited. Even though six-month follow-up could be considerate an adequate time in many studies, it is hard to conclude that participants have changed their lifestyle in the long run.

Other limitations should also be taken into consideration in Study A. Firstly, the lack of control group weakens conclusion about causality of physical activity on prescription and changes in the different outcome. Not all patients that were in need of increased physical activity or might be appropriate for physical activity on prescription were recruited. This was partly because the study was conducted in the early implementation phase of physical activity on prescription in Sweden, and not all professionals were familiar with the method, which was still under development. It is not possible to determine a number of possible candidates to receive physical activity on prescription in this study, as the study design reflect a clinical setting where the health care professional and the patient together agree upon treatment with physical activity on prescription or not. This problem is common in primary health care studies [181]. It can also be argued that there might have been a selection bias with more motivated patients, as the patients were not randomised to treatment or not. However, the method of physical activity on prescription might have its best potential for people in the stages of contemplation or preparation for increased physical activity, or those who have relapsed in an earlier attempt. People in the stage of pre-contemplation are not ready for change yet and should, therefore, not be forced to receive physical activity on 
prescription. Other methods for promoting physical activity might then be better. The assessment method for physical activity was only based on questionnaire. However this was the only realistic method due to minimize burden of work for the participating healthcare units as well as for the patients. The dropout rate was $38 \%$ from baseline to the 6-month follow-up. Contributing reason for this dropout might be the lack of reminders at follow-up and that participating health care units handled the procedure a bit different. However, this strengthens the external validity as this is the case in real life. No differences in physical activity level or other baseline characteristics were found between those who finished the study and those who dropped out. To compensate for the drop-outs, we also used a conservative method of intention-to-treat analyses that showed that the significant increases nonetheless existed. The high proportion of women (75\%) in this study is similar to other studies and reflect the situation that more women than men visit primary health care units $[30,116]$.

The main limitation of the present randomised controlled study is the small study population in combination with the fact that the control group also received an intervention, although minimal. This might have resulted in a lack of power to detect differences between the intervention and the control group. Because it is not ethical to withhold evidence-based knowledge about the importance of physical activity on health $[16,27]$, a "true control group" was impossible. The generalization of the results from the randomised controlled study can be questioned as it only included 67- to 68-yearold individuals. However, both women and men were included and the participants were recruited from a population-based sample. Other experiences from assessing physical activity in the randomised controlled study that might be a limitation is the altered approach that seems to occur in classification of activities from baseline to follow-up, as several participants, especially in the intervention group, spontaneously reported that they classified less activities to be a physical activity and consequently registered less low intensity activities at follow-up. They tended to change focus in the diary from all possible every day activities towards more intense physical activities or exercise. Objective measurements with pedometer has the advantage of being simple and inexpensive, but assesses only number of steps and consequently miss to detect several important types of physical activities that were prescribed in Study B, such as bicycling, training of strength and swimming. Nor do pedometers detect changes in intensity from baseline to follow-up that might be one of the most important increases in physical activity level from an intervention such as physical activity on prescription, i.e. the participants were encouraged to increase the intensity of walking to at least moderate intensity walk or Nordic walking. Although the used pedometer (Yamax Digiwalker SW-200) was chosen as it has been shown to be the most accurate in brandto-brand comparisons and is frequently used in research [164-167], it has been shown to have less accuracy at speeds less than $4 \mathrm{~km} / \mathrm{h}$ and both pedometer accuracy and walking speed decreases with age, weight, BMI, waist circumference and pedometer tilt [13-15]. A problem that seldom is discussed or described in the literature is what the lowest reasonable step value for one day is. As one subject in the present study were bed-bound due to an operation during several days of his 7-day registration, we were able to get a value of the lowest reasonable step count in the population with overweight and central obese older women and men. He registered approximately 250 steps during these days, when he only left bed for using the toilet. We analyzed if there was any differences in results if we excluded those few values below this point, but no differences were found. A problem with assessing sedentary behaviour with the IPAQ sitting item was found, it seems to be difficult for individuals to estimate average time sitting. One fourth answered "I do not know/can not estimate" and equal amount did 
not answer this particular question at all. This problem was not evident for any other questions.

\subsection{STRENGTHS}

The strength of this thesis is the combined approach of evaluating physical activity on prescription in "real-life" and at controlled conditions, i.e. with clinical studies in routine primary health care and a randomised controlled study. We worked the other way round than usual, we started to find a feasible method for use in clinical practice and then we conducted a randomised controlled study to evaluate the efficacy of the method. Because both studies included participants during several months, a whole year respectively from winter to summer, we avoided the problem of seasonal differences of physical activities. Both studies were representative concerning selfreported physical activity level as study populations reported lower or the same physical activity levels at baseline as population levels.

The strength of Study A was the fact that the study was conducted in everyday clinical practice and that the patients received the intervention from their usual health care professional as a part of routine primary health care. The findings from the present study have the potential for generalizability to patients in primary health care, as the study included a socio-economic diverse sample from divergent care units. The participating units were recruited from a large geographical area in Sweden, and worked under different conditions as regards their size, location (urban and rural), primary care and occupational health care units and had heterogeneous populations. Different professions could prescribe physical activity, as the head of the respective unit had to handle that decision. All the units had the model of physical activity on prescription, training initiatives, the written prescription form and FYSS in common, but adapted the model to regional and local conditions. It was also up to each unit to establish interaction between health care and leisure time services personnel and to create a community-based network. Since the health care professional and the patient together agree upon treatment with physical activity on prescription, or not, the recruitment of participants to the study reflect a wide variation of patients (as regard age, health problems, reason for prescribing physical activity, suitable prescribe physical activity, etc.) that usually are met in primary health care practice without any systematic exclusion. This shows that our study could bridge some of the problems identified earlier with translating research into health promotion practice [191, 192]. Testing physical activity on prescription in a clinical setting strengthens the external validity $[148,149]$.

The well defined and described intervention in the randomised controlled study is central. Physical activity is a complex behaviour and the strength of Study B is the use of, and agreement between, multiple assessment methods that compensate for each other. Several complementary methods may be needed to detect a real improvement in physical activity level. This study used methods suitable for use in clinical practice. Borg's RPE-scale has been shown to be useful in controlling exercise intensity, and in monitoring and prescribing exercise in elderly and/or obese populations [193, 194]. Measurement of physical activity in people who are sedentary or who have low physical activity is difficult. Existing self-report methods suffer from "floor effects". It is important to measure sedentary behaviour and not define it merely as lack of physical activity $[7,17]$. For that reason we used self-reported sitting time to measure sedentary behaviour, as it has been shown to correlate with sedentary time measured by 
accelerometer [17]. The drop-out rate in Study B was low and 90\% completed the 6month follow-up. The present study is one of few randomised controlled study that evaluate the effects of intervention methods for promoting physical activity and reducing sedentary behaviour. Additional strengths are that the study participants were recruited from a population based sample and were well characterised. Multiple beneficial effects of the increased physical activity on many cardio-metabolic risk factors are encouraging.

\subsection{TRANSLATION OF THE METHOD PHYSICAL ACTIVITY ON PRESCRIPTION INTO HEALTH CARE PRACTICE}

The gap between research and practice in many areas of health care and public health is large, well documented, and troubling and there is a need to translate effective interventions into practice [151-153].

Research findings concerning how and to what extent healthcare institutions promote physical activity are limited in number. Studies indicate that physical activity in prevention and treatment is not used to its full potential in primary health care. Even though general practitioners believe they should give advice or counsel about physical activity, they are less likely to do so in practice, and more than half are sceptical about their ability to help patients practise regular physical exercise [102, 103]. Around half of the GPs in Europe counsel sedentary patients [103] and in US 59\% of the GPs report that they counsel more than $50 \%$ of their patients about physical activity, and $18 \%$ prescribe physical activity for more than $50 \%$ of their patients [102]. Twenty eight percent of adults in the US report receiving physician advice to increase their level of physical activity, and of this only $40 \%$ also reported receiving help in making a plan for physical activity or follow-up support [105]. Methods like physical activity on prescription have received increased attention during the last decade. However, only $30 \%$ of patients visiting health care system over the past year in Sweden reported that they had discussed lifestyle issues with doctors or nurses, and only between $20 \%$ and $40 \%$ of these (depending on counties) received a prescription of physical activity (i.e. physical activity on prescription) [195]. A survey of clinical practice in Sweden indicates that healthcare units regard the promotion of physical activity as a vital ingredient of their overall responsibility [107]. The use of oral recommendation for promoting physical activity is common, but written prescriptions or referring patients to other healthcare professionals is more infrequent and the real effort to promote physical activity varies greatly among and within various healthcare segments. However, the prospect for making clinical practice more effective appears to be good. Health care professionals have great confidence in the benefits of physical activity and generally regard its promotion as integral to their duties [107].

Our studies will hopefully help to overcome some of the barriers for the increased use of prescription of physical activity identified earlier [102, 103], as this thesis shows that prescription of physical activity is an effective and feasible method for increased physical activity. Physical activity on prescription might promote increased everyday physical activity in a part of the population who otherwise are hard to reach or have a low motivation for lifestyle changes. We also showed that it is possible to incorporate physical activity on prescription in routine primary health care when the instruments (handbook of physical activity, prescription form, knowledge about physical activity and health as well as patient-focused counselling) and structures (for interaction and networking with the community and sport and recreational organisations that help 
patients to be active participants) are available. Assessment of physical activity level has several known limitations, and in primary health care practice it can be difficult to assess small but clinical significant changes. Therefore the use of a simple question, as the question about adherence used in Study A, is an encouraging new possibility. Selfreported adherence can be a suitable measure for follow-up at return-visits or during telephone calls, and could be used to complement short questions concerning physical activity level, as patients may have changed their activity pattern despite maintaining the same physical activity frequency.

The intervention in Study B is suitable in clinical practice. Each subject in the intervention group was offered intervention contacts of total approximately 90 minutes. Physician counselled for a few minutes on individual level, wrote an individualized letter with advice based on risk profile and offered one hour group meeting for 12-18 participants, in total approximately 20 minutes per patients. In addition approximate 30 (20-40) minutes counselling by a health care professional trained in motivational counselling for physical activity, a few minutes of telephone follow-up of counselling, and the one hour group meeting, the renewed counselling at 6 month should also be included, giving at total of approximately 70 minutes per patient.

\subsubsection{A Swedish perspective}

The Swedish version of individualized physical activity on prescription are now evaluated and found to be effective in uncontrolled studies in ordinary clinical practice (in Paper I, II and [180]). The efficacy of the method is confirmed (at least in older individuals) in the present randomised controlled study. The Swedish version of physical activity on prescription, developed over the last decade, is based on earlier research, best practice, and continuing evolution as the knowledge base extends [55, 90, 139]. Currently, the physical activity on prescription method is in use in primary health care settings in all counties, but to differing degrees. The Swedish Government stresses in their renewed Swedish Public Health bill (Mars 2008) that the physical activity on prescription is a promising method that should be used and evaluated systematic [196]. Several Governmental commissions states that the Swedish National Institute of Public Health should evaluate and disseminate the physical activity on prescription method thorough education of health care professionals and other strategies together with the new version of the evidence based handbook on the effects of physical activity in the prevention and treatment of diseases "FYSS" [55] as an important strategy to promote physical activity level and counteract overweight in the population.

This combined approach with a method that is evaluated for effectiveness in clinical practice in several primary health care units and found to have high efficacy according to the present randomised controlled study, together with "FYSS" and national strategies for dissemination of physical activity on prescription gives good opportunities for the translation of physical activity on prescription into clinical practice.

\subsection{CLINICAL IMPLICATIONS}

Physical activity is the evidence-based treatment known to be the most effective and entailing the fewest side effects or risks in several chronic diseases [16, 27, 95]. There is, however, insufficient evidence for feasible methods to promote physical activity in health care settings [107]. Positive effects of individualized physical activity on prescription were found in Study A as well as in two other studies in everyday practice in Sweden $[50,144,180]$. These results show that an individualized prescription of 
physical activity can be integrated in the primary health care system and that the counselling could be delivered by several different professionals. The need for using a range of approaches and designs of studies in order to develop evidence-based practice is newly highlighted $[197,198]$. The present randomised controlled study was conducted to evaluate the efficacy of the method under controlled conditions, but with a population based sample. This combined approach, including detailed descriptions of all identified components of the intervention and the efforts to secure that the intervention is usable in clinical practice and provides a good opportunity for the dissemination of physical activity on prescription in promoting physical activity.

The fact that serious health problems is related to sedentary behaviour, together with the reduced total sitting time found in Study B, suggest that health care professionals should consider this issue with their patients in particular.

As lack of time and inadequate training, are the most common barrier for physician to counsel about physical activity, results from the present randomised controlled study and other studies $[124,130,131,199]$ suggest that a short counselling by physician combined with involving a broader set of healthcare team members for providing a longer and more thorough counselling could be a practical approach to use limited resources in clinical practise.

\subsection{FUTURE PERSPECTIVES}

The studies included in this thesis have expanded the knowledgebase of a method for promoting physical activity in health care settings, i.e. individualized physical activity on prescription. Still, there are major gaps in our knowledge about the long-term effectiveness of both this particular method as well as various other methods of promoting physical activity in these settings. Future research should be designed to enable long-term follow-up of the efficacy of physical activity on prescription, and make comparisons with other methods, while considering ethical and social aspects, including those related to gender and ethnic background.

There is a need for studies with longer follow-up periods ( $\geq 1$ to 2 year); studies that allow separate analysis for women and men including diverse populations (such as varied age, health problems, preferred physical activities, socioeconomic status, ethnicity etc.), more studies in clinical settings under controlled conditions, and to test the method in different settings (primary health care as well as hospitals). In further studies it is important to include thorough descriptions of used intervention and to apply several methods for assessing changes in physical activity levels. Translating research results into feasible clinical practice is essential.

One way to increase extern validity would be a multi-centre study with several counties or regions, preferable as Nordic countries collaboration. There is a need for several studies with different designs: randomised controlled studies, controlled clinical studies as well as quality studies to develop better knowledge how to promote physical activity in insufficiently physical active individuals. A health economic study concerning the costs and efficacy of physical activity on prescription is also desirable. Further investigation is also needed to develop validated measurements of adherence to lifestyle counselling. 


\section{SAMMANFATTNING (SUMMARY IN SWEDISH)}

Fysisk aktivitet är en av de viktigaste faktorerna för vår hälsa. Hälso- och sjukvården är en viktig aktör för att främja fysisk aktivitet hos såväl den enskilda individen som hos befolkningen i stort. Hittills har det inte funnits tillräckligt med vetenskapliga belägg för att en viss metod är bättre än en annan för att öka den fysiska aktiviteten. Trots detta har en metod där läkare och annan sjukvårdspersonal förskriver fysisk aktivitet -Fysisk Aktivitet på Recept $\left(\mathrm{FaR}^{\circledR}\right)$ - rönt stort intresse.

Effektiviteten av Fysisk Aktivitet på Recept har undersökts i denna avhandling med hjälp av två studier. Studierna hade olika vetenskapligt upplägg. De är gjorda på patienter i primärvård och företagshälsovård ( $\mathrm{n}=481,75 \%$ kvinnor, medelålder 50 år [12-81]) samt på otillräckligt fysiskt aktiva äldre individer med övervikt och bukfetma ( $n=101,57$ \% kvinnor, 67-68 år) som rekryterades från en pågående populationsbaserad kohortstudie.

Huvudfyndet var att individualiserad förskrivning av fysisk aktivitet leder till en ökad fysisk aktivitetsnivå under minst sex månader. Fysisk Aktivitet på Recept kan vara lämpligt att använda som behandling i hälso- och sjukvården som ett sätt att främja en fysiskt aktiv livsstil. Självrapporterad fysisk aktivitetsnivå, förändringsbenägenhet för en ökad fysiskt aktiv livsstil (stages of change) och livskvalitet ökade signifikant. Följsamhet till $\mathrm{FaR}$ var $65 \%$, vilket är minst lika bra som till annan långtidsbehandling. Fysisk Aktivitet på Recept är en effektiv metod för att öka den fysiska aktivitetsnivån hos äldre överviktiga individer, eftersom den grupp som fick FaR ökade sin aktivitetsnivå två till tre gånger mer än en kontrollgrupp, oberoende av vilken mätmetod som användes. Även kroppssammansättning och andra riskfaktorer för hjärtkärlsjukdom förbättrades av hos otillräckligt aktiva överviktiga äldre individer som fått FaR.

Sammanfattningsvis visar denna avhandling att individuellt utformad förskrivning av fysisk aktivitet $(\mathrm{FaR})$ är effektiv i klinisk vardag;

- FaR kan användas i hälso- och sjukvården och är en effektiv metod för att öka patienters fysiska aktivitetsnivå.

- Följsamhet till FaR är minst lika bra som till annan behandling vid kronisk sjukdom.

- Både fysisk- och mental livskvalitet ökade sex månader efter att patienter fått FaR.

- FaR ökar den fysiska aktivitetsnivån två till tre gånger mer än hos en kontrollgrupp.

- FaR minskar riskfaktorer för hjärt-kärlsjukdom hos otillräckligt aktiva, överviktiga, äldre kvinnor och män.

Fysisk Aktivitet på Recept har därför en potential att vara en viktig metod för att $\mathrm{i}$ ett folkhälsoperspektiv främja en fysiskt aktiv livsstil, och därmed förbättra hälsa och livskvalitet samt minska sjukdomsbördan hos både individ och samhälle. 


\section{CONCLUSIONS}

This thesis shows that an individualized physical activity on prescription (PAP) is effective in clinical settings and has high efficacy in risk population for at least six months.

- PAP can be carried out as a part of routine care and is effective in promoting physical activity.

- Adherence to PAP in primary health care settings is as good as adherence to other treatments of chronic diseases.

- Self-reported quality of life, both in physical and mental aspects, increased 6 months after receiving PAP.

- PAP increases physical activity level three times more than in a control group.

- PAP reduced several cardiometabolic risk factors in elderly women and men with low physical activity level, overweight and abdominal obesity.

Physical activity on prescription is one important strategy for public health care system to promote physical activity, and, thereby, positively influence public health 


\section{ACKNOWLEDGEMENTS}

This thesis is a result of a fruitful collaboration with Karolinska Institutet and Swedish National Institute of Public Health. There are many people who have contributed to the realization of these studies and I am very grateful to everyone. I would especially like to express my sincere gratitude to the following:

Mai-Lis Hellénius, my principal supervisor who has been the best support a $\mathrm{PhD}$ student could have, who has guided me through all steps of clinical intervention research and trusted me with the responsibly in all parts. For placing necessary facilities at my disposal, for never ending enthusiasm and encouragement throughout these years, and for sharing her deep knowledge in preventive medicine and lifestyle interventions as a crucial component in health and disease.

Agneta Ståhle, my co-supervisor, for fruitful discussions and support, for skilful and constructive criticism during preparation of manuscripts and for good advice. Also for walks with our dogs and chats about puppies and hunting dogs.

Jan Sundquist, head of Center for Family and Community Medicine (CeFAM) at the Department of Neurobiology, Care Sciences and Society, for placing necessary facilities at my disposal and for the inspiring writing course in Spain.

Gunnar Ågren, director general at the Swedish National Institute of Public Health, who has believed in my capacity as a $\mathrm{PhD}$ student and in the research project and provided economical resources.

All other co-authors for constructive collaboration and sharing your knowledge within different areas; Matti Leijon for all interesting discussions on public health aspects in general and in particular regarding physical activity on prescription and for being a good friend. Jan Kowalski for sharing your experiences in statistics. Erik Hemmingsson for sharing your knowledge in interventions with physical activity among people with overweight and for being a great friend. Rachel Fisher and Justo Sierra Johnson for interesting and valuable scientific meetings. Ulf de Faire for providing the "60-year" cohort and for suggestions during design of the RCT. Christer Höglund for conducting a great deal of the medical screening, with exercise tests at the GlobenHeart centre, in the RCT.

All other co-workers within the RCT regarding individualized physical activity on prescription to older adults with overweight, for constructive collaboration and sharing your knowledge and technical skills within different areas; Stephan Rössner for constructive discussions during the design of the study and providing the clinical research centre. Viveca Larsson Petré, Birgitta Spetz, Lena Mannström, Veronica Dittmer, Mats Halldin, Birgitta Söderholm, Ingeborg Eriksson and Aster Bocray for skilled work and generous support during baseline and six months follow-up data collection. Christina Edman Jönsson and Eva Wallgren for their work with the longterm follow-up. To all other researchers involved in the study: Mats Eriksson, Bo Angelin, Paolo Parini, Anders Hamsten, Kerstin Brismar, Peter Lindgren, Anna Ringborg, Bengt Vessby, Samir Basu and Siv Tengblad. 
All people involved in the study within primary health care; Mona Ringbjer, Christina Samuelsson, Birgitta Seijmer Andersson, Annika Strandell and Anna Östbom and all health care professionals at the 13 primary care and occupational health care units. Furthermore all people working within the sport- and leisure organisations who contributed to the study, as well as other former colleagues working with "Sweden on the move" at Swedish National Institute of Public Health.

The project group of the SBU report about methods of promoting physical activity, for all worthwhile discussions on different research questions such as design and quality of studies and how to promote physical activity in health care practice, especially Hans Lingfors, Lasse Hagberg, Margareta Emtner and Bernt Lindahl.

Lillemor Nyberg for sharing your knowledge in how to counsel patients, for all refreshing discussions about physical activity in theory and practice, how to translate physical activity on prescription into health care practice and about life in general. And for being a great friend.

All colleagues at CeFAM and former "Livsstilsenheten" and in particular; Birgitta Andersson, Birgitta Lindvall, Kimberly Kane, Daphne Macris, Krisitina Sundquist, Jill Taube and Ing-Mari Dohrn. A special thank to Ann Nicolausson for all your help with different practicalities. Julia-Aneth Mbalilaki for scientific discussions, walks and chats in different places in Europe. Anna Andreasson, my room mate during the last years, for discussions about research, life and other important things.

All study participants for taking part in the studies.

I also want to thank all friends outside the research world for providing other aspects of life. Especially: Irene, Morgan and Åsa for long friendship and knowing that we always can share ups and downs in life; Mona, Anna and Kajsa for all outdoor activities such as kayak and skiing; Lena-Karin for being a great neighbour and company during walks with the dogs.

My parents Kerstin and Lars Olof, my brother and sisters Peter, Christina, Birgitta and Torun with their families for always believing in me and standing by my side.

Henrik, for love, support and understanding.

This work has been supported by grants from the Swedish National Institute of Public Health, the Swedish Heart and Lung Foundation, the Swedish National Centre for Research in Sports, the Tornspiran Foundation, Karolinska Institutet funds, Svenssons Foundation, Goljes Minne Foundation and the Capio Foundation. 


\section{REFERENCES}

1. Caspersen CJ, Powell KE, Christenson GM. Physical activity, exercise, and physical fitness: definitions and distinctions for health-related research. Public Health Rep. 1985;100:126-31.

2. Vanhees L, Lefevre J, Philippaerts R, Martens M, Huygens W, Troosters T, et al. How to assess physical activity? How to assess physical fitness? Eur J Cardiovasc Prev Rehabil. 2005;12:102-14.

3. Welk GJ, editor. Physical Activity Assessments for Health-Related Research. Champaign, Ill: Human Kinetics; 2002.

4. Ainsworth BA, Levy SS. Assessment of health-enhancing physical activity: methodological issues. In: Oja P, Borms J, editors. Health enhancing physical activity. Oxford: Meyer \& Meyer Sport; 2004. p. 239-69.

5. Lamonte MJ, Ainsworth BE. Quantifying energy expenditure and physical activity in the context of dose response. Med Sci Sports Exerc. 2001;33:S370-S8.

6. Schutz Y, Weinsier RL, Hunter GR. Assessment of Free-Living Physical Activity in Humans: An Overview of Currently Available and Proposed New Measures. Obes Res. 2001;9:368-79.

7. Tudor-Locke CE, Myers AM. Challenges and opportunities for measuring physical activity in sedentary adults. Sports Med. 2001;31:91-100.

8. Warms C. Physical activity measurement in persons with chronic and disabling conditions: methods, strategies, and issues. Fam Community Health. 2006;29(1 Suppl):S78-S88.

9. Treuth MS. Applying multiple methods to improve the accuracy of activity assessments. In: Welk GJ, editor. Physical Activity Assessments for Health-Related Research. Champaign: Human Kinetics; 2002. p. 213-25.

10. Dale D, Welk GJ, Matthews CE. Methods for Assessing Physical Activity and Challenges for Research. In: Welk GJ, editor. Physical Activity Assessments for Health-Related Research. Champaign: Human Kinetics; 2002. p. 19-34.

11. Booth M. Assessment of physical activity: An international perspective. Res Q Exerc Sport. 2000;71:114-20.

12. Shephard RJ, Vuillemin A. Limits to the measurement of habitual physical activity by questionnaires Br J Sports Med. 2003;37:197-206.

13. Melanson EL, Knoll JR, Bell ML, Donahoo WT, Hill JO, Nysse LJ, et al. Commercially available pedometers: considerations for accurate step counting. Prev Med. 2004;39:3618.

14. Crouter SE, Schneider PL, Bassett DRJ. Spring-Levered versus Piezo-Electric Pedometer Accuracy in Overweight and Obese Adults. Med Sci Sports Exerc. 2005;37:1673-9.

15. Le Masurier GC, Tudor-Locke C. Comparison of Pedometer and Accelerometer Accuracy under Controlled Conditions. Med Sci Sports Exerc. 2003;35:867-71.

16. U.S. Department of Health and Human Services. Physical Activity and Health: A report of the Surgeon General. Atlanta, Ga: U.S. Department of Health and Human Services, Centers for Disease Control and Prevention, National Center for Chronic Disease Prevention and Health Promotion; 1996.

17. Rosenberg DE, Bull FC, Marshall AL, Sallis JF, Bauman AE. Assessment of sedentary behavior with the International Physical Activity Questionnaire. J Phys Act Health. 2008;5 (Suppl):S30-S44.

18. Bauman A, Phongsavan P, Schoeppe S, Owen N. Physical activity measurement-a primer for health promotion. Promot Educ. 2006;13:92-103.

19. Bernstein MS, Morabia A, Sloutskis D. Definition and prevalence of sedentarism in an urban population. Am J Public Health. 1999;89:862-7. 
20. Bauman A, Miller Y. The public health potential of health enhancing physical activity. In: Oja P, Borms J, editors. Health enhancing physical activity. Oxford: Meyer \& Meyer Sport; 2004. p. 125-47.

21. World Health Organization. The World Health Report 2002. Reducing risks, promoting healthy life. Geneva: WHO; 2002.

22. World Health Organization. Preventing chronic diseases: a vital investment: WHO global report. Geneva; 2005.

23. Bull FC, Armstrong TP, Dixon T, Ham S, Neiman A, Pratt M. Physical inactivity. In: Ezzati M, Lopez AD, Rodgers A, Murray CJL, editors. Comparative Quantification of Health Risks Global and Regional Burden of Disease Attributable to Selected Major Risk Factors. Geneva: World Health Organization; 2004. p. 729-881.

24. Ezzati M, Rodgers A, Lopez AD, Vander Hoorn S, Murray CJL. Mortality and burden of disease attributable to individual risk factors. In: Ezzati M, Lopez AD, Rodgers A, Murray CJL, editors. Comparative Quantification of Health Risks Global and Regional Burden of Disease Attributable to Selected Major Risk Factors. Geneva: World Health Organization; 2004. p. 2141-65.

25. World Health Organization Europe. The European health report 2005: public health action for healthier children and populations. Copenhagen; 2005.

26. Agardh E, Moradi T, Allebeck P. Riskfaktorernas bidrag till sjukdomsbördan i Sverige. Jämförelse mellan svenska och WHO-data [The contribution of risk factors to the burden of disease in Sweden] (In Swedish with English summary). Läkartidiningen. 2008;11:81621.

27. Pedersen BK, Saltin B. Evidence for prescribing exercise as therapy in chronic disease. Scand J Med Sci Sports. 2006;16 (Suppl 1):S3-S63.

28. Hu FB, Sigal R, Rich-Edwards J, Colditz GA, Solomon CG, Willett W, et al. Walking compared with vigorous physical activity and risk of type 2 diabetes in women. JAMA. 1999;282:1433-9.

29. Wannamethee S, Shaper A. Physical activity in the prevention of cardiovascular disease: an epidemiological perspective. Sports Med. 2001;3:101-14.

30. Elley CR, Kerse N, Arroll B, Robinson E. Effectiveness of counselling patients on physical activity in general practice: cluster randomised controlled trial. BMJ. 2003;326:793-6.

31. Brown DW, Balluz LS, Heath GW, Moriarty DG, Ford ES, Giles WH, et al. Associations between recommended levels of physical activity and health-related quality of life: Findings from the 2001 Behavioral Risk Factor Surveillance System (BRFSS) survey. Prev Med. 2003;37:520-8.

32. Vuillemin A, Boini S, Bertrais S, Tessier S, Oppert J-M, Hercberg S, et al. Leisure time physical activity and health-related quality of life. Prev Med. 2005;41:562-9.

33. Church TS, Earnest CP, Skinner JS, Blair SN. Effects of Different Doses of Physical Activity on Cardiorespiratory Fitness Among Sedentary, Overweight or Obese Postmenopausal Women With Elevated Blood Pressure: A Randomized Controlled Trial. JAMA. 2007;297:2081-91.

34. Lee IM. Dose-Response Relation Between Physical Activity and Fitness: Even a Little Is Good; More Is Better. JAMA. 2007;297:2137-9.

35. Kesaniemi YA, Danforth E, Jensen MD, Kopelman PG, Lefebvre P, Reeder BA. Doseresponse issues concerning physical activity and health: an evidence-based symposium. Med Sci Sports Exerc. 2001;33:S351-S8.

36. James WPT, Jackson-Leach R, Mhurchu CN, Kalamara E, Shayeghi M, Rigby NJ, et al. Overweight and obesity (high body mass index), Chapter 8, In: Comparative Quantification of Health Risks. Global and Regional Burden of Disease Attributable to Selected Major Risk Factors In: Ezzati M, Lopez AD, Rodgers A, Murray CJL, editors.: World Health Organization; 2004. p. 497-596.

37. Yusuf S, Hawken S, Ounpuu S, Dans T, Avezum A, Lanas F, et al. Effect of potentially modifiable risk factors associated with myocardial infarction in 52 countries (the INTERHEART study): case-control study. Lancet. 2004;364:937-52. 
38. Janssen I, Katzmarzyk PT, Ross R. Body Mass Index, Waist Circumference, and Health Risk: Evidence in Support of Current National Institutes of Health Guidelines. Arch Intern Med. 2002;162:2074-9.

39. Janssen I, Katzmarzyk PT, Ross R. Waist circumference and not body mass index explains obesity-related health risk. Am J Clin Nutr. 2004;79:379-84.

40. Palaniappan L, Carnethon MR, Wang Y, Hanley AJG, Fortmann SP, Haffner SM, et al. Predictors of the Incident Metabolic Syndrome in Adults: The Insulin Resistance Atherosclerosis Study. Diabetes Care. 2004;27:788-93.

41. Snijder MB, van Dam RM, Visser M, Seidell JC. What aspects of body fat are particularly hazardous and how do we measure them? Int J Epidemiol. 2006;35:83-92.

42. Lee CD, Blair SN, Jackson AS. Cardiorespiratory fitness, body composition, and all-cause and cardiovascular disease mortality in men. Am J Clin Nutr. 1999;69:373-80.

43. Hu FB, Willett WC, Li T, Stampfer MJ, Colditz GA, Manson JE. Adiposity as compared with physical activity in predicting mortality among women. N Engl J Med. 2004;351:2694-703.

44. Manini TM, Everhart JE, Patel KV, Schoeller DA, Colbert LH, Visser M, et al. Daily activity energy expenditure and mortality among older adults. JAMA. 2006;296:171-9.

45. Franco OH, de Laet C, Peeters A, Jonker J, Mackenbach J, Nusselder W. Effects of Physical Activity on Life Expectancy With Cardiovascular Disease. Arch Intern Med. 2005;165:2355-60.

46. Pan X, Li G, Hu Y, Wang J, Yang W, An Z, et al. Effects of diet and exercise in preventing NIDDM in people with impaired glucose tolerance. The Da Qing IGT and Diabetes Study. Diabetes Care. 1997;20:537-44.

47. Tuomilehto J, Lindstrom J, Eriksson JG, Valle TT, Hamalainen H, Ilanne-Parikka P, et al. Prevention of Type 2 Diabetes Mellitus by Changes in Lifestyle among Subjects with Impaired Glucose Tolerance. N Engl J Med. 2001;344:1343-50.

48. Diabetes Prevention Program Research Group. Reduction in the Incidence of Type 2 Diabetes with Lifestyle Intervention or Metformin. N Engl J Med. 2002 February 7, 2002;346:393-403.

49. Wei M, Gibbons LW, Kampert JB, Nichaman MZ, Blair SN. Low Cardiorespiratory Fitness and Physical Inactivity as Predictors of Mortality in Men with Type 2 Diabetes. Ann Intern Med. 2000;132:605-11.

50. Hellenius M-L, de Faire U, Berglund B, Hamsten A, Krakau I. Diet and exercise are equally effective in reducing risk for cardiovascular disease. Results of a randomized controlled study in men with slightly to moderately raised cardiovascular risk factors. Atherosclerosis. 1993;103:81-91.

51. Irwin ML, Yasui Y, Ulrich CM, Bowen D, Rudolph RE, Schwartz RS, et al. Effect of exercise on total and intra-abdominal body fat in postmenopausal women. A randomized controlled trail. JAMA. 2003;289:323-30.

52. Hamilton MT, Hamilton DG, Zderic TW. Role of low energy expenditure and sitting in obesity, metabolic syndrome, type 2 diabetes, and cardiovascular disease. Diabetes. 2007;56:2655-67.

53. Hu FB. Sedentary lifestyle and risk of obesity and type 2 diabetes. Lipids. 2003;38:103-8.

54. Hu FB, Li TY, Colditz GA, Willett WC, Manson JE. Television watching and other sedentary behaviors in relation to risk of obesity and type 2 diabetes mellitus in women. JAMA. 2003;289:1785-91.

55. Yrkesföreningar för Fysisk Aktivitet (YFA). FYSS 2008 -Fysisk aktivitet i sjukdomsprevention och sjukdomsbehandling [FYSS 2008 -Physical activity in prevention and treatment of disease]. In Swedish. Stockholm: National Institute of Public Health, Sweden; 2008. Report No.: 4. www.fyss.se.

56. Brown WJ, Burton NW, Rowan PJ. Updating the Evidence on Physical Activity and Health in Women. Am J Prev Med. 2007;33:404-11.e25.

57. Cavill N, Kahlmeier S, Racioppi F, editors. Physical Activity and Health in Europe: Evidence for Action. Copenhagen: World Health Organization; 2006. 
58. Swedish National Institute of Public Health. The Swedish National Survey of Public Health 2007. 2007 [cited 2008 April 18th]; Available from: www.fhi.se

59. Ezzati M, Lopez AD, Rodgers A, Murray CJL, editors. Comparative Quantification of Health Risks. Global and Regional Burden of Disease Attributable to Selected Major Risk Factors Geneva: World Health Organization; 2004.

60. Li C, Ford ES, McGuire LC, Mokdad AH. Increasing Trends in Waist Circumference and Abdominal Obesity among U.S. Adults. Obesity. 2007;15:216-23.

61. Lahti-Koski M, Harald K, Mannisto S, Laatikainen T, Jousilahti P. Fifteen-year changes in body mass index and waist circumference in Finnish adults. Eur J Cardiovasc Prev Rehabil. 2007; 14:398-404.

62. Hollmann W, Struder HK, Tagarakis CVM, King G. Physical activity and the elderly. Eur J Cardiovasc Prev Rehabil. 2007;14:730-9.

63. Halldin M, Rosell M, de Faire U, Hellenius ML. The metabolic syndrome: prevalence and association to leisure-time and work-related physical activity in 60-year-old men and women. Nutr Metab Cardiovasc Dis. 2007;17:349-57.

64. Hellenius M, Rosell M, de Faire U. High prevalence of overweight and metabolic syndrome among 60 year old women and men in Stockholm, Sweden (abstract). Atherosclerosis. 2000;151:276.

65. Persson G. Chapter 2: Demography and public health. Scand J Public Health. 2006;34:19 25.

66. United Nations Population Division. World Population Ageing: 1950-2050. New York: United Nations Publications; 2001.

67. Pate RR, Pratt M, Blair SN, Haskell WL, Macera CA, Bouchard C, et al. Physical activity and public health. A recommendation from the Centers for Disease Control and Prevention and the American College of Sports Medicine. JAMA. 1995;273:402-7.

68. Haskell WL, Lee IM, Pate RR, Powell KE, Blair SN, Franklin BA, et al. Physical Activity and Public Health: Updated Recommendation for Adults from the American College of Sports Medicine and the American Heart Association. Med Sci Sports Exerc. 2007;39:1423-34.

69. Nelson ME, Rejeski WJ, Blair SN, Duncan PW, Judge JO, King AC, et al. Physical activity and public health in older adults: recommendation from the American College of Sports Medicine and the American Heart Association. Med Sci Sports Exerc. 2007;39:1435-45.

70. Norman A, Bellocco R, Vaida F, Wolk A. Age and Temporal Trends of Total Physical Activity in Swedish Men. Med Sci Sports Exerc. 2003;35:617-22.

71. Brownson RC, Boehmer TK, Luke DA. Declining rates of physical activity in the United States: what are the contributors? Annual Review of Public Health. 2005;26:421-43.

72. Barengo NC, Nissinen A, Tuomilehto J, Pekkarinen H. Twenty-five-year trends in physical activity of 30- to 59-year-old populations in eastern Finland. Med Sci Sports Exerc. 2002;34:1302-7.

73. Talbot LA, Fleg JL, Metter EJ. Secular trends in leisure-time physical activity in men and women across four decades. Prev Med. 2003;37:52-60.

74. Anderssen SA, Engeland A, Søgaard AJ, Nystad W, Graff-Iversen S, Holme I. Changes in physical activity behavior and the development of body mass index during the last 30 years in Norway. Scand J Med Sci Sports. 2008;18:309-17.

75. Lanningham-Foster L, Nysse LJ, Levine JA. Labor Saved, Calories Lost: The Energetic Impact of Domestic Labor-saving Devices. Obes Res. 2003 October 1, 2003;11:1178-81.

76. National Center for Health Statistics. Health, United States 2007, With Chartbook on Trends in the Health of Americans. Washington: Hyattsville, MD; 2007.

77. Sjöström M, Oja P, Hagströmer M, Smith BJ, Bauman A. Health-enhancing physical activity across European Union countries: the Eurobarometer study J Public Health. 2006;14:291-300

78. Rütten A, Abu-Omar K. Prevalence of physical activity in the European Union Soz Praventivmed. 2004;49:281-9. 
79. Hagstromer M, Bergman P, Bauman A, Sjostrom M. The international prevalence study (IPS): health-enhancing physical activity in Sweden J Public Health 2006;14:301-8.

80. Matthews CE, Chen KY, Freedson PS, Buchowski MS, Beech BM, Pate RR, et al. Amount of Time Spent in Sedentary Behaviors in the United States, 2003-2004. Am J Epidemiol. 2008:875-81.

81. Varo JJ, Martinez-Gonzalez MA, de Irala-Estevez J, Kearney J, Gibney M, Martinez JA. Distribution and determinants of sedentary lifestyles in the European Union. Int J Epidemiol. 2003;32:138-46.

82. European Commission Directorate General Health and Consumer Protection. Health and Food (Special Eurobarometer 246 / wave 64.3). Brussels: European Commission; 2006.

83. Hagstromer M, Oja P, Sjostrom M. Physical Activity and Inactivity in an Adult Population Assessed by Accelerometry. Med Sci Sports Exerc. 2007;39:1502-8.

84. World Health Organization. Global Strategy on Diet, Physical Activity and Health; 2004.

85. U.S. Department of Health and Human Services. Healthy People 2010: Understanding and Improving Health. Washington, DC: U.S. Government Printing Office; 2000. p. 76.

86. Nordic Council of Ministers. Health, food and physical activity. Nordic Plan of Action on better health and quality of life through diet and physical activity. Copenhagen; 2006. Report No.: ANP 2006:745.

87. Swedish National Institute of Public Health. Healthy dietary habits and increased physical activity - the basis for an action plan. Stockholm; 2005.

88. Ågren G. Sweden's new public health policy. National public health objectives for Sweden: Swedish National Institute of Public Health, ; 2004. Report No.: Revised edition 2003:58.

89. The Swedish Government. Regeringens proposition 2002/03:35 "Mål för folkhälsan" [Government Bill 2002/03:35 - Public health objectives]. (In Swedish). Stockholm; 2003. p. 133.

90. Kallings LV, Leijon M. Erfarenheter av Fysisk aktivitet på recept, FaR [Physical activity on prescription (FaR)] (In Swedish with English summary). Stockholm: The Swedish National Institute of Public Health; 2003. Report number 53. www.fhi.se.

91. Tranquist J, Kallings L, Leijon M. Sweden on the move 2001- a year of success! (abstract). Stockholm: National Institute of Public Health; 2002.

92. Strandell A, Tranquist J, Kallings L, Lamming P. Sätt Sverige i rörelse 2001 -Redovisning och erfarenheter. [Sweden on the move 2001 -description and experiences] (In Swedish). Stockholm: Swedish National Insitute of Public Health; 2002. Report 20.

93. World Health Organization. The Ottawa Charter for Health Promotion. First International Conference on Health Promotion, Ottawa, 21 November 1986; 1986.

94. National Public Health Committee. Motion och idrott -födelar eller faror för hälsan? (In Swedish). Stockholm; 2000. Report No.: 15.

95. FYSS -Fysisk aktivitet i sjukdomsprevention och sjukdomsbehandling [Physical activity in prevention and treatment of diseases]. In Swedish. Stockholm: Yrkesföreningar för Fysisk Aktivitet (Professional Federation of Physical Activity) - in cooperation with the Swedish National Institute of Public Health; 2003. FHI Report no. 44 www.fyss.se.

96. Hillsdon M, Foster C, Naidoo B, Crombie H. The effectiveness of public health interventions for increasing physical activity among adults: a review of reviews. Evidence briefing. 1st ed. London: Health Development Agency; 2004.

97. Rose G. Sick individuals and sick populations. Int J Epidemiol. 2001;30:427-32.

98. Socialstyrelsen. Hälso- och sjukvård - Lägesrapport 2003 [Health Care Status Report 2003] (In Swedish with English summary). Stockholm; 2004.

99. Aittasalo M. Promoting physical activity of working aged adults with selected personal approaches in primary health care. Feasibility, effectiveness and an example of nationwide dissemination. Doctoral Thesis. Jyväskylä: University of Jyväskylä; 2008.

100. Jacobson DM, Strohecker L, Compton MT, Katz DL. Physical Activity Counseling in the Adult Primary Care Setting. Position Statement of the American College of Preventive Medicine. Am J Prev Med. 2005;29:158-62. 
101. National Institute for Health and Clinical Excellence. Four commonly used methods to increase physical activity: brief interventions in primary care, exercise referral schemes, pedometers and community-based exercise programmes for walking and cycling. London; 2006. Report No.: 2.

102. Walsh JME, Swangard DM, Davis T, McPhee SJ. Exercise counseling by primary care physicians in the era of managed care. Am J Prev Med. 1999;16:307-13.

103. Brotons C, Bjorkelund C, Bulc M, Ciurana R, Godycki-Cwirko M, Jurgova E, et al. Prevention and health promotion in clinical practice: the views of general practitioners in Europe. Prev Med. 2005;40:595-601.

104. Anis NA, Lee RE, Ellerbeck EF, Nazir N, Greiner KA, Ahluwalia JS. Direct observation of physician counseling on dietary habits and exercise: patient, physician, and office correlates. Prev Med. 2004;38:198-202.

105. Glasgow RE, Eakin EG, Fisher EB, Bacak SJ, Brownson RC. Physician advice and support for physical activity: Results from a national survey. Am J Prev Med. 2001;21:189-96.

106. The Swedish Council on Technology Assessment in Health Care (SBU). Methods of promoting Physical Activity, A systematic Review (In Swedish with Summary and Conclusions in English); 2007. Report No.: 181.

107. The Swedish Council on Technology Assessment in Health Care (SBU). Methods of Promoting Physical Activity, a Systematic Review (Summary and Conclusions). Stockholm: SBU; 2007. Report No.: 181.

108. The National Board of Health and Welfare. Hälsofrämjande hälso- och sjukvård? En kartläggning av hälsofrämjande och sjukdomsförebyggande insatser [Health-promoting health service? A mapping of efforts](In Swedish). Stockholm; 2005.

109. Marcus BH, Williams DM, Dubbert PM, Sallis JF, King AC, Yancey AK, et al. Physical Activity Intervention Studies: What We Know and What We Need to Know: A Scientific Statement From the American Heart Association Council on Nutrition, Physical Activity, and Metabolism (Subcommittee on Physical Activity); Council on Cardiovascular Disease in the Young; and the Interdisciplinary Working Group on Quality of Care and Outcomes Research. Circulation. 2006;114:2739-52.

110. U.S. Preventive Services Task Force. Behavioral counseling in primary care to promote physical activity: recommendation and rationale. Ann Intern Med. 2002;137:205-7.

111. Hellenius M-I, de Faire U., Krakau I., Berglund B. Prevention of cardiovascular disease within the primary health. Scand J Health Care. 1993;11:68-73.

112. Hellenius M-L, Arborelius E. Motion på recept kan hjälpa patienten ändra sina vanor (In Swedish). Läkartidningen. 1999;96:3343-6.

113. The Writing Group for the Activity Counseling Trial Research Group. Effects of physical activity counseling in primary care. The activity counseling trial: a randomized controlled trial. JAMA. 2001;286:677-87.

114. Riddoch C, Puig-Ribera A, Cooper A. Effectiveness of physical activity promotion schemes in primary care: a review [Health promotion effectiveness review: summary bulletin 14]: Health Education Authority; 1998.

115. Hellénius M-L, Johansson J, Elofsson S, de Faire U, Krakau I. Four years experience of a cardiovascular opportunistic screening and prevention programme in the primary health care in Sollentuna, Sweden. Scand J Prim Health Care. 1999;17:111-5.

116. Aittasalo M, Miilunpalo S, Kukkonen-Harjula K, Pasanen M. A randomized intervention of physical activity promotion and patient self-monitoring in primary health care. Prev Med. 2006;42:40-6.

117. Sørensen JB, Skovgaard T, Puggaard L. Exercise on prescription in general practice: A systematic review. Scand J Prim Health Care. 2006;24:69-74.

118. Hillsdon M, Thorogood M, White I, Foster C. Advising people to take more exercise is ineffective: a randomized controlled trial of physical activity promotion in primary care. Int J Epidemiol. 2002;31:808-15. 
119. Smiths BJ, Bauman AE, Bull FC, Both ML, Harris MF. Promoting physical activity in general practice: a controlled trial of written advice and information materials. Br J Sports Med. 2000;34:262-7.

120. Bull FC, Jamrozik K. Advice on exercise from a family physician can help sedentary patients to become active. Am J Prev Med. 1998;15:85-94.

121. Harland J, White M, Drinkwater C, Chinn D, Farr L, Howel D. The Newcastle exercise project: a randomised controlled trial of methods to promote physical activity in primary care. BMJ. 1999;319:828-32.

122. Eden KB, Orleans CT, Mulrow CD, Pender NJ, Teutsch SM. Does counseling by clinicians improve physical activity? A summary of the evidence for the U.S. Preventive Services Task Force. Ann Intern Med. 2002;137:208-15.

123. National Cancer Institute. US Department of Health and Human Services. Theory at a Glance: Application to Health Promotion and Health Behavior. 2nd ed; 2005.

124. Smitherman TA, Kendzor DE, Grothe KB, Dubbert PM. State of the Art Review: Promoting Physical Activity in Primary Care Settings: A Review of Cognitive and Behavioral Strategies. American Journal of Lifestyle Medicine. 2007;1:397-409.

125. Smith BJ. Promotion of physical activity in primary health care: update of the evidence on interventions. J Sci Med Sport. 2004;7:67-73.

126. Prochaska JO, Velicer WF, Rossi JS, Goldstein MG, Marcus BH, Rakowski W, et al. Stages of Change and Decisional Balance for 12 Problem Behaviors. Health Psychol. 1994;13:39-46.

127. Spencer L, Adams TB, Malone S, Roy L, Yost E. Applying the transtheoretical model to exercise: a systematic and comprehensive review of the literature. Health Promot Pract. 2006;7:428-43.

128. Marcus BH, Simkin LR. The transtheoretical model: applications to exercise behavior. Med Sci Sports Exerc. 1994;26:1400-4.

129. West R. Time for a change: putting the Transtheoretical (Stages of Change) Model to rest. Addiction. 2005;100:1036-9.

130. Whitlock EP, Orleans T, Pender N, Allan J. Evaluating primary care behavioral counceling interventions. An evidence-based approach. Am J Prev Med. 2002;22:267-83.

131. Estabrooks PA, Glasgow RE, Dzewaltowski DA. Physical Activity Promotion Through Primary Care. JAMA. 2003;289:2913-6.

132. World Health Organization. The 5 As. 2008 [cited 2008 July 22]; Available from: http://www.who.int/diabetesactiononline/about/fiveAs/en/

133. Stange KC, Woolf SH, Gjeltema K. One Minute for Prevention. The Power of Leveraging to Fulfill the Promise of Health Behavior Counseling. Am J Prev Med. 2002;22:320-3.

134. Morgan O. Approaches to increase physical activity: reviewing the evidence for exercisereferral schemes. Public Health. 2005;119:361-70.

135. Kahn EB, RAmsey LT, Brownson RC, Heath GW, Howzw EH, Powell KE, et al. The effectiveness of interventions to increase physical activity. A systematic review. Am J Prev Med. 2002;22 (4S):73-107.

136. Sørensen JB, Kragstrup J, Kjær K, Puggaard L. Exercise on Prescription: trial protocol and evaluation of outcomes. BMC Health Serv Res 2007;7.

137. Isaacs A, Critchley J, See TS, Buckingham K, Westley D, Harridge S, et al. Exercise Evaluation Randomised Trial (EXERT): a randomised trial comparing GP referral for leisure centre-based exercise, community-based walking and advice only. Health Technol Assess. 2007;11:1-184.

138. Sørensen JB, Kragstrup J, Skovgaard T, Puggaard L. Exercise on prescription: a randomized study on the effect of counseling vs counseling and supervised exercise. Scand J Med Sci Sports. 2008;18:288-97.

139. Faskunger J, Leijon M, Ståhle A, Lamming P. Fysisk aktivitet på recept (FaR) -en vägledning för implementering [Physical activity on prescription (FaR) -a guidance for implementation] (In Swedish with English summary). Stockholm: The Swedish National Institute of Public Health; 2007. Report No.: Report number 2007:01. www.fhi.se. 
140. Department of Health. National Quality Assurance Framework for Exercise Referral Systems. London: Department of Health; 2001.

141. Hellenius M-L, de Faire U, Krakau I, Berglund B. Prevention of cardiovascular disease within the primary health care system: Feasibility of a prevention programme within the Sollentuna primary health care catchment area. Scandinavian Journal of Primary Health Care. 1993;11:68-73.

142. Weinehall L. Partnership for health. On the role of primary health care in a community intervention programme. Doctoral Thesis. Umeå: Umeå University; 1997.

143. Lingfors H, Lindstrom K, Persson LG, Bengtsson C, Lissner L. Evaluation of "Live for Life", a health promotion programme in the County of Skaraborg, Sweden. J Epidemiol Community Health. 2001;55:277-82.

144. Hellénius M-L, Krakau I, de Faire U. Favourable long-term effects from advice on diet and exercise given to healthy men with raised cardiovascular risk factors. Nutr Metab Cardiovasc Dis. 1997;7:293-300.

145. World Health Organization. Adherence to long-term therapies: Evidence for action. Geneva; 2003.

146. Dominick KL, Morey M. Adherence to physical activity. In: Bosworth HB, editor. Patient Treatment Adherence: Concepts, Interventions, and Measurement. Mahawah, NJ, USA: Lawrence Erlbaum Associates, Incorporated; 2005. p. 49-94.

147. Bosch CX, Garner P. Contracts between patients and healthcare practioners for improving patient's adherence to treatment, prevention and health promotion activities. (Protocol). Cochrane Database of Syst Rev. 2003:1-9.

148. Glasgow RE, Lichtenstein E, Marcus AC. Why Don't We See More Translation of Health Promotion Research to Practice? Rethinking the Efficacy-to-Effectiveness Transition. Am J Public Health. 2003;93:1261-7.

149. Estabrooks PA, Gyurcsik NC. Evaluating the impact of behavioral interventions that target physical activity: issues of generalizability and public health. J Sport Exerc Psychol. 2003;4:41-55.

150. Vitolins MZ, Rand CS, Rapp SR, Ribisl PM, Sevick MA. Measuring Adherence to Behavioral and Medical Interventions. Control Clin Trials. 2000;21:S188-S94.

151. Estabrooks PA, Glasgow RE. Translating effective clinic-based physical activity interventions into practice. Am J Prev Med. 2006;31:S45-S56.

152. Glasgow RE, Bull SS, Gillette C, Klesges LM, Dzewaltowski DA. Behavior change intervention research in healthcare settings: a review of recent reports with emphasis on external validity. Am J Prev Med. 2002;23:62-9.

153. Glasgow RE, Emmons KM. How Can We Increase Translation of Research into Practice? Types of Evidence Needed. Annu Rev Public Health. 2007;28:413-33.

154. Miller W, Rollnick S. Motivational interviewing: preparing people to change. 2nd ed. New York: Gilford Press; 2002.

155. Cress ME, Buchner DM, Prohaska T, Rimmer J, Brown M, Macera C, et al. Physical activity programs and behavior counseling in older adult populations. Med Sci Sports Exerc. 2004;36:1997-2003.

156. Borg G. Borg's perceived exertion and pain scales. Champaign, Ill: Human Kinetics; 1998.

157. Mazzeo RS, Cavanagh P, Evans WJ, Fiatarone M, Hagberg J, McAuley E, et al. ACSM Position Stand on exercise and physical activity for older adults. Med Sci Sports Exerc. 1998;30:992-1008.

158. Ekberg K, Noorlind-Brage H, Dastserri M. Östgötens hälsa och miljö 2000. (In Swedish). Linköping: Folkhälsovetenskapligt Centrum Landstinget i Östergötland; 2000

159. American College of Sports Medicine Position Stand. The recommended quantity and quality of exercise for developing and maintaining cardiorespiratory and muscular fitness, and flexibility in healthy adults. Med Sci Sports Exerc. 1998;30:975-91.

160. Ekelund U, Sepp H, Brage S, Becker W, Jakes R, Hennings M, et al. Criterion-related validity of the last 7-day, short form of the International Physical Activity Questionnaire in Swedish adults. Public Health Nutr. 2006;9:258-65 
161. Marcus BH, Selby V, Niaura R, JS. R. Self-efficacy and the stages of exercise behavior change. Res Q Exerc Sport. 1992;63:60-6.

162. Marshall SJ, Biddle S. The Transtheoretical Model of Behaviour Change: A meta-analysis of applications to physical activity and exercise. Ann Behav Med. 2001;23:229-46.

163. Kearney JM, Graaf Cd, Damkjaer S, Engstrom LM. Stages of change towards physical activity in a nationally representative sample in the European Union. Public Health Nutr. 1999;2:115-24.

164. Bohannon RW. Number of pedometer-assessed steps taken per day by adults: a descriptive meta-analysis. Phys Ther. 2007;87:1642-50.

165. Crouter SE, Schneider PL, Karabulut M, Bassett DRJ. Validity of 10 electronic pedometers for measuring steps, distance, and energy cost. Med Sci Sports Exerc. 2003;35:1455-60.

166. Bassett J, D. R., Ainsworth BE, Leggett SR, Mathien CA, Main JA, Hunter DC, et al. Accuracy of five electronic pedometers for measuring distance walked. Med Sci Sports Exerc. 1996;28 1071-7.

167. Tudor-Locke C, Bassett Jr DR, Rutherford WJ, Ainsworth BE, Chan CB, Croteau K, et al. BMI-referenced cut points for pedometer-determined steps per day in adults. J Phys Act Health. 2008;5(Suppl 1):S126-S39.

168. Tudor-Locke C, Bassett Jr DR. How many steps/day are enough? Preliminary pedometer indices for public health. Sports Med. 2004;34:1-8.

169. Ware JJ, Sherbourne C. The MOS 36-item short-form health survey (SF-36) I Conceptual framework and item selection. Med Care. 1992;30:473-83.

170. McHorney C, Ware JJ, Raczek A. The MOS 36-Item Short-Form Health Survey (SF-36): II. Psychometric and clinical tests of validity in measuring physical and mental health constructs. Med Care. 1993;31:247-63.

171. Brooks R. EuroQol: the current state of play. Health Policy. 1996;37:53-72.

172. van Agt H, Essink-Bot M-L, Krabbe P, Bonsel G. Test-retest reliability of health state valuations collected with the EuroQol questionnaire. Soc Sci Med. 1994;39:1537-44.

173. Sullivan M, Karlsson J, Ware J. The Swedish SF-36 health survey - I. Evaluation of data quality, scaling assumptions, reliability and construct validity across general populations in Sweden. Soc Sci Med. 1995;41:1349-58.

174. Sullivan M, Karlsson J, Ware J. SF-36. Hälsoenkät. Manual och Svensk Tolkningsguide [SF-36 Health Survey. Swedish manual and Interpretation guide] (In Swedish). Göteborg; 1994.

175. Dolan P. Modelling valuations for EuroQol health states. Med Care. 1997;35:1095-108.

176. Swedish National Institute of Public Health. The Swedish National Survey of Public Health 2006. 2006 [cited 2008 April 18th]; Available from: www.fhi.se

177. Rowe DA, Kemble CD, Robinson TS, Mahar MT. Daily walking in older adults: day-today variability and criterion-referenced validity of total daily step counts. J Phys Act Health. 2007;4:434-46.

178. Lakka T, Laaksonen D. Physical activity in prevention and treatment of the metabolic syndrome. Appl Physiol Nutr Metab. 2007;32:76-88.

179. Foster C, Hillsdon M, Thorogood M. Interventions for promoting physical activity. Cochrane Database Syst Rev. 2005. Issue 1:Art. No.: CD003180. DOI: 10.1002/14651858.CD003180.pub2. .

180. Leijon ME, Bendtsen P, Nilsen P, Festin K, Ståhle A. Does a physical activity referral scheme improve the physical activity among routine primary health care patients? Scand J Med Sci Sports. In press.

181. Gidlow C, Johnston LH, Crone D, James D. Attendance of exercise referral schemes in the UK: A systematic review. Health Educ J. 2005;64:168-86.

182. Jimmy G, Martin BW. Implementation and effectiveness of a primary care based physical activity counselling scheme. Patient Educ Couns. 2005;56:323-31.

183. King AC, Baumann K, O'Sullivan P, Wilcox S, Castro C. Effects of moderate-intensity exercise on physiological, behavioral, and emotional responses to family caregiving: a randomized controlled trial. J Gerontol A Biol Sci Med Sci. 2002;57:26-36. 
184. Castro CM, Wilcox S, O'Sullivan P, Baumann K, King AC. An exercise program for women who are caring for relatives with dementia. Psychosom Med. 2002;64:458-68.

185. Halbert JA, Silagy CA, Finucane PM, Withers RT, Hamdorf PA. Physical activity and cardiovascular risk factors: effect of advice from an exercise specialist in Australian general practice. Med J Aust. 2000;173:84-7.

186. Myers J. Physical activity: the missing prescription. Eur J Cardiovasc Prev Rehabil. 2005;12:85-6.

187. Bravata DM, Smith-Spangler C, Sundaram V, Gienger AL, Lin N, Lewis R, et al. Using pedometers to increase physical activity and improve health: a systematic review. JAMA. 2007;298:2296-304.

188. Dunn AL, Garcia ME, Marcus BH, Kampert JB, Kohl HW, III, Blair SN. Six-month physical activity and fitness changes in Project Active, a randomized trial. Med Sci Sports Exerc. 1998;30:1076-83.

189. Kerse N, Elley CR, Robinson E, Arroll B. Is Physical Activity Counseling Effective for Older People? A Cluster Randomized, Controlled Trial in Primary Care. J Am Geriatr Soc. 2005;53:1951-6.

190. van Sluijs EMF, van Poppel MNM, Twisk JWR, van Mechelen W. Physical activity measurements affected participants' behavior in a randomized controlled trial. J Clin Epidemiol. 2006;59:404-11.

191. Dzewaltowski DA, Estabrooks PA, Glasgow RE. The future of physical activity behaviour change research: What is needed to improve translation of research into health promotion practice? Exerc Sport Sci Rev. 2004;32:57-63.

192. Tunis SR, Stryer DB, Clancy CM. Practical Clinical Trials: Increasing the Value of Clinical Research for Decision Making in Clinical and Health Policy. JAMA. 2003;290:1624-32.

193. Groslambert A, Mahon AD. Perceived exertion: influence of age and cognitive development. Sports Med. 2006;36:911-28.

194. Jakicic JM, Donnelly JE, Pronk NP, Jaward A, Jacobsen D. Prescription of exercise intensity for the obese patient: the relationship between heart rate, $\mathrm{VO} 2$ and perceived exertion. Inter J Obes. 1995;19:382-7.

195. The Swedish Association of Local Authorities and Regions. Vårdbarometern, befolkningens syn på vården (In Swedish). 2007 [cited 17th September 2007]; Available from: www.vardbarometern.nu

196. The Swedish Government. Regeringens proposition 2007/08:110. En förnyad folkhälsopolitik [Government Bill 2007/08:110. Renewed Swedish Public Health bill]. In Swedish. Stockholm; 2008 Mars 13, 2008.

197. Gidlow C, Johnston LH, Crone D, James DVB. State of the Art Reviews: Methods of Evaluation: Issues and Implications for Physical Activity Referral Schemes. American Journal of Lifestyle Medicine. 2008;2:46-50.

198. Victora CG, Habicht J-P, Bryce J. Evidence-Based Public Health: Moving Beyond Randomized Trials. Am J Public Health. 2004 March 1, 2004;94:400-5.

199. Pinto BM, Goldstein MG, Ashba J, Sciamanna CN, Jette A. Randomized Controlled Trial of Physical Activity Counseling for Older Primary Care Patients. Am J Prev Med. 2005;29:247-55. 